\section{Pacific Northwest}

National Laboratory

Operated by Battelle for the

U.S. Department of Energy

\title{
Compact Fluorescent Lighting in America: Lessons Learned on the Way to Market
}

\author{
LJ Sandahl \\ HE Steward \\ TL Gilbride \\ C Calwell \\ MR Ledbetter
}

May 2006

Prepared for the U.S. Department of Energy under Contract DE-AC05-76RL01830 
DISCLAIMER

This report was prepared as an account of work sponsored by an agency of the United States Government. Neither the United States Government nor any agency thereof, nor Battelle Memorial Institute, nor any of their employees, makes any warranty, express or implied, or assumes any legal liability or responsibility for the accuracy, completeness, or usefulness of any information, apparatus, product, or process disclosed, or represents that its use would not infringe privately owned rights. Reference herein to any specific commercial product, process, or service by trade name, trademark, manufacturer, or otherwise does not necessarily constitute or imply its endorsement, recommendation, or favoring by the United States Government or any agency thereof, or Battelle Memorial Institute. The views and opinions of authors expressed herein do not necessarily state or reflect those of the United States Government or any agency thereof.

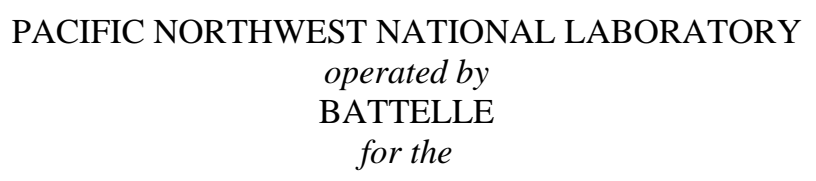

UNITED STATES DEPARTMENT OF ENERGY

under Contract DE-AC05-76RL01830

Printed in the United States of America

Available to DOE and DOE contractors from the

Office of Scientific and Technical Information,

P.O. Box 62, Oak Ridge, TN 37831-0062;

ph: (865) 576-8401

fax: (865) $576-5728$

email: reports@adonis.osti.gov

Available to the public from the National Technical Information Service, U.S. Department of Commerce, 5285 Port Royal Rd., Springfield, VA 22161

ph: (800) 553-6847

fax: (703) 605-6900

email: orders@ntis.fedworld.gov

online ordering: http://www.ntis.gov/ordering.htm 


\title{
Compact Fluorescent Lighting in America: Lessons Learned on the Way to Market
}

\author{
LJ Sandahl \\ TL Gilbride \\ MR Ledbetter \\ HE Steward \\ C Calwell ${ }^{(\mathrm{a})}$
}

May 22, 2006

Prepared for

The U.S. Department of Energy

Under Contract DE-AC05-76RLO 1830

Pacific Northwest National Laboratory

Richland, Washington 99352

${ }^{(\mathrm{a})}$ Ecos Consulting 



\section{Executive Summary}

Compact fluorescent lamps (CFLs) were introduced in the 1970s; however, it has taken more than 30 years for them to gain widespread recognition in the U.S. residential lighting market. Government and utilities have invested significant public and ratepayer funds in promoting the technology because CFLs represent an effective energy efficienct resource: they decrease lighting energy consumption by one-half or more for each incandescent lamp replaced. While CFLs still have only about $2 \%$ of the national market in terms of unit sales, they have achieved higher market penetration in some parts of the country, including California (5\%) [43] and the Pacific Northwest (12\%) [44].

This report reviews efforts to increase market acceptance of CFLs and barriers to that acceptance. The report was prepared by the Pacific Northwest National Laboratory for the U.S. Department of Energy's Office of Building Technologies, Emerging Technologies Program. Lessons to be learned from this study of CFLs are identified in hopes of assisting future market introduction efforts for other promising energyefficient lighting technologies.

Lessons learned from reviewing the efforts of the many parties involved in increasing consumer acceptance of residential CFL lighting and from studies of CFL manufacturers, retailers, and consumers are summarized below. These lessons are grouped into three categories: those pertaining to technology, to marketing, and to program design. A fourth category lists lessons learned from recent interviews PNNL conducted with CFL manufacturers Philips, GE, Osram Sylvania, and TCP regarding how their experiences would apply to the market introduction of LEDs (light emitting diodes) or other new lighting technologies.

\section{Technology}

- Introduce new lighting technology first in niche applications where benefits are clearly defined, and consistent with buyer needs.

- Be aggressive about dealing with technology failures that affect main benefit claims.

- Performance is more important than appearance (e.g. twister CFLs).

- Know and admit technology limitations.

- Manufacturers and energy-efficiency groups should coordinate to establish minimum performance requirements.

\section{Marketing and Consumer Education}

- Identify and focus first on niche markets where the benefits of the new technology make sense.

- Focus message where the technology can meet/exceed expectations.

- In marketing literature show comparisons of savings to the standard technology, e.g., $1 \mathrm{CFL}=10$ incandescents.

- Back up long-life claims with guarantees.

- Let consumers see new technology - use lit in-store displays and see-through packaging. 
- Work toward consistent, industry-wide terminology. Identify and avoid terms with negative connotations.

- Be specific about benefits. How long do they last? How much do they save?

- Shift consumer focus from product price to product value. Build a message of value (costs more/worth more).

- Use advertising messages that celebrate distinct advantages of new technology and disadvantages of old.

- Conduct in-store product demonstrations.

- Promote products through several different mediums to reinforce familiarity.

- Target training programs/awareness campaigns to market channels such as builders, designers, and retailers.

- Provide retailers with many education tools including brochures, posters, demonstrations, and wall displays. Support retailer efforts with utility bill stuffers and product demonstrations at local fairs, home shows, and energy shows.

- Use public service advertising.

- Offer consumers a pathway for answering questions through telephone hotlines and websites printed on product packaging.

- Arrange shelf displays by lighting application rather than manufacturer and identify good/better/best options that correlate to longer product life and greater energy efficiency.

- Strive to make new lighting technologies available through market channels where products are typically purchased (e.g., lighting purchases are often made at grocery stores).

- Avoid the short-term fix of a rebate unless it is tied to an overall campaign that includes an education campaign.

- Use mass media, both paid (TV, radio, newspaper, and magazine ads) and unpaid (host press events, tie news releases to current events).

\section{Program Design}

- Study market structure to see how best to introduce a new technology.

- Don’t rely on utility giveaway programs that bypass normal distribution routes or undermine retail sales.

- Avoid give-aways and programs that obscure retail price, leading to sticker shock when consumers return for repeat purchase.

- Incentives are typically most effective when directed at manufacturers versus consumers.

- Tie retailer incentives to retailer training.

- Focus product marketing on attribute that is most important to consumers (e.g., energy savings and long life for CFLs).

- Require action on part of consumer, in give-away programs, for higher installation and retention rates, and greater consumer awareness, e.g., make customers mail in a request card to get the free bulb, don't just hand them out door-to-door to customers who may not want them. 
- Use utility or manufacturer field representatives as link between manufacturers and retailers; they can educate and train retailers, set up displays, distribute promotions, and iron out problems.

- Encourage and applaud enthusiastic and ongoing retailer participation.

- Delay program launch rather than introduce inferior products; first impressions are long lasting.

- Design multi-year programs around the lighting season (Sept to April) not the calendar year.

- Invest in visible, attractive point-of-purchase displays and signage.

- Educate retailers and provide them with tools - in-store displays, signage, brochures, more informative packaging, etc. (See 2.5.1, 4.2)

- Coordinate incentive programs; avoid overlapping, inconsistent promotions.

- Join forces with others in national energy-efficiency programs (e.g., ENERGY STAR).

\section{Application to LED and Other New Lighting Technologies}

- A lot of consumer research is needed to determine what the consumer does and does not know before the initial product launch so that the launch is done right the first time.

- Accurate incandescent equivalency on packaging is critical.

- Rely as much as possible on retailers for customer education. Product packaging can also be a very powerful way to convey product benefits.

- Industry collaboration, perhaps through NEMA, would be helpful, though difficult to achieve given the large number of manufacturers.

- Coordinate with energy-efficiency programs once products are available but don’t start before products are ready.

- Don't rely on giveaways and coupons or other programs that confuse consumers about the actual retail price.

- Avoid market introduction programs that distribute products outside normal retail channels, for example utility mail-order programs.

- Performance claims must be accurate. Don’t launch a product until performance issues are ironed out.

- Initial education and performance issues will be more difficult to iron out if many manufacturers are involved in the initial introduction of LEDs.

- Pricing is critical but tricky - low enough to encourage consumer demand, high enough to generate profit for the retailer and manufacturer.

- Education, of both consumers and retailers, is critical.

- Understand that many people will not try a new product until price drops to a range near that of existing products providing similar functionality.

- $\quad$ Niche marketing is the best approach for now. 


\section{Contents}

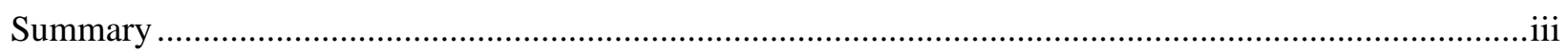



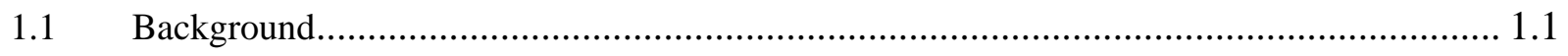

1.1.1 Early Utility Programs - 1980s-1990s ................................................................... 1.1

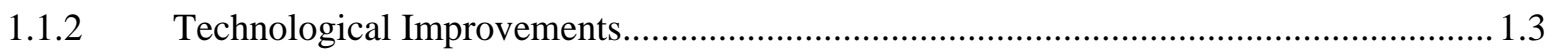

1.1.3 Slow U.S. Market Adoption ................................................................................... 1.3



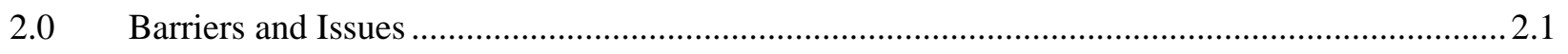

2.1 Early Consumer Barriers - Technical Challenges and Performance Issues ........................ 2.1

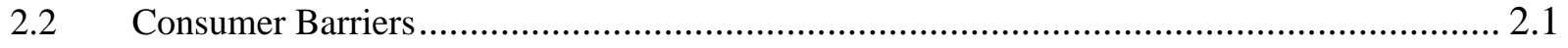

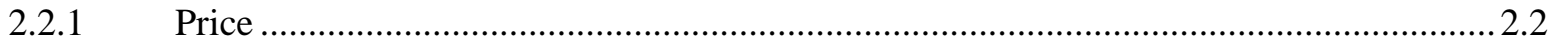

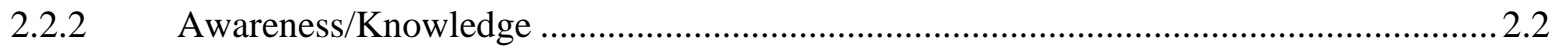

2.2.3 Attitudes, Fears, and Perceptions ..................................................................................... 2.3

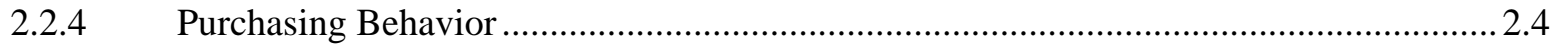

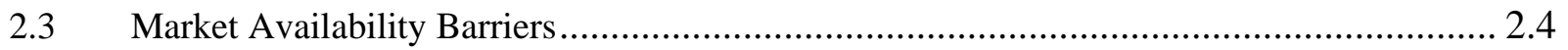

2.4 Manufacturer Barriers ................................................................................... 2.5

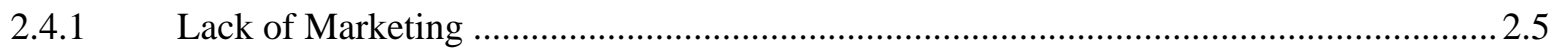

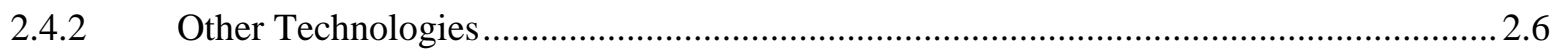

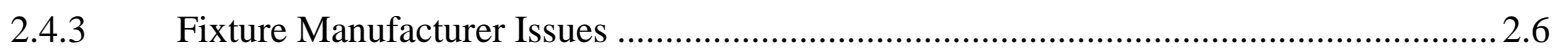

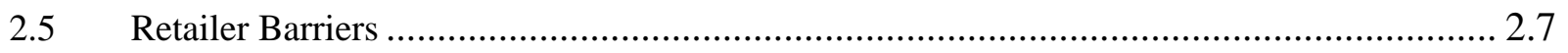

2.5.1 Lack of Awareness and Misinformation ...................................................................... 2..

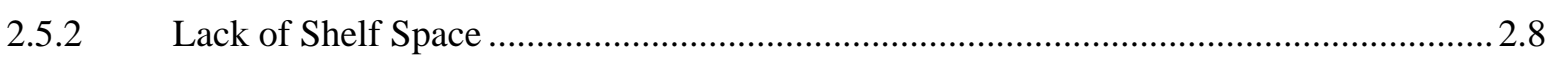

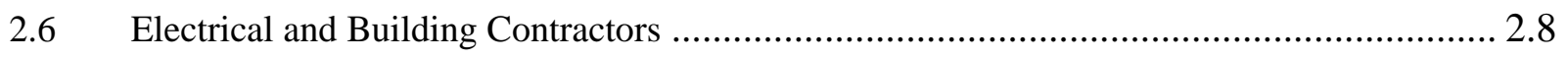

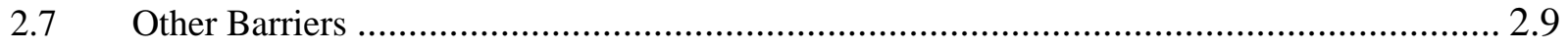

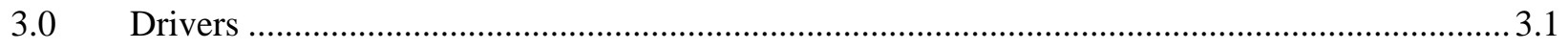

$3.1 \quad$ Utility Programs ................................................................................................ 3.1

3.1.1 Utility Give-Aways, Direct Installs, and Mail Order Programs ...................................... 3.3

3.1.2 Retailer Rebate and Coupon Programs ........................................................................... 3.3

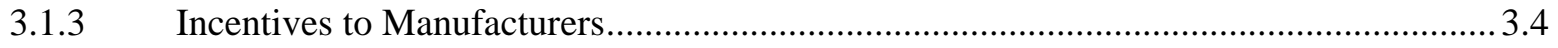

3.1.4 Niche Marketing - Multifamily, Elderly, Urban, Ethnic, and Rural .............................. 3.4

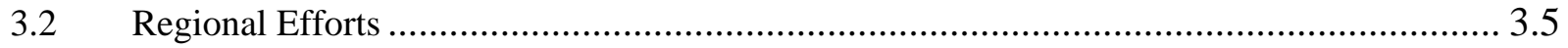

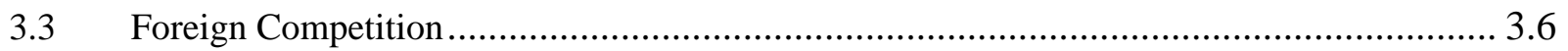




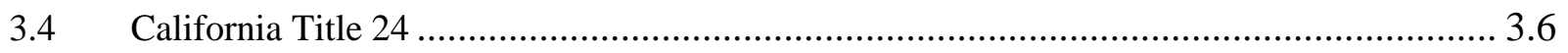

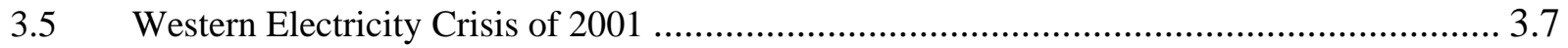

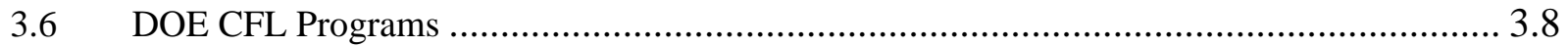

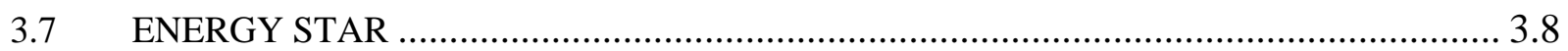

3.7.1 Program for the Evaluation and Analysis of Residential Lighting (PEARL) ................. 3.9

3.7.2 Revised ENERGY STAR Requirements .................................................................. 3.9

3.7.3 National Marketing: Change a Light Change the World ............................................... 3.13

3.7.4 ENERGY STAR Participation and Lessons Learned.................................................. 3.13

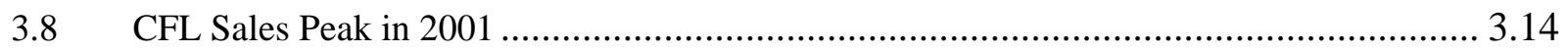

4.0 Marketing Messages, Tactics, and Trends - Suggestions from the Field .................................. 4.1

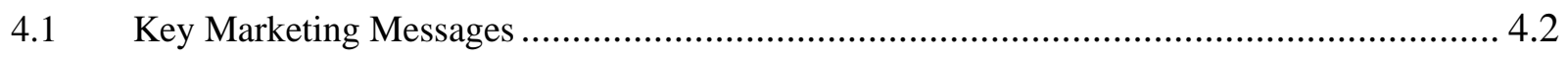

4.2 Transition from Utility to Retailer Marketing ............................................................. 4.4

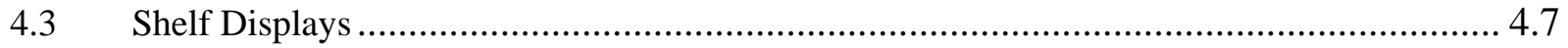

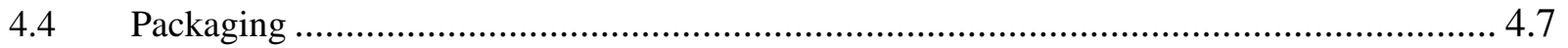

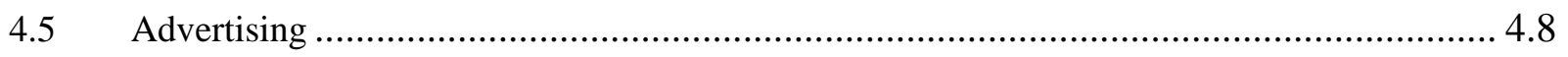

4.6 The Growth of Home Improvement Stores and their Influence on CFL Sales................... 4.10



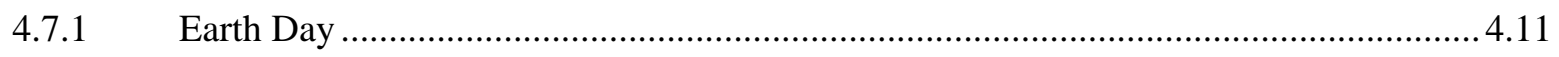

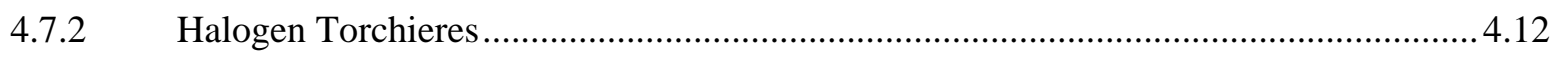

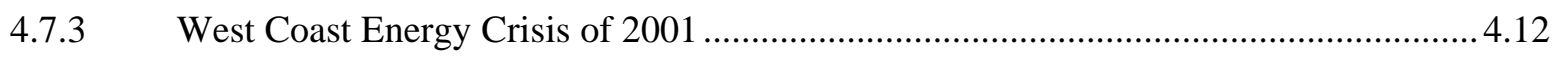

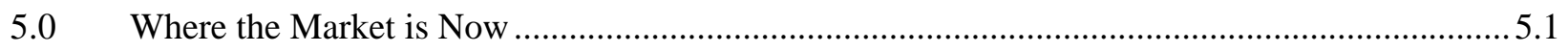

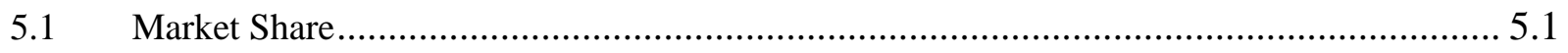

5.2 Four Examples of Transforming Markets: the Pacific Northwest, British Columbia, New England, and California ............................................................................... 5.3

5.2.1 The Pacific Northwest Case Study …........................................................................... 5.3

5.2.2 The British Columbia Case Study ................................................................................. 5.5

5.2.3 The Connecticut and Massachusetts Case Study .......................................................... 5.6

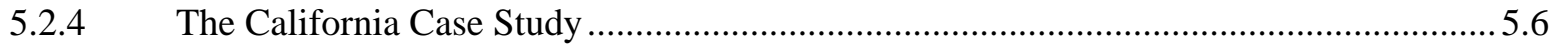

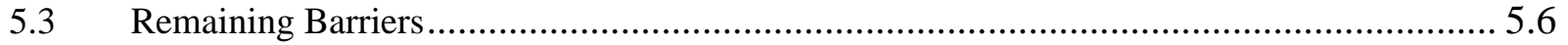

5.4 A Growth Area - CFL Fixtures ................................................................... 5.7

5.4.1 New California Title 24 Requirements ....................................................................... 5.7

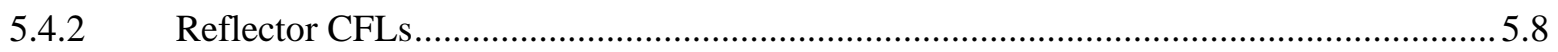

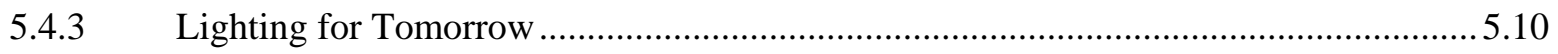

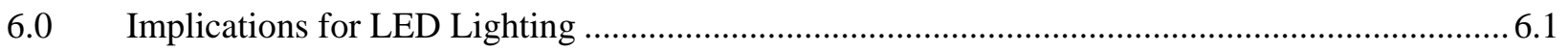


6.1 Recent Feedback from Lamp Manufacturers............................................................ 6.1



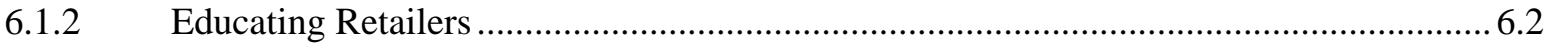

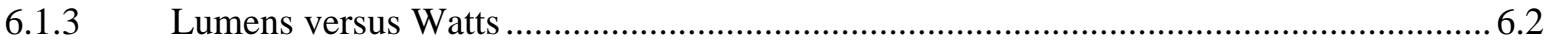

6.1.4 Negative Perceptions of Fluorescent Lighting ................................................................ 6.3

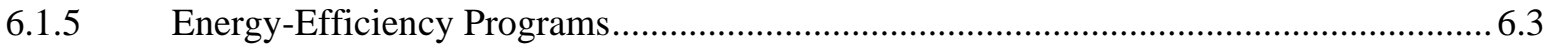

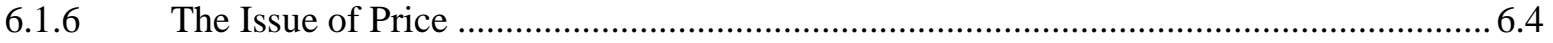



6.1.8 Potential Approaches for Introducing New Lighting Technology.................................6.6

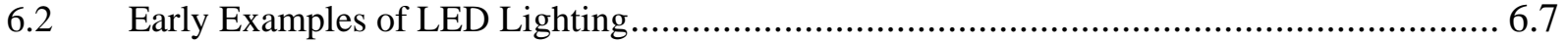

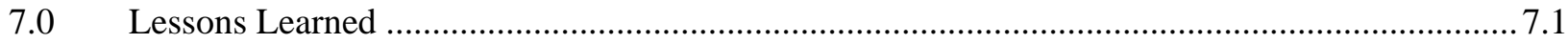

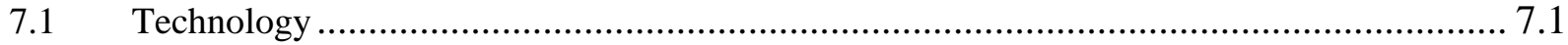

7.2 Marketing and Consumer Education ...................................................................... 7.1

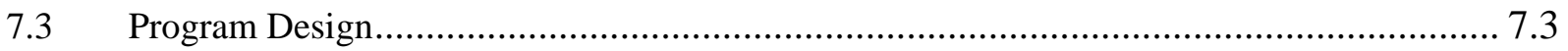

7.4 Application to LEDs and Other New Lighting Technologies ....................................... 7.4

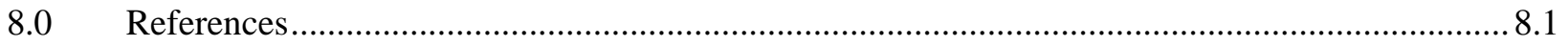

Appendix A - A Brief History of the Development of Fluoresecent Lighting ........................................ A.1

Appendix B - A Timeline of Events in CFL History …….......................................................................... 


\section{Figures}

Figure 1.1. Evolution of Compact Fluorescent Lamp Designs ........................................................ 1.2

Figure 3.1. Evolution of a Utility Market Transformation Program $\{23\}$............................................. 3.1

Figure 3.2. National CFL Market Share, Third Quarter 1998 to Fourth Quarter 2001......................... 3.15

Figure 4.1. Proposed Lamp Color Label for CFL Product Packaging ................................................... 4.8

Figure 5.1. CFL Market Penetration. Incandescents filled 85\% of sockets in 2002

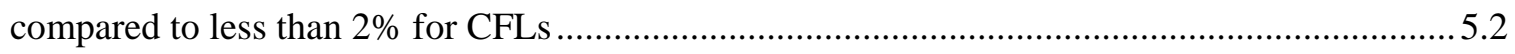

Figure 5.2. Can anyone in the U.S. get a CFL through a major retailer at a reasonable price with no utility support?......................................................................................................... 5.3

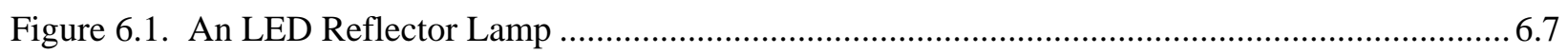

Figure 6.2. Two Examples of LEDs Configured as Replacements for a White Light

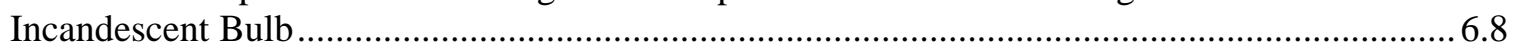

\section{Tables}

Table 3.1. Pros and Cons of Utility CFL Programs ........................................................................... 3.2

Table 3.2. ENERGY STAR CFL Program Minimum Qualification Criteria ........................................ 3.10

Table 3.3 Comparison of Minimum Efficacy Requirements for Past, Current, and Proposed

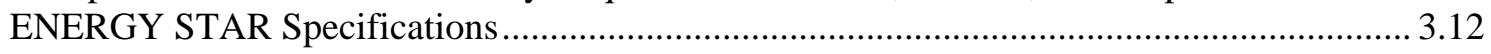

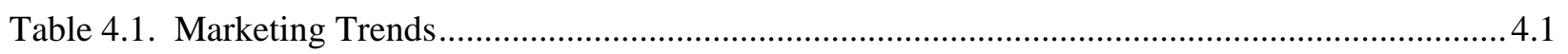

Table 5.1. How CFLs Have Changed ............................................................................................... 5.1

Table 5.2. New 2005 California Title 24 Requirements Compared to 2001 Requirements ....................5.9 


\subsection{Introduction}

Compact fluorescent lamps (CFLs) were introduced in the 1970s; however, it has taken more than 30 years for them to gain widespread recognition in the U.S. residential lighting market. This report, prepared by Pacific Northwest National Laboratory (PNNL) for the U.S. Department of Energy's Appliances and Emerging Technologies Program, reviews efforts to increase market acceptance of CFLs and barriers to that acceptance. Drivers and effective marketing messages are discussed. Lessons to be learned from this study of CFLs are identified in hopes of assisting future market introduction efforts for other promising energy-efficient technologies, such as LEDs.

\subsection{Background}

The first commercially available fluorescent lamps were introduced in the late 1930s $\{2\}$ and compact fluorescent lamps were introduced to the U.S. market in the late 1970s (see Appendix A for a brief history of this development). Fluorescent lamps convert more of the power used to usable light; consequently, they are three to six times more efficient than incandescent lamps $\{2\}$. But compact fluorescents didn't gain widespread acceptance or even acknowledgment among U.S. consumers until after 2001, despite efforts by electric utilities and CFL manufacturers in several parts of the country.

\subsubsection{Early Utility Programs - 1980s-1990s}

Beginning in the late 1980s, incentive regulation allowed many utilities for the first time to generate revenue from investments in energy efficiency programs, $\{24\}$ and utilities eager to undertake new demand side management opportunities latched onto the fledgling CFL technology $\{8\}$.

The pursuit of residential lighting programs made sense. Studies showed that residential lighting comprised a significant percentage of U.S. energy expenditures. A 1997 study for the California Energy Commission noted that, in California, residential lighting energy use was about two-thirds the size of commercial lighting energy use and $8 \%$ of the overall statewide electricity use $\{20\}$. According to the National Association of Home Builders, the average U.S. home size increased 22\% from 1987 to 2001 $\{40\}$ and a 1999 study noted that average installed watts per home had increased by an average of 100 watts per decade in California, attributable to that steady increase in the size of homes $\{20\}$. A 2002 report for DOE estimated average household lighting energy use at 1,946 kWh/yr \{39\}, double a 1993 estimate by the Energy Information Administration, which put average annual lighting energy consumption at 940 $\mathrm{kWh} / \mathrm{yr}$ per household $\{40$, although other researchers have noted that this may be a low estimate $\}$. A later California study also noted an increase in the average number of lamps (bulbs) per home from 34 in 2000 to 41 per home in $2005\{37\}$.

Throughout the 1990s, CFLs were promoted aggressively in certain markets of the country through a variety of individual utility programs (see examples of utility programs in Chapter 3). Utilities promoted CFLs as a replacement for the standard A line incandescent lamp, doubtless wishfully eyeing the savings potential from whole-house changeovers from incandescents to CFLs. Unfortunately the early-model CFLs were not quite ready for prime time, with a host of technical challenges including bulkiness, low light output, and inconsistent performance, still to be worked out before they would be considered comparable to incandescents in any application. 


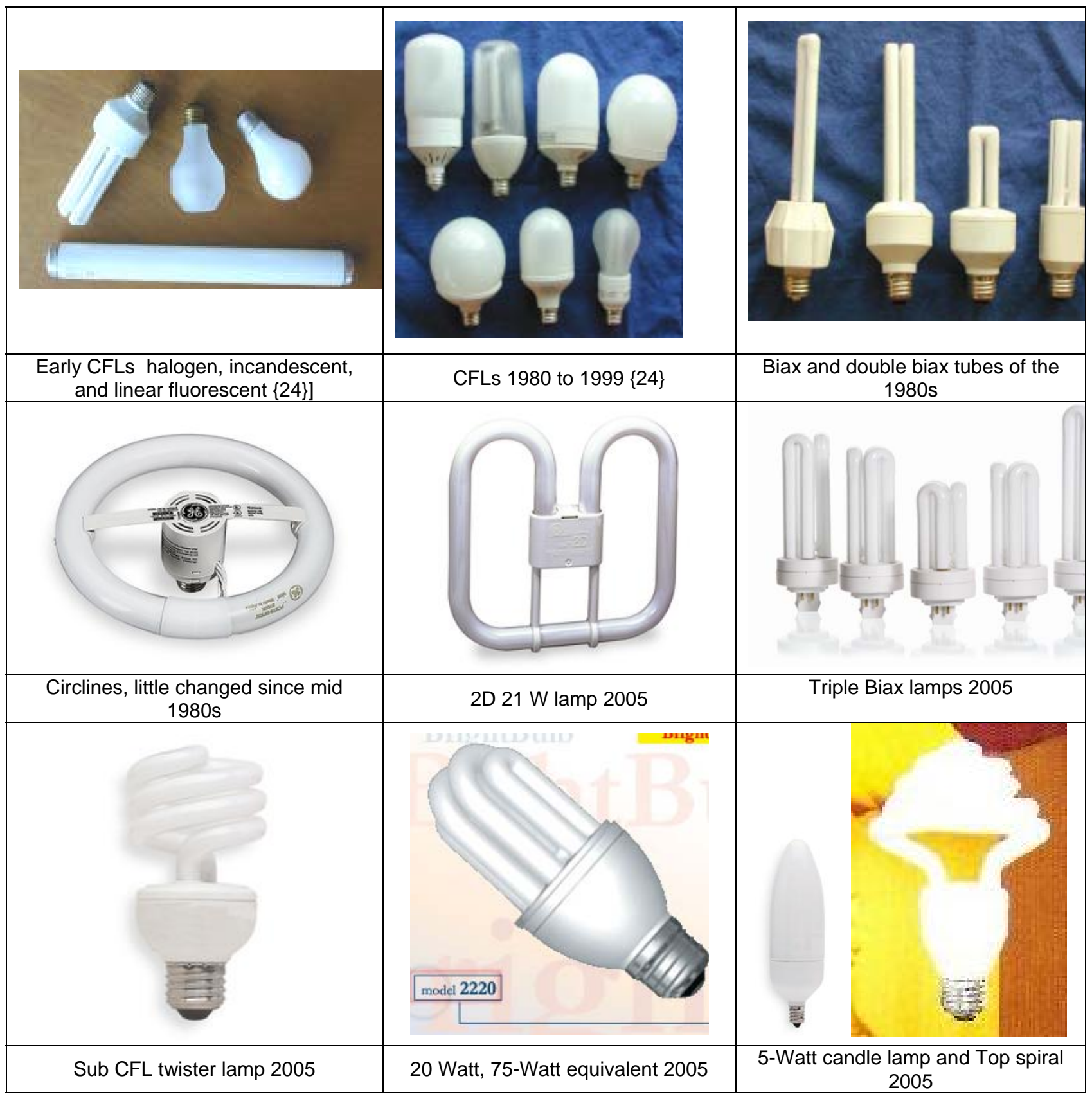

Figure 1.1. Evolution of Compact Fluorescent Lamp Designs. CFLs have come in a variety of shapes and sizes, but the overall trend has been downsizing from the early 2-feet-long U-tubes of the 1970s (which were basically a 4-ft long, 1.5 -inch-diameter T-12 bent in half) to the T6 0.5-in.diameter U-tube (6-in. lamp length plus ballast) of the mid 1980s, to the triple tube or triple biax lamps (4.9 in. lamp, 6 in. with ballast) and double U tube (3-in. lamp length plus ballast) designs of the mid 1990s, to the 4.0-in. twister lamps that first appeared in 1995. 


\subsubsection{Technological Improvements}

Many of the technical barriers were resolved over time with technological advances. The greenish tint of early fluorescents, due to the halophosphate phosphors used, was eliminated with the development of rare earth phosphors in the late 1970s. These phosphors provided warmer colors, better color rendition, increased light output, and higher efficacy, which enabled reductions in lamp length $\{6\}$. The ballasts, which fluorescent lamps need to provide starting voltage and regulate current during lamp operations, were also in need of improvement. Early magnetic ballasts were replaced in the late 1980s with electronic ballasts that enabled reduced weight, lower energy consumption, less humming, and less flicker than their magnetic predecessors $\{21\}$. Overall size continued to decrease as engineering improvements were made in lamp and ballast designs (see Figure 1.1). Unfortunately not all of these improvements were made in every model all at once, especially in lower cost lamps.

\subsubsection{Slow U.S. Market Adoption}

Even with resolution of these technical barriers, U.S. residential adoption of CFLs seemed slow in coming, especially compared to European and Asian markets. A two-year study concluded in 1996 found that $56 \%$ of households in the Netherlands, $50 \%$ of households in Germany, $46 \%$ of households in Denmark, and 20\% of households in the United Kingdom had CFLs installed compared to under 10\% in the United States $\{23\}$. In Japan by 1993, 80\% of household lighting was provided by fluorescent lamps (including tubes and circulars) while in the U.S. CFLs accounted for less than $1 \%$ of incandescent sales. $\{10\}$

As Calwell stated in a 1999 report to NRDC, "The reasons for the difference between the western European experience and the U.S experience are due to many factors, including national coordination of promotional efforts, different cultural attitudes about resource consumption and, to some extent, higher electricity prices. One particularly interesting example is from Poland, which has electricity rates similar to the US, but with much lower average household income. CFL penetration in Poland went from almost nothing in 1993 to over 30\% nationally by 1998. The reasons appear to be a combination of broad manufacturer advertising and a national, market based, CFL promotion program. Despite national differences, there are valuable lessons from programs in other countries that can be incorporated into U.S. program designs.” $\{23\}$

What was holding the U.S. market back? In addition to the technical barriers, there were other consumer barriers, some persisting from the 1980s through to today. These included high CFL price compared to low incandescent prices and relatively low electricity prices, lack of awareness of and knowledge about CFLs, consumer buying habits, negative perceptions and skepticism about fluorescent lighting, and factors particular to the US lighting market]Other market forces and market players had roles in both hindering and helping to increase acceptance of CFLs. These barriers, drivers to acceptance, and lessons learned are described in the chapters below.

\subsection{Overview of this Report}

Consumer, manufacturer, retailer, and market barriers are described in Chapter 2 of this report. Drivers for increased acceptance of CFLs including utility programs, regional programs, nationwide efforts like ENERGY STAR, the impact of the Western electric energy crisis of 2001, and the impact of California's Title 24 are described in Chapter 3. Chapter 4 describes key marketing messages and trends in advertising, promotion, and consumer education and lessons learned from these activities. 
Chapter 5 gives a snapshot of where the market is now in terms of consumer awareness, consumer satisfaction, availability, and market share. Chapter 6 describes future challenges, what barriers remain, what areas are being pursued, and new California Title 24 requirements. Chapter 7 describes implications of the CFL experience for LED lighting. Chapter 8 lists lessons learned. Chapter 9 is references. Appendix A provides a brief history of CFL development. Appendix B is a timeline of important events in the evolution of CFLs in the United States. 


\subsection{Barriers and Issues}

Many barriers and issues have been identified that in one way or another impeded the adoption of CFLs in the U.S. residential market. It should be noted that some of these issues are inherent in the adoption of most new technologies.

\subsection{Early Consumer Barriers - Technical Challenges and Performance Issues}

Throughout the 1980s, and even into the early '90s, consumers who tried the early models of CFLs found plenty not to like about the new technology. And early utility programs may have unwittingly added to consumer dissatisfaction by distributing lower cost (and lower performing) models to keep program costs down. $[\{24\}$.

In addition to the high initial cost of CFLs, there were a number of other barriers to increased use of CFLs encountered by consumers in the 1980s and ' 90 s, including:

Size/fit - In 1990 CFLs were still so big and bulky consumers had to replace lamp shades, change lamp harps, or get modification kits to make the lamps fit in some of their fixtures. A 1993 study showed that even with modifications the CFLs still wouldn't fit in over $60 \%$ of the fixtures in an average home $\{13\}$ \{9\} $\{7\}$.

Performance - Several utility surveys and consumer focus group studies pointed to performance issues such as the humming, buzzing, and flickering associated with early magnetic ballasts, delayed start, lack of dimmability, and poor outdoor performance as reasons for consumer dissatisfaction $\{8\}\{17\}\{20\}$ NEEP specifically stopped promoting more compact and high performance electronically ballasted units in favor of magnetically ballasted units in the early 1990s, because its engineers imposed stringent power factor and THD requirements that the early electronically ballasted models could not meet.

Light quality, output, brightness - Poor light levels and color rendition were an early and ongoing source of dissatisfaction and a primary reason for early removal of installed CFLs. $\{7\}\{9\}\{16\}\{20\} 50 \%$ of those who installed then removed CFLs in a 1990 Pacific Gas and Electric program felt that the 27-watt CFLs they purchased had not lived up to the program's claims that they were equivalent to a 100 -watt incandescent. \{7\} While some aspects of light quality might be due to consumer perceptions, light quality studies by Rensselaer's Lighting Research Center confirmed that color measurements vary between and even within a manufacturers' CFL product lines. \{36\}

Early failure - early bulb burnouts were a major source of dissatisfaction for participants in utility programs, especially since long life was one of the advertised strengths of CFLs $\{17\}\{24\}$. This would be problematic for any technology, but especially for one that demanded such a price premium compared to the conventional product it replaced.

\subsection{Consumer Barriers}

In addition to the technical barriers identified above, several other barriers that could be seen as directly related to the consumer have been identified. These include price, awareness and knowledge of CFLs, attitudes and fears about CFLs (and fluorescent lighting in general), skepticism of product claims, and buying habits. The fact that so many of these barriers relate to consumers' perceptions about the product 
should be a wake-up call to the important role that marketing and consumer education can play in increasing consumer acceptance of a new technology.

\subsubsection{Price}

Price was a huge initial barrier with retail prices of $\$ 25$ to $\$ 35$ per bulb common in the mid 1980s $\{24\}$. In study after study consumers pointed to price as their number one obstacle to purchasing a CFL $\{8\}$ \{9\} $\{10\}\{11\}\{13\}$. Even if the products lasted as long as 10 to 15 incandescent bulbs, they cost more than buying that many incandescents and required the purchase to be made all at once, rather than over time. To put it bluntly, how do you convince someone to mail order a bulky, odd looking "fluorescent device" they've never seen in operation for $\$ 30$ when they can buy a four pack of familiar incandescents for a dollar at the neighborhood grocery store?

Many utility studies indicated that $\$ 10$ was a magic price point. As an EPRI consumer focus group reported, consumers considered prices over $\$ 10$ to be “outrageous.” \{8\} But a 1993 Southern California Edison study found 70\% of respondents wouldn’t pay more than \$5 for a CFL $\{11\}$ and a 1992 San Diego Gas and Electric study found many unwilling to pay more than $\$ 2$ for a CFL. Utility give-away programs and rebates helped many customers clear the price barrier to at least try a CFL but in some ways these programs were also detrimental to consumer opinions. According to a 1991 EPRI focus group study, the deep discounts and free CFLs offered by utilities only served to confirm many customers' feelings that CFLs "were drastically over-priced" $\{8\}$. Consumers who did purchase early CFLs at retail prices usually purchased lower cost (and often inferior) products $\{8\}$.

Due in part to various utility promotions, CFL prices varied widely. A Southern California Edison study found that the same model of CFL carried five different prices ranging from $\$ 6.97$ to $\$ 19.99$ at five different stores in their service territory on the same day in January $1997\{18\}$. This wide variation in price made it difficult for consumers to put a value on the new product. A 1999 report written by Ecos Consulting for NRDC noted that when asked about the cost of incandescent bulbs, most Southern California Edison customers correctly guessed prices of about $\$ 2$ for a pack of four. Likewise, most correctly guessed that the cost of a typical four-foot fluorescent tube would be $\$ 3$ to $\$ 5$. However, when the researchers questioned those already familiar with CFLs about the typical cost of a CFL, more than half responded that they did not know and they wouldn't even guess at a price $\{24\}$.

As is often the case with new products, prices did eventually come down from an average of \$19 in 1996 \{17\} to $\$ 11$ in 1999 \{23\} to \$6 or less in 2003 \{35\}, thanks in part to increasing competition, increased demand and production spurred by utility and national marketing programs, the West Coast energy crisis, and other drivers discussed in Chapter 3.

\subsubsection{Awareness/Knowledge}

When Madison Electric started its CFL program in 1990, only 5\% of its customer base had tried CFLs and only 4 of the 100 retailers it polled carried them \{11\}. A review of studies done in 1992 and 1993 with three different utilities showed $40 \%$ of their customers were unaware of CFLs and close to $80 \%$ had never purchased one. $\{13\}$ This review concluded that "consumer awareness and misperception about CFL performance, along with lack of retail availability, may be bigger obstacles to CFL adoption than physical limitations”. \{13\} A 1998 study of over 500 Southern California Edison customers found only 15\% had CFLs installed \{18\}. A 1999 study of 500 customers in the Pacific Northwest, where CFLs had been promoted by local utilities for years, found only 57\% had heard of CFLs and of those only $42 \%$ had tried them. $\{17,22\}$ 
Clearly, there was a great deal of early confusion about CFLs. In an EPRI 1991 consumer focus group study, 1 in 3 consumers who initially defined themselves as non-CFL users discovered in the course of the discussion that they had actually tried compact fluorescent lighting but were confused about the correct terminology. \{8\} In an SDG\&E 1992 focus group some participants were unsure whether CFLs could be installed upside down. \{9\} Many were also unaware that CFLs could be used in typical incandescent fixtures. $\{9\}$ Adding to the confusion was the lack of a consistent name for the new product. The consulting firm Heschong Mahone Group noted in 1999 \{20\} that manufacturers referred to their CFL products by very different terminology. These have included CFBs $\{13\}$, triple tubes, biax bulbs, triple CFLs, triple biax lights, quad tubes, Earth Light SLs $\{12\}$, cf bulbs $\{9\}$, SL-lamps, and PLlamps. $\{6\}$

Several studies showed that consumers were unsure about the terms "watts" versus "lumens;" consumers consistently underestimated the amount of energy CFLs save or how long they last. $\{8\}\{9\}\{18\}\{23\}$ \{24\} A 1995 survey by Phillips of 1,000 consumers found 42\% did not know the difference between incandescent and fluorescent bulbs. \{23\} Even as late as May 2006, lumens versus watts was still a confusing issue for consumers, with consumers wondering if they could replace incandescents with higher wattage equivalent CFLs, for example using a 100 watt CFL equivalent in a 60 watt fixture (personal comm.. My Ton, Ecos Consulting May 2, 2006.)

\subsubsection{Attitudes, Fears, and Perceptions}

CFLs had an image problem that was hard to overcome. In many consumer focus groups, the very word "fluorescent" invoked connotations such as "harsh, cold, glaring, flickering, buzzing, artificial, and ugly" and fluorescent lighting was associated with eye strain, noise, greenish skin tones, and institutional settings $\{8\}\{9\}\{20\}$. Consumers expressed concerns about the safety of CFL lighting in general and its potential impacts on their health. Some participants in a focus group thought the CFLs they were given to try looked unsafe and that the tubes should have some kind of covering. \{9\} Surveys have shown that some customers would refuse to install CFLs under any circumstances due to health and safety concerns. Some individuals maintained that fluorescent lighting causes headaches and even cancer, regardless of the ballast and phosphor technologies employed.

Several early consumer studies showed consumers were skeptical of packaging claims of long life and energy savings. Consumers could not relate to the claims of 6,000 or 8,000 hour bulb lives $\{9\}$. Consumer who had tried CFLs had difficulty believing the energy savings claims because most households were only willing to purchase one or two test lamps due to their high initial cost; thus, the savings would not make enough of a dent in the monthly bill to be noticeable $\{9\}$. Several consumers specifically questioned why long life claims were not backed by a guarantee $\{8\}\{9\}$. In a 1998 telephone survey of over 200 Pacific Northwest customers who had not heard of CFLs, when asked if they would purchase an energy-efficient bulb that costs $\$ 10$ but lasts 10 times as long as incandescent bulbs and was good for the environment, one-fourth said they would not because they were skeptical about environmental claims and didn't think light bulbs could have anything to do with helping the environment \{22\}. Focus group studies by EPRI in five major U.S. cities in 1991 found that some consumers

distrusted utility motives and actually felt that reduced energy usage would result in higher rates. $\{8\}$ This sentiment was echoed by participants in a 1992 SDG\&E focus group study. \{9\} Marketing aimed at overcoming these attitudes would be necessary to win over significant portions of the market. 
An early San Diego Gas and Electric study (1992) proved that actual experience with CFLs can change consumers' perceptions. SDG\&E gave a group of customers six very different looking styles of CFLs ranging from circline to biax, to tubes covered with a plastic dome to resemble an oversized A-lamp. At first introduction, before using the bulbs, several consumers said that manufacturers should make all CFLs look more like incandescents. After trying the bulbs for 4 weeks, the customers independently chose a new favorite, the circline model, this time basing their choice not on appearance but on light quality. The 30-watt circline gave a light output equivalent to nearly 150 watts, the highest of any of the bulbs in the program. $\{9\}$. And, as later LBNL research would show, it directed that light primarily upward and downward, where it would be of greatest use to those relying on table and floor lamps to provide enough light for reading. This posed a conundrum for early program implementers, since a circline is arguably not a new compact fluorescent at all, but simply a conventional, large-diameter, linear fluorescent lamp curved into a circular shape and self-ballasted. The new, high-tech, electronically ballasted, small CFLs were being given large utility rebates and extensive promotion, but were gaining less consumer support than the much cheaper, technically "inferior" circular fluorescents already on the market.

\subsubsection{Purchasing Behavior}

Americans typically purchase light bulbs at grocery stores; however, until recently it was not likely that CFLs could be found there in any significant numbers or at competitive prices $\{8\}\{11\}\{17\}$. This lack of availability of CFLs at the location where consumers are making light bulb purchases doubtless hurt early sales. Strong promotion of CFLs through mass merchandise and home improvement stores has changed some consumer bulb buying habits. But old habits die hard, especially when buying incandescents is as convenient as buying a gallon of milk. Habit is what made $26 \%$ of those surveyed return to buying incandescents after they had purchased, and been satisfied with CFLs, according to a 2004 report prepared by ECONorthwest for the Northwest Energy Efficiency Alliance. \{35\}

\subsection{Market Availability Barriers}

This consumer practice of buying light bulbs at grocery stores collided with another barrier that could be termed both a retailer barrier or a manufacturing barrier or even a market structure barrier. It has to do with the way incandescent light bulbs have traditionally been sold in this country.

According to a November-December 1994 Home Energy article, “As a nation we buy most of our light bulbs at the grocery store. The incandescent bulb industry in the United States has been dominated by three manufacturers: General Electric, Philips, and Osram-Sylvania. Grocery stores typically carry only one of these three brands because of exclusivity agreements, so when customers go to the store they only have one brand to choose from." $\{14\}$ One study asserted that this lack of competition limits the potential for an innovative product to challenge traditional buying patterns. \{15\} Other smaller manufacturers that wished to introduce CFLs would have to compete fiercely for a small amount of additional grocery store shelf space, normally segregated from the rest of the lighting display area in a fluorescent-only section or in temporary end-cap displays. $\{24\}$ This phenomenon was and is not limited to grocery stores. Philips was for many years the nearly exclusive provider of lamps to Home Depot as Osram Sylvania was to Lowe's and General Electric was to Wal-Mart. This meant that comparison shopping across CFL models and technologies had to be done store-to-store, rather than within a single store.

Manufacturers themselves recognized the problem. According to the Home Energy article, GE and other manufacturers noted that what will save the CFL is the fact that consumers are purchasing more of their lighting products in stores other than grocery stores, such as hardware, home improvement (Home Depot, 
Home Base), and discount general merchandise (Target, Wal-Mart) stores--and that they're willing to spend larger amounts of money on lighting products in this type of store. "As light bulbs become thought of less as a commodity like eggs and milk, and more as a home improvement purchase, price sensitivity will go down." $\{14\}$ A report published in 1999 by the Natural Resources Defense Council (NRDC) $\{24\}$ noted that "among the largest national chain retailers, niche CFL manufacturers could gain a foothold if they offered types of products not already provided by the full-line manufacturers. Indeed, smaller CFL manufacturers were able to garner substantial market share because of their ability to sell next to products made by General Electric, Osram Sylvania, or Philips in stores that would otherwise rarely carry products by two of the Big Three.” $\{24\}$ Smaller CFL manufacturers were also able to make advances through independent retailers and smaller franchised hardware stores like Ace and TruServ who do not have exclusivity agreements with the big three but purchase instead through regional distributors. Other non-traditional sales channels included mail order catalogs and Internet sites hosted by private companies and DOE. $\{24\}$

\subsection{Manufacturer Barriers}

Main manufacturer barriers include the market structure issues discussed above along with lack of profit motivation, lack of marketing, competition from other technologies, and fixture manufacturer issues.

\subsubsection{Lack of Marketing}

A report by the NRDC noted that before 1990, CFLs were really not marketed to residential customers at all; despite some isolated media demonstrations, they were nearly impossible to find in U.S. retail stores and instead were selling primarily to commercial and industrial customers through wholesale channels. Any residential customer who obtained a CFL likely got it through a utility program. At the beginning of the 1990s, major manufacturers began explicitly packaging CFLs to the residential consumers with fullcolor packaging instead of plain white boxes. $\{24\}$

However mass-market advertising was still lacking. "Consumer education is critical, yet no manufacturer promotes CFLs on radio or television” a Home Energy magazine article stated in November 1993. \{10\} A 1994 Home Energy article noted, "Forget educational campaigns; up until now, none of the major manufacturers have had any kind of advertising at all for CFLs aimed at the residential market." $\{14\}$

Manufacturers claimed that educating the consumer was difficult. "We're trying to educate the consumer," Dick Dowhan, manager of corporate communications for Osram Sylvania was quoted as saying in the 1994 Home Energy article, "but it's a very difficult sell." "The single biggest challenge facing the industry is education," said Gary Gumz of GE. $\{14\}$ "You have to get the consumer to make a trial purchase." GE was the only major manufacturer planning a television commercial to support their bulbs according to the 1994 article. $\{14\}$

A 1999 study by Heschong Mahone for the California Energy Commission noted that news about the technological advances in CFLs had not widely reached the residential consumer because CFLs were not advertised as a consumer product in the mass media. "While the three major lamp companies do engage in competitive advertising to commercial customers, they have rarely used consumer based advertising for promotion of efficient lighting products in homes. Instead competition for market share among the lamp companies seems to be based more on competition for the loyalty of retail distribution outlets, rather than directly reaching out to the consumer about the merits of a particular product,” the report noted. \{20\}

A 1999 NRDC report noted that utilities and energy efficiency organizations were spending over \$23 million a year to try to shift $\$ 1$ billion of consumer purchases from incandescent to compact fluorescent 
bulbs. "This is quite a challenge in a country where $\$ 100$ million nationwide, TV-focused advertising campaigns are normally deployed to introduce new consumer products. Without more effective leveraging of advertising funding from manufacturers and retailers, this will continue to be an uphill battle," the report stated. $\{23\}$

That national marketing did not really kick in until the ENERGY STAR and "Change a Light, Change the World” programs of the early 2000s.

\subsubsection{Other Technologies}

A 1998 study for the Northwest Energy Efficiency Alliance noted that competition from other nonincandescent lighting products (such as the halogen infrared PAR lamp and high-performance metalhalide lamps) also contributed to the market's slow adoption of CFLs. $\{17\}$ A Smithsonian article noted that GE shelved several early compact fluorescent designs in favor of the Electronic Halarc, a small metal halide lamp, and that its failure temporarily placed the company in a difficult competitive position. $\{1\}$ While competing technologies is not an issue unique to residential lighting, it does point to some important lessons to be learned for those wishing to promote a specific technology, in particular the need for consumer education and clear marketing messages and terminology. For example how is the consumer to distinguish between several different lighting technologies all promoted under the name “energy efficient lights” or with vague monikers like "Earth Light”? $\{41\}$

\subsubsection{Fixture Manufacturer Issues}

While this report deals primarily with integrated screw-based CFLs, there is a growing market for lighting fixtures that use dedicated, pin-based CFLS with a separate ballast, thanks in part to new 2005 California Title 24 energy code requirements requiring dedicated energy-efficient lighting fixtures (or motion sensors) in most rooms of the house. And it can be argued that dedicated fluorescent fixtures can be economically, optically, and thermally optimized for use with fluorescent light sources, while screwbased CFLs are a compromise placed in fixtures intended for use with conventional incandescent sources, and requiring the user to discard both ballast and lamp every time one or the other fails.

In focus group studies throughout the 1990s fixture manufacturers identified barriers to CFL adoption not identified by integrated CFL manufacturers. They expressed concerns about the rapid change in CFL lamp designs and difficulties and costs in retooling their manufacturing lines to keep up with these changes. $\{16\}\{20\}$ They noted poor performing ballasts and as late as 1997 some fixture manufacturers said they were going back to the (less efficient) magnetic ballasts because of performance issues. $\{16\}$ They expressed concern about foreign competitors copying their fixture designs and selling lower priced, inferior lamps that would turn off U.S. consumers to CFL fixtures due to their poor performance $\{16\}$. They were also concerned about the lack of standardization and compatibility in CFL lamp-ballast combinations and expressed fears that when it came time for consumers to find replacement lamps to fit the ballasts in their fixtures they would not be able to find compatible lamps. $\{16\}\{20\}$ Coordination and communication in the fluorescent lamp and fixture manufacturing industries and standards organizations could help address compatibility issues.

Lighting retailers who were interviewed in 1996 identified lack of CFL fixtures as a significant barrier to CFL adoption and noted that the few CFL or linear fluorescent fixtures that were available were very utilitarian looking. \{16\} A lighting design competition conducted by the American Lighting Association, the Consortium for Energy Efficiency, and DOE that was started in 2003 and has received positive media and enthusiastic participation by some lighting manufacturers is addressing this need. 


\subsection{Retailer Barriers}

Significant retailer barriers to CFL market introduction were lack of awareness of and misinformation about the technology, which resulted in a reluctance to commit shelf space to CFLs.

Retailers employed a variety of different profitability targets. CFLs might be more profitable than incandescents on a dollars per million-lumen hours basis. However, retailers might conclude they were less profitable than incandescents on a percentage markup or "turns" basis (number of products sold per linear foot of shelf space per day).

Home improvement retailers were largely employing the "bazaar" or "flea market” business model at this time, whereby they competitively allocated selling space to various manufacturers and expected them to do much of the work of earning them a reasonable rate of return on that space. Slow performers would lose their allocations to other manufacturers. Thus retailers relied on manufacturer representatives to train their staff on how to educate consumers about the benefits of their products, set up point of purchase displays, and even maintain inventory on the shelves. Utilities increasingly found in the late 1990s that they needed to step in and assist with these functions through field staff to ensure that CFL sales would be brisk, since many of the new, niche CFL manufacturers that used utility incentive awards to secure retail allotments lacked the infrastructure to provide retailer training, inventory maintenance, and compelling point-of-purchase displays.

\subsubsection{Lack of Awareness and Misinformation}

A 1992 EPRI study of lighting retailers found that many saw it as a temporary technology that would be replaced by something else within the decade. $\{8\}$ This study found chain store lighting department managers had many misconceptions about the technology and seemed to have no more technical knowledge than the average residential customer. $\{8\}$

A California Energy Commission 1997 study of retailers showed their understanding of energy efficient lighting was surprisingly rudimentary. When asked to name their best-selling energy-efficient products, one-third included standard incandescent lamps. If they did mention fluorescent lighting, they usually mentioned four-foot fluorescent tubes, not CFLs. $\{16\}$

This same 1997 California Energy Commission study of retailers showed a majority perceived fluorescent fixtures and lamps to have low light output and other objectionable characteristics such as poor light color and ballast hum. These attitudes reflect poor experiences with early models of CFLs. There seemed to be no awareness of the major changes in technology that had occurred within fluorescent lighting (i.e., electronic ballasts) to address these problems. Most of the products they were selling were older fluorescent technologies like tubes and circline lamps. "The [retailers'] lack of understanding of fluorescent technology would seem to be a major market barrier for residential consumers.” $\{16\}$

Retailers acknowledged the problem. As early as 1991 retailers told EPRI that more advertising and consumer education was needed and that utilities should provide this to help break down the high firstcost barrier. They also wanted to see more programs from manufacturers. They praised utility coupon programs. $\{8\}$

In a 1999 report on the Northwest LightWise program, 60\% of the retailers interviewed still did not feel they had enough information about CFLs to adequately sell the product. Overall they felt unprepared to explain CFL benefits, wattage conversions, power quality, and differences in ballasts. $\{21\}$ 
This lack of awareness and education on the part of retailers could be a major hindrance to furthering any new consumer technology. In a 1998 telephone survey of 500 Northwest utility customers, only 57\% acknowledged that they had ever seen, read, or heard anything about CFLs and of those, $62 \%$ mentioned retailers as a primary source of information about the bulbs. \{17\} From 2,000 customer response cards turned in by customers who had purchased CFLs through the LightWise program in 1997, 65\% said they had heard about LightWise from retailers, either from store displays or from store employees while only $23 \%$ mentioned utility bill inserts as their source of information. $\{17\}$ This barrier has been addressed by utility programs that offered retailer training as key program components.

\subsubsection{Lack of Shelf Space}

An NRDC report published in 1999 noted that even in parts of the country where utilities had funded efficient residential lighting programs for nearly a decade, CFLs still occupied only $4 \%$ to $7 \%$ of the retail shelf space for household light bulbs, and less than that in grocery stores. $\{24\}$ Even in 2006 many grocery, drug, and small hardware stores carry only a limited variety of bulbs (personal communication M. Ton, Ecos Consulting, 5/2//06).

CFLs were fighting ingrained retailer practices. For example, conventional bulbs are an important promotional item for hardware stores, especially during "light bulb season" (fall and winter) when many hardware stores give away free light bulbs to attract customers. $\{14\}$

A 1998 evaluation of the LightWise program for the Northwest Energy Efficiency Alliance found that many retailers did not stock CFLs on a year-round basis. Retailers did not see CFLs as a profitable product line and were hesitant to devote the necessary shelf space in their stores. $\{17\}$

A program evaluation of the Northwest LightWise Program by the Northwest Energy Efficiency Alliance found that, in 1996 among retailers who did carry CFLs, over 70\% of the CFLs were stocked in the undesirable shelf location 2 to 3 feet above the floor or in dump bins. However utility programs could be effective in changing this. The LightWise Program evaluation found total lineal footage devoted to CFLs increased from 182 feet in January 1996 to 261 feet in May 1997 in Oregon and Washington. Over the three years covered in the program, LightWise products began to be placed in mid-aisle locations, areas where permanent products are normally stocked. $\{17\}$

\subsection{Electrical and Building Contractors}

Electrical and home building contractors can be significant influencers on CFL purchases both by the choices they make for lighting fixtures in new construction and the suggestions they make to homeowners doing remodels, so lack of awareness or enthusiasm on their part can be a barrier to CFL adoption. Studies have noted a reluctance among some in the home construction industry toward innovation. Fear of callbacks might be one reason. CFL fixture light quality, color, and amount of light were mentioned as reasons for customer complaints and callbacks by one-third of the 26 California residential contractors surveyed in a California Energy Commission 1997 study. \{16\} An NRDC 1999 report noted that utility program efforts to date to encourage major increases in electrical contractor CFL sales had been less well received than retail-based programs because contractors are generally constrained by very tight project budgets and derive no benefit from lower future energy bills. \{24\} Education aimed at this group could pay respectable dividends. 


\subsection{Other Barriers}

EPRI pointed to the United State's segmented lighting industry, lack of product performance standards, and lack of coordination among manufacturers, utilities, and retailers as additional barriers to CFL market growth in the United States according to a 1993 Home Energy article. \{10\} 
2.10 


\subsection{Drivers}

There were several drivers for increased acceptance of CFLs because of their energy-efficiency benefits: utility programs, regional energy efficiency programs, nationwide efforts like ENERGY STAR, the impact of the Western electric energy crisis of 2001, and the impact of California's Title 24. These and other drivers are described in this chapter.

\subsection{Utility Programs}

In the early 1990s many utilities sponsored programs intended to drive consumers toward CFLs. As a 1990 PG\&E study reported, 72\% of participants said they would not have purchased CFLs without the program. $\{7\}$ The goal of utility financial incentive programs (like giveaways, coupons, and rebates) is to temporarily lower the cost to whet the consumer's appetite for high-efficiency products, thus driving up demand which hopefully will lead to increased production, affording economies of scale in production and distribution, resulting in permanent price reductions, a process otherwise known as market transformation as shown in Figure $3.1\{23\}$

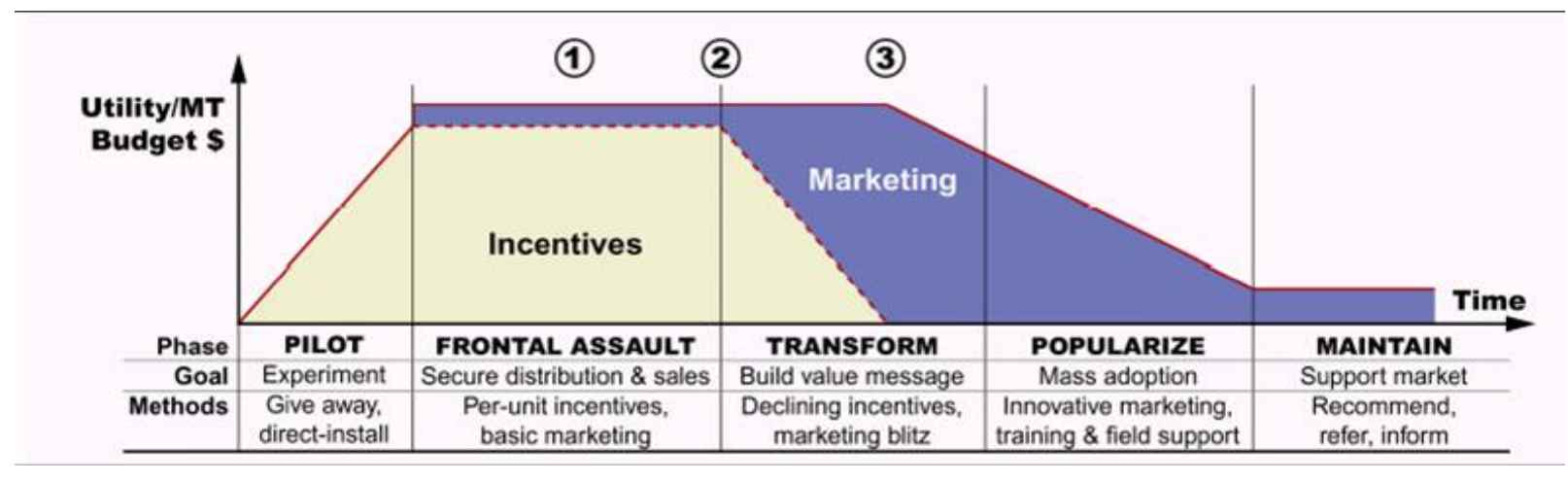

Figure 3.1. Evolution of a Utility Market Transformation Program \{23\}

Many early programs were simply product giveaways intended to familiarize customers with CFLs by distributing free samples. Through the 1990s, utility programs evolved from incentives given directly to the consumer, to utility-run mail order programs, to incentives delivered through retailers via rebate and coupon programs, to incentives delivered to manufacturers, who passed greater savings on to consumers through discounted wholesale prices.

In the late 1990's electric utilities substantially reduced their program budgets for energy-efficient residential lighting as part of broad-based cost-cutting in response to utility industry restructuring. A 1999 NRDC report noted that utility energy-efficiency investments dropped by about \$736 million between 1993 and 1997, and 42 utilities stopped funding efficiency programs entirely. \{23\} Several West Coast utilities stepped up funding of lighting programs again in response to the energy crisis of 2001 fueled by emergency state funding to minimize blackouts.

The pros and cons of the various types of utility programs that have been implemented are outlined in Table 3.1. 
Table 3.1. Pros and Cons of Utility CFL Programs

\begin{tabular}{|c|c|c|c|}
\hline $\begin{array}{l}\text { CFL Delivery } \\
\text { Mechanism }\end{array}$ & Pros & Cons & Notes \\
\hline $\begin{array}{l}\text { Manufac- } \\
\text { turer } \\
\text { Buydown }\end{array}$ & $\begin{array}{l}\text { Offers better control over pricing, distribution, } \\
\text { andtracking } \\
\text { - Minimizes over-subscription } \\
\text { - } \quad \text { with manulipulate 'sell-through' rates in agreements } \\
\text { - Also offers utility an opportunity to promote } \\
\text { selected CFLs }\end{array}$ & $\begin{array}{ll}\text { - } & \text { Less customer recognition of utility } \\
\text { - } & \text { efforts. } \\
\text { - } & \text { Difficult to target end customers } \\
\text { - } & \text { Can be disruptive in more mature } \\
\text { markets } \\
\text { - } \quad \text { Less opportunities for customer } \\
\text { education/outreach coordination }\end{array}$ & $\begin{array}{l}\text { Examples include BPA's } 2005 \\
\text { Fall Campaign, early Alliance } \\
\text { and regional efforts, SCE's } \\
1995 / 6 \text { programs } \\
\text { - Costs: can be low, } \$ 0.015 \text { or less } \\
\text { per lifetime kWh, depending on } \\
\text { buy-down level }\end{array}$ \\
\hline $\begin{array}{l}\text { Customer } \\
\text { Coupons }\end{array}$ & $\begin{array}{l}\text { - Stimulates sales through implied cash value } \\
\text { - } \quad \text { Exclusivity- customers feel they are getting a deal } \\
\text { coupomer recognition of utility effort is higher with } \\
\text { - Coupon expirations create urgency to buy now } \\
\text { rather than later } \\
\text { - Provides more opportunities for } \\
\text { promotions/education/outreach }\end{array}$ & 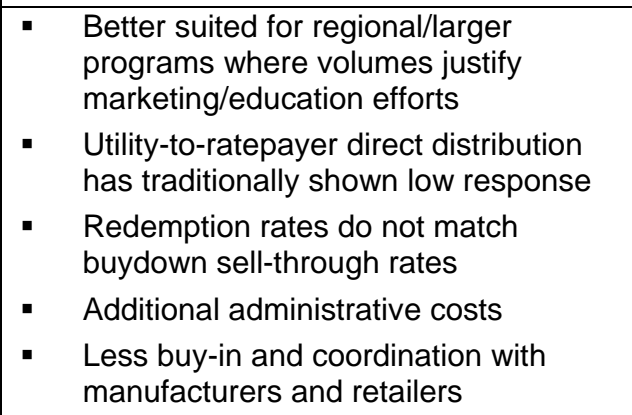 & $\begin{array}{l}\text { Examples include BPA's } 2001 \\
\text { Campaign, IPCo 2004, and } \\
\text { PSE's 2002 - 2003, and } 2005 \\
\text { Programs } \\
\text { - Costs: can also be low, ranging } \\
\text { from } \$ 0.014 \text { (PSE 2004) to } \\
\$ 0.021 \text { (BPA 2001) per lifetime } \\
\text { kWh }\end{array}$ \\
\hline Direct Install & 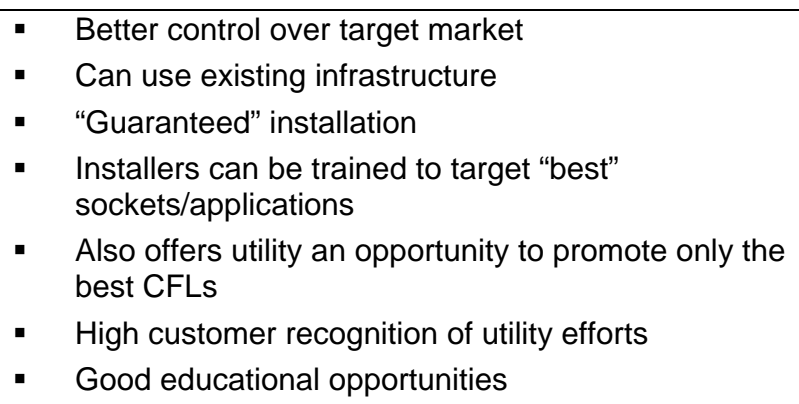 & $\begin{array}{ll}\text { - } & \text { Need additional infrastructure } \\
\text { (contractors/call centers) } \\
\text { - } & \text { Better suited for regional/larger } \\
\text { programs due to infrastructure required } \\
\text { - } \quad \text { Additional administrative costs, } \\
\text { depending on utility } \\
\text { - } \quad \text { May not work for rural areas }\end{array}$ & $\begin{array}{ll}\text { - } & \text { Successful examples } \\
\text { includeETO 2002-2005 } \\
\text { - } \quad \text { Costs: ETO's cost is about } \$ 0.03 \\
\text { per lifetime kWh }\end{array}$ \\
\hline $\begin{array}{l}\text { Bundled } \\
\text { Delivery }\end{array}$ & $\begin{array}{l}\text { - } \quad \text { Provides additional opportunity for savings } \\
\text { - } \quad \text { low-income, etc.) } \\
\text { - } \quad \text { Installers can be trained for best CFL applications } \\
\text { - } \quad \text { High customer recognition/satisfaction } \\
\text { Good educational opportunities }\end{array}$ & 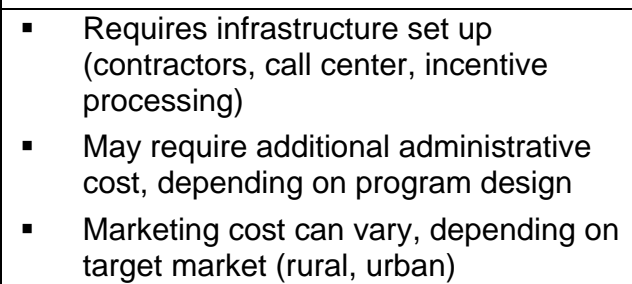 & $\begin{array}{l}\text { - Successful examples include } \\
\text { ETO's } 2002-2005 \\
\text { - Costs: ETO's cost is about } \\
\$ 0.017 \text { (multi-family) to } \$ 0.022 \\
\text { (single family). Cost includes } \\
\text { CFL savings only. }\end{array}$ \\
\hline
\end{tabular}


Industry consultants caution that utilities manage their expectations about controlling product flow. For example, under some buy-down scenarios, where products are shipped to distribution centers, manufacturers tend to have less control over timely shipment, availability, or distribution, which can result in missed promotional dates, (personal comm.. with My Ton, Ecos Consulting May 2, 2006).

\subsubsection{Utility Give-Aways, Direct Installs, and Mail Order Programs}

During the late 1980s and early 1990s, utility give-away, direct install, and discount mail-order programs put millions of CFLs into the hands and homes of consumers and helped many to try CFLs for the first time. CFLs were handed out at state fairs, included in new home packets by realtors, sold through school and civic group fundraisers, and distributed door to door by utilities. $\{9\}\{11\}\{13\}\{29\}$

Some utilities conducted direct installation programs, where utility employees or contractors entered people's homes to install CFLs in the fixtures. This guaranteed the CFLs were installed, which was an important issue for utilities attempting to ensure program quotas especially with early CFLs, which didn't fit many fixtures, and again after the West Coast energy crisis when California utilities were anxious to get participation to reduce load. Over time, giveaways became limited primarily to low-income programs, as utilities sought ways of encouraging most of their customers to make at least a partial investment in efficient lighting products on their own. Some utilities established mail order catalog programs with embedded utility incentives so customers could have qualifying products sent directly to their door. Utilities also set up programs aimed at the hotel and multifamily housing industries. Some utilities even leased CFLs to their customers, recouping payments on a monthly basis as a bill surcharge.

While give-away programs did increase local awareness and temporarily reduced the price barrier, subsequent program evaluations noted several drawbacks. Many of the CFLs initially distributed were low-cost, low-quality lamps. Chosen in an effort to keep the unit price low, these poor-performing demonstration lamps may have only reinforced negative attitudes. \{20\} As an NRDC report noted "It is difficult to convince consumers to purchase something that was once given to them for free and that did not provide a positive experience.” $\{24\}$ Direct install rates did not guarantee retention or consumer acceptance and side-stepped the process of customer choice altogether. "At least one direct-install program in New England in the early 1990s experienced removal rates of over 30\% within the first year of installation." $\{24\}$ (However, it should be noted that customer satisfaction rates with CFLs did go up as the technology improved $\{31\}$ ) A Seattle City Light report noted the nearly universal opinion of conservation professionals that, in contrast to unsolicited give-aways, programs that required customers to take some action to receive CFL bulbs would have a much higher installation rate and would strengthen customers' knowledge of and commitment to the technology. $\{31\}$ \{32\} Another danger with give-away programs and utility direct sales programs is their potential to undermine sales of CFLs at retail stores. $\{11\}$

\subsubsection{Retailer Rebate and Coupon Programs}

Many utilities mailed coupons to their customers as utility bill stuffers, encouraging the customers to redeem them at participating retailers for discounts off of qualifying products. In an effort to further reduce customer hassle, some utilities made arrangements with retailers to offer price reductions with instore coupons and then reimbursed the retailers for discounts after the sale. These programs brought purchase prices down considerably for customers. For example, through a 1994 Central Maine Power program customers could buy CFLs for \$3.99 that had retailed for \$19 to \$24. Of the coupon and rebate programs, point-of-purchase coupons had nearly $100 \%$ redemption rates, while mail-in rebates had redemption rates of $20 \%$ to $80 \%$, and coupons mailed to customers' homes had similar redemption 
rates. $\{11\}$ However, retailers were sometimes reluctant to participate in instant rebate programs due to the paperwork involved. $\{13\}$ The enthusiastic and on-going participation of retailers is one of the building blocks of the program, and one that needs to be acknowledged sincerely and frequently, as a 1999 program evaluation of the Northwest Energy Efficiency Alliance’ LightWise program evaluation report noted. $\{17\}$

\subsubsection{Incentives to Manufacturers}

Several utilities switched to programs that gave the financial incentive directly to the manufacturer when they realized the larger savings to the consumer and to themselves in terms of lower program costs. $\{10\}$ $\{17\}\{18\}\{22\}\{24\}\{28\}$ In 1992, Southern California Edison switched its \$5 per lamp rebate from the customer to the manufacturer and found much better results at lower program costs. For example if the wholesale cost of a given CFL was $\$ 10$, and the typical retail markup was $67 \%$ (\$6.70), the lamp would retail for $\$ 16.70$. A $\$ 5$ customer rebate would lower the retail price to $\$ 11.70$ but a $\$ 5$ manufacturer rebate would cut the wholesale price to $\$ 5$. With a $67 \%$ markup (\$3.35), the retail price would only go up to $\$ 8.35$. SCE gave manufacturers additional incentives for higher power factor, good color rendering, and high lumen output and also for offering additional discounts and cooperative advertising money for their retailers. SCE gained from lower administrative costs - they went from $70 \%$ of program funds for the consumer rebate program to $10 \%$ of program funds for the manufacturer program. In 1992, almost 1 million CFLs were sold under the program and annual electricity savings amounted to 53 million kWh. SCE repeated the program in 1993 and 1994 and it became the model for larger regional and national programs thereafter. $\{11\}$

\subsubsection{Niche Marketing - Multifamily, Elderly, Urban, Ethnic, and Rural}

Multifamily housing and senior citizens were two markets perceived to be drivers for energy efficiency in residential fixtures identified by fixture manufacturers in a 1997 CEC study. Apartment owners who foot the bill for outdoor and common area lighting would see the gains of large-scale replacement of incandescents with energy-efficient lighting. It was thought that older consumers would be interested in the inherent safety that longer lasting bulbs would provide by requiring less frequent trips up a ladder to do light bulb changes, especially with fixtures located on high ceilings. $\{16\}$

The hotel industry was also targeted by DOE and some utility programs. Hotels could save significantly on their lighting bill by replacing incandescents with CFL in common areas and guest rooms. In addition to energy savings, hotels also benefit from lower maintenance costs due to less frequent lamp failures. Large orders for CFLs from buyers like hotels and multi-family housing helped support increased CFL production and economies of scale.

San Diego Gas \& Electric (SDG\&E) and Southern California Edison (SCE) were two utilities who joined forces in a program specifically aimed at hard-to-reach residential customers in rural hardware stores and ethnic grocery markets that serve non-English-speaking customers (Hispanic, Chinese, Vietnamese, and Korean). They hired Ecos Consulting to run their 2002-04 program which offered a \$5 per CFL incentive to manufacturers, distributors, and retailers participating in the program. Ecos also provided marketing materials and one-on-one support to retailers and manufacturers through program field representatives. The program resulted in participation by dozens of retailers in the service territories. Most manufacturers praised the program and said they would participate again in similar programs, although they cautioned against confusion caused by multiple programs (there was a separate state-wide program in effect at the same time aimed at larger retailers.) Lessons learned included that programs with this audience take at least two or three years to build trust among the retailers. One-on-one education of retailers through field 
representatives was crucial to build trust and to educate retailers and customers about the value of the new technology and the difference in quality between ENERGY STAR and non-ENERGY STAR products. There is a need for consistency among programs. Having multiple programs operating at the same time with different incentives made program delivery difficult and engendered confusion and resistance among affected customers. $\{34\}$

Several studies noted the slow adoption of CFLs in rural America and throughout the South, due to the lack of utility programs in those areas and, especially in rural areas, to the lack of competition due to the limited number of retailers, limited shelf space, and exclusivity agreements between retailers and large bulb manufacturers. The increase in the availability of CFLs to rural areas in the early 2000s was due notably to the expansion of large home improvement center chains and Wal-Mart.

\subsection{Regional Efforts}

As early as 1989, utilities began joining forces to develop regional energy efficiency programs, including CFL programs. In 1989 two groups of Northwest utilities formed with support from Bonneville Power Administration and the Washington State Energy Office: the Northwest Residential Efficient Lighting Group and the Northwest Residential Efficient Appliance Group. These later combined and changed their name to the Residential Efficient Appliance and Lighting group (REAL). \{11\} In 1991, Pacific Gas and Electric (PG\&E) worked with the NRDC and other utilities to form the California Compact, a non-profit corporation dedicated to increasing consumer awareness of efficient lighting and increasing the availability and affordability of CFLs. \{11\} In late 1991, the Western Utility Consortium was formed among utilities in California and other West Coast states, especially for those whose demand-side management (DSM) programs involved trade allies such as appliance and lighting product retailers and manufacturers. \{11\} Also formed in 1991 was the Consortium for Energy Efficiency (CEE), a non-profit, public benefit corporation that promotes energy-efficient products with members including electric, gas, and water utilities; research and development organizations; and state energy offices; with support from the U.S. Environmental Protection Agency (EPA) and the U.S. Department of Energy (DOE). \{16\}

The LightWise Program was started in 1996 by the Northwest Energy Efficiency Alliance, representing 120 public and private electric utilities, to accelerate awareness of CFLs. $\{17\}$ In the Northeast, Northern Lights and then the Northeast Energy Efficiency Partnership (NEEP) were formed to coordinate efficiency activities. Wisconsin Energy Conservation Corporation (WECC) developed a similarly uniform program concept across multiple utilities in Wisconsin. At the same time, energy officials from eight states in the upper Midwest (Minnesota, Wisconsin, Illinois, Michigan, Indiana, Ohio, Iowa and Missouri) launched the Midwest Energy Efficiency Alliance (MEEA) to formulate new efficiency initiatives for the region. $\{24\}$

Regional programs worked with and learned from manufacturers in developing these programs. For example, Lightwise changed its requirements on power factor after losing major manufacturer participants. Lightwise initially required manufacturers who wished to be in the program to provide bulbs with a power factor of 0.9 or higher. They lost Osram Sylvania as a participant in 1998 after Osram Sylvania decided it would no longer produce high power factor bulbs, which it perceived as a "niche" market. $\{21\}$

These regional groups sponsored conferences, coordinated programs, and conducted promotional activities to encourage the use of CFLs. A 2003 article by Platts, a consulting firm for utilities, highlighted one of the roles they can play. "Retail outlets typically provide space for the products that they carry, but little else in the way of support. Whether it's breakfast cereals or CFLs, it's up to the 
manufacturers or some other party to provide any extra promotion that a product may need. The California Residential Lighting and Appliance Program (CRLAP) and the Northwest Energy Efficiency Alliance's programs both used field services teams that included staff and subcontractors to play that role. Typical activities included product merchandising — fashioning product displays, providing end-cap displays, verifying product pricing, ensuring product availability, and generally making the products more visible to shoppers-as well as employee training, on-site promotions, and reporting and responding to signals in the marketplace. In 2002, outreach activities for the Alliance's program handled by field services teams included 37 training sessions, 102 on-site promotions, and 2,349 retailer visits.” $\{30\}$

"The relative cost of participating in regional and national collaborative forums is small," a 1994 Home Energy article summarized, "but the potential effectiveness of such efforts in simplifying and leveraging the response of trade allies is enormous." $\{11\}$ Now that these regional efforts are in place, a new lighting technology with strong energy-saving potential is likely to benefit from regional support and coordinated approaches to promotional programs, versus a variety of approaches introduced by individual utilities.

\subsection{Foreign Competition}

According to a 1994 Home Energy article, "Resistance to change by the big 3 manufacturers may have been the policy in the past, but the U.S. market is not a closed system, and U.S. manufacturers can't ignore pressure from outside.” The article went on to discuss Panasonic, a small player in the U.S. lighting market, but a division of Matsushita Electric Corporation, which controlled a large portion of the lighting market worldwide and was planning a significant U.S. launch in 1994. \{14\} Panasonic achieved market penetration with a range of other energy-efficient products, but made limited inroads in the US the CFL market, pinned between the three largest full-line lamp manufacturers on one side and the CFL-only niche manufacturers on the other. Foreign owned and smaller U.S. manufacturers were eager to participate in government-sponsored CFL procurements in the late 1990s. \{19\} -

In 2001, the European Union imposed steep tariffs (up to 75\%) on Asian manufacturers in response to charges of dumping (below-cost selling) of CFLs. This caused numerous suppliers from Asia to shift their marketing efforts to North America, greatly increasing the available supply of CFLs, especially low-cost products, and driving additional price competition. $\{28\}$

\subsection{California Title 24}

California has traditionally had some of the most stringent minimum building energy efficiency requirements in the nation. California's Title 24 Building Energy Standards, instituted in 1978, required that efficient lighting fixtures be installed in the kitchen and bathrooms of new homes. While California's Title 24 deals primarily with pin-based lighting, not screw-based CFLs, it is an interesting case study of the impact of legislated requirements on lighting choices. And, due to the sheer size of the California residential market, revisions to Title 24 enacted in October 2005 (described in Chapter 6 below) requiring dedicated, non-screw-based energy-efficient lighting (or controls) in every room of the house will undoubtedly influence the market, at least in terms of increasing fixture availability, competition, and attention to CFL design by manufacturers.

In a 1997 survey of 40 national manufacturers of CFL and standard residential lighting fixtures conducted by Heschong Mahone Group for the California Energy Commission, California’s Title 24 energy code was acknowledged as one of the most important influences in the national fixture marketplace. Some manufacturers said it was the biggest single impact on the market. They felt it had accelerated development of the electronic ballast and forced the lighting industry to be more creative. $\{16\}$ The survey 
of fixture manufacturers found that "while Title 24 was mentioned 22 times as a major influence on energy efficiency in lighting products, the Green Lights program was mentioned only once. Utility DSM programs were mentioned four times, always in the past tense. They were seen as a brief perturbation in the market, sometimes as a positive influence, but just as often as a negative influence. Manufacturers rightly do not want to be subject to multiple, conflicting standards or frequent or erratic changes in the market. Stable, long-term horizons allow manufacturers to plan for the future and make more secure investments. Appliance standards, especially those that are coordinated at a national level and phased in over a multi-year period, provide that stability for wise investments.” \{20\} A survey of California residential contractors in 1997 found most were installing fluorescent fixtures most of the time, even though half their jobs were remodels (not new construction) and therefore were not required to follow Title 24. $\{16\}$

\subsection{Western Electricity Crisis of 2001}

The crisis was due to several factors: California's early foray into electric utility deregulation, which removed the safety cap allowing rates to skyrocket; a hot summer of 1999 followed by a cold winter, which together with a booming economy greatly increased demand; high natural gas prices; and droughts and cold weather in the Northwest, which diminished power available in the Northwest for export to California. All of these factors set the stage for a crisis that got worse, not better as 2001 progressed, with episodic power shortages, rolling blackouts, and California's largest utility, PG\&E declaring bankruptcy. California experienced 70 days of Stage 1 emergencies (voluntary conservation requested), 65 days of Stage 2 emergencies (interruptible customers curtailed), and 38 days of Stage 3 emergencies (involuntary rolling blackouts) in 2001. $\{28\}$

In response to these events, California's state and local governments mobilized a massive campaign to cut consumption. The California legislature authorized \$20 million in emergency funding for the California Conservation Corps (CCC) to purchase and distribute 1.9 million CFLs and 1.4 million "Flex Your Power" brochures to low-income households in every county in the state. Elected officials made public service announcements urging customers to conserve. The state convinced nearly a third of California's households to participate in the state's "20/20" program. This granted $20 \%$ electric bill rebates to households that reduced their overall summer electric use by $20 \%$ compared to the previous year. \{28\} Rising electricity rates, especially for usage above baseline amounts, gave consumers a powerful new motivation to cut demand. While baseline electric rates held steady, Californians saw very steep increases in their incremental rates for consumption above baseline. (www.sce.com/NR/sc3/tm2/pdf/ce12-12.pdf). $\{28\}$

These events drove up CFL demand and, together with the sudden appearance of low-cost Asian CFLs, sparked unprecedented competition among manufacturers and retailers to gain or at least maintain market share. This apparently resulted in substantial internal discounting and created a "virtuous cycle" in which "price cuts drove greater sales, increasing economies of scale in manufacturing and making possible even lower prices on subsequent orders. These competitive forces may well have done more to reduce average bulb prices than utility incentives, especially outside of California and the Pacific Northwest.” \{28\}

"One of the clear lessons from 2001 is that disruptions in electricity supply (and the resulting inconvenience, higher rates, and saturated media coverage) can drive the same kinds of short-term improvements in product efficiency that the oil crises of 1973 and 1979 did with vehicles. However, such responses are, by themselves, inherently transitory, and consumer behavior can be expected to revert back to previous levels if not sustained by other factors." $\{28\}$ 
Other factors were at play though; marketing efforts were finally moving from local and regional utilitysponsored efforts to a national movement with the ENERGY STAR program.

\subsection{DOE CFL Programs}

In March 1998, DOE announced that Link USA, Lights of America and Sunpark Electronics had won a competitive procurement conducted by PNNL for DOE to promote the introduction and early sales of subcompact CFLs (sub-CFLs). These lamps were no longer than 5.75 inches, had a screw-in base and provided significant energy-efficiency benefits, met high performance requirements, and came with a one year manufacturer warranty. A second phase of the program in 1999 resulted in additional sub-CFL models produced by Phase 1 manufacturers as well as new models offered by JKRL and Surya. These smaller sub-CFLs met high technical specifications for color rendition and light output, and were comparable in length to ordinary incandescent bulbs. Sub-CFL sales were promoted to large-volume buyers primarily through the web site www.pnl.gov/cfl. DOE's program succeeded in introducing 17 new sub-CFL models to the market at volume prices (including delivery) ranging from $\$ 5.75$ to $\$ 9.61$. By the program's cessation in May 2001, over 3.3 million sub-CFLs had been sold. DOE transitioned the program to the Northwest Energy Efficiency Alliance (NEEA) who changed the name to BetterBulbsDirect.com and promoted many of these same lamps to small- and medium-sized retailers as a way for them to access high-quality, competitively priced sub-CFLs. Many of the Sub-CFL Program performance specifications were subsequently adopted by DOE as the first ENERGY STAR specification for CFLs.

DOE has supported other CFL development projects, for example the Berkeley table lamp project, the ballast-in-a-socket device, and development of electrodeless lamps through R\&D cooperative agreements and support of national laboratory research. $\{26\}$.

\subsection{ENERGY STAR}

ENERGY STAR $^{\circledR}$, an energy-efficient product labeling program sponsored by U.S. Department of Energy (DOE) and the U.S. Environmental Protection Agency, launched a program for residential light fixtures in 1997. This brought a clearly recognizable national brand to a fragmented marketplace. It gave utilities and regional energy efficiency groups a benchmark of lighting performance and quality around which to rally their marketing strategies. This program inaugurated a number of high-visibility marketplace efforts, including the compact fluorescent torchiere. The establishment of the ENERGY STAR (only need to have the registration mark once in a document) fixture program and the DOE-SubCFL Technology Procurement caused many utilities and regional organizations to argue for the establishment of an ENERGY STAR labeling program for screw-base CFLs as well. This program was launched by the DOE in May 1999 and garnered participation by more than a dozen of the major CFL manufacturers and numerous utilities. \{28\} ENERGY STAR offered national branding and a single set of specifications for manufacturers to design to. $\{24\}$

Prior to the 1999 introduction of the ENERGY STAR CFL Program, CFLs were required only to meet certain reference standards for performance, safety, and labeling by the American National Standards Institute (ANSI), Illuminating Engineering Society of North America (IESNA), and Underwriters Laboratory (UL). Market share of CFLs nationally was less than 1\%, but a number of new products were entering the market from unknown manufacturers and of questionable performance. Consumers were unfamiliar with CFLs and had no way of knowing how to distinguish between better performing lamps and poor performing ones. 
DOE's motivation for introducing the ENERGY STAR CFL program was to "provide specific parameters and direction" to encourage the production of "high quality, highly efficient CFLs.” The program included minimum product performance specifications and outlined what manufacturers needed to do to become an ENERGY STAR partner (see Table 3.2). Since 1999, the CFL qualified product list has grown substantially. At the beginning of 2001, the program included 17 manufacturers offering 161 qualifying products. By the end of the year, that list had grown to include 94 manufacturers and 455 qualifying products. \{28\} However, the initial 1999 ENERGY STAR specification and 2001 revisions allowed manufacturers to do their own product testing at their internal NVLAP accredited laboratory that they met the requirements. Complaints about product performance led to changes in the specifications as shown in Table 3.1. For example, DOE added new testing requirements including the 1,000-hour rapid cycle test, and life testing. These new requirements were developed in close coordination with industry and stakeholder groups in an effort to improve the overall quality and performance of ENERGY STAR qualified CFLs.

\subsubsection{Program for the Evaluation and Analysis of Residential Lighting (PEARL)}

In January 1999, Consumer Reports published a critical product evaluation saying that many CFLs failed to live up to their claims of product performance and longevity. Home Depot, Costco, and other retailers imposed a number of testing requirements and ultimately made changes in their list of approved vendors, heightening aspects of competition well beyond price. In response, DOE, EPA, NRDC, and a number of utilities worked together to establish PEARL. PEARL performs formal off the shelf random testing obtaining samples from a number of retail locations around the country and sending them to the Lighting Research Center (at Rensselaer Polytechnic Institute in New York) for testing.

Two rounds of testing identified a number of ENERGY STAR qualified CFLs that, based on PEARL testing, did not meet program requirements. DOE acted on these findings and in some cases disqualifiednon-compliant CFLs. (the ENERGY STAR criteria has always required testing at a NVLAP accredited facility - not an independent laboratory. The independent laboratory is a requirement of the Third Party Testing and Verification Program. $\{28\}$

\subsubsection{Revised ENERGY STAR Requirements}

The bar for ENERGY STAR qualification has been raised a number of times by DOE. Qualified CFLs must now meet more stringent performance requirements, and the program has moved from accepting initial qualification at 1,000-hours of rated life to requiring at least $40 \%$ of rated lifetime test information for ENERGY STAR qualification. In addition, DOE will require manufacturers to assist in funding independent, third-party testing to help provide quality control in the marketplace. DOE's goal is to work cooperatively with manufacturers and stakeholders to continue to drive the market to offer the highest quality products and to maintain the integrity of the ENERGY STAR label. Table 3.3 provides an overview of how some of the key ENERGY STAR performance requirements have been updated (made more stringent) over the years. 
Table 3.2. ENERGY STAR CFL Program Minimum Qualification Criteria

\begin{tabular}{|c|c|c|c|c|}
\hline & 1999 & 2001 & 2003 & 2005 \\
\hline Certification & $\begin{array}{l}\text { All photometric and lifetime tests } \\
\text { to be done at a Nat'l Voluntary } \\
\text { Lab. Accreditation Program } \\
\text { accredited facility. }\end{array}$ & $\begin{array}{l}\text { All photometric and lifetime tests to } \\
\text { be done at a Nat'l Voluntary Lab. } \\
\text { Accreditation Program accredited } \\
\text { facility. Three steps to qualification: } \\
\text { initial, interim, and final }\end{array}$ & $\begin{array}{l}\text { Initial qualification increased } \\
\text { from } 1,000 \text {-hours to } 40 \% \text { of } \\
\text { rated lifetime. } \\
\text { Two steps to qualification: } \\
\text { initial and final qualification. }\end{array}$ & $\begin{array}{l}\text { Two steps to qualification: initial and } \\
\text { final qualification. Required } \\
\text { participation within the Third Party } \\
\text { Testing and Verification program. }\end{array}$ \\
\hline $\begin{array}{l}\text { PEARL or } \\
\text { Third Party } \\
\text { Testing }\end{array}$ & none & $\begin{array}{l}\text { PEARL - off the shelf testing of } \\
\text { efficacy, power factor, CRI, CCT, } \\
\text { lumen maintenance }\end{array}$ & $\begin{array}{l}\text { PEARL - off the shelf testing } \\
\text { of efficacy, CRI, CCT, power } \\
\text { factor, run-up time, 1,000-hour } \\
\text { lumen maintenance, lumen } \\
\text { maintenance at } 40 \% \text { of rated } \\
\text { life,, rapid cycle stress test, } \\
\text { interim life testing } \\
\text { Third Party Testing and } \\
\text { Verification program } \\
\text { established as a program } \\
\text { requirement }\end{array}$ & $\begin{array}{l}\text { PEARL - Same as } 2003 \\
\text { Additional mandatory test cycle } \\
\text { completed for elevated temperature } \\
\text { life testing for CFL reflector products } \\
\text { Continuation of Third Party Testing } \\
\text { and Verification Program } \\
\text { development as part of the ENERGY } \\
\text { STAR criteria for CFLs. Program } \\
\text { slated to go into effect on 1/1/07. }\end{array}$ \\
\hline $\begin{array}{l}\text { Efficacy } \\
\text { (lumens/watt) }\end{array}$ & \multicolumn{3}{|l|}{ depends on wattage, see Table 3.2} & Increased, see Table 3.2 \\
\hline $\begin{array}{l}\text { Correlated } \\
\text { Color } \\
\text { Temperature } \\
\text { (CCT) }\end{array}$ & $\begin{array}{l}\text { Between } 2700 \mathrm{~K} \text { and } 3000 \mathrm{~K} \text {. If } \\
\text { not, packaging should clearly } \\
\text { state the temperature and color } \\
\text { of product (cool or warm). }\end{array}$ & Same & Same & $\begin{array}{l}\text { Manufacturer must identify products } \\
\text { as one of these correlated color } \\
\text { temperatures: } 2700 \mathrm{~K}, 3000 \mathrm{~K}, 3500 \mathrm{~K} \text {, } \\
4100 \mathrm{~K}, 5000 \mathrm{~K} \text {, or } 6500 \mathrm{~K} \text {, }{ }^{(\mathrm{a})}\end{array}$ \\
\hline $\begin{array}{l}\text { Lumen } \\
\text { maintenance }\end{array}$ & $\begin{array}{l}40 \% \text {. Average lumen levels of } 10 \\
\text { sample lamps must be }>80 \% \text { of } \\
\text { initial ( } 100 \text { hour) rating at } 40 \% \text { of } \\
\text { model's rated life }\end{array}$ & $\begin{array}{l}\text { Same, plus must meet or exceed } \\
90 \% \text { lumen maintenance at } 1,000 \\
\text { hours. Prequalification }\end{array}$ & Same & $\begin{array}{l}\text { Proposed changes are } 1,000 \text { Hours } \\
\text { Lumen Maintenance and lumen } \\
\text { maintenance at } 40 \% \text { of Rated Life(b) }\end{array}$ \\
\hline $\begin{array}{l}\text { Average rated } \\
\text { lifetime test }\end{array}$ & $\begin{array}{l}\text { Manufacturer declared length of } \\
\text { time at which } 50 \% \text { of tested } \\
\text { lamps (typically } 10 \text { ) reach end of } \\
\text { their individual lives }\end{array}$ & $\begin{array}{l}\text { Same plus the addition of Interim } \\
\text { Lifetime Testing (see below) }\end{array}$ & Same; & Same \\
\hline $\begin{array}{l}\text { Rapid } \\
\text { CycleStress } \\
\text { Test }\end{array}$ & None & Must meet 5 out of 6 cycles & Same; & Same \\
\hline $\begin{array}{l}\text { Interim Life } \\
\text { Test }\end{array}$ & None & $\begin{array}{l}\text { Must now have at least } 8 \text { out of } 10 \\
\text { samples burning at } 40 \% \text { of rated life; } \\
2 \text { failures= need justification, } \\
3 \text { failures=immediate delisting }\end{array}$ & $\begin{array}{l}\text { Same but included in initial } \\
\text { qualification (in } 2001 \text {, was } \\
\text { required test during interim } \\
\text { test). }\end{array}$ & same \\
\hline $\begin{array}{l}\text { Warranty } \\
\text { (residential } \\
\text { use) }\end{array}$ & $\begin{array}{l}1 \text { year OR a 1-800 number for } \\
\text { consumers }\end{array}$ & $\begin{array}{l}\text { At least } 1 \text { year AND a 1-800 number } \\
\text { or web site for consumers } \\
\text { Adherence to Federal Trade }\end{array}$ & $\begin{array}{l}\text { At least } 2 \text { years for residential } \\
\text { use; at least } 1 \text { year for } \\
\text { commercial use }\end{array}$ & same \\
\hline
\end{tabular}




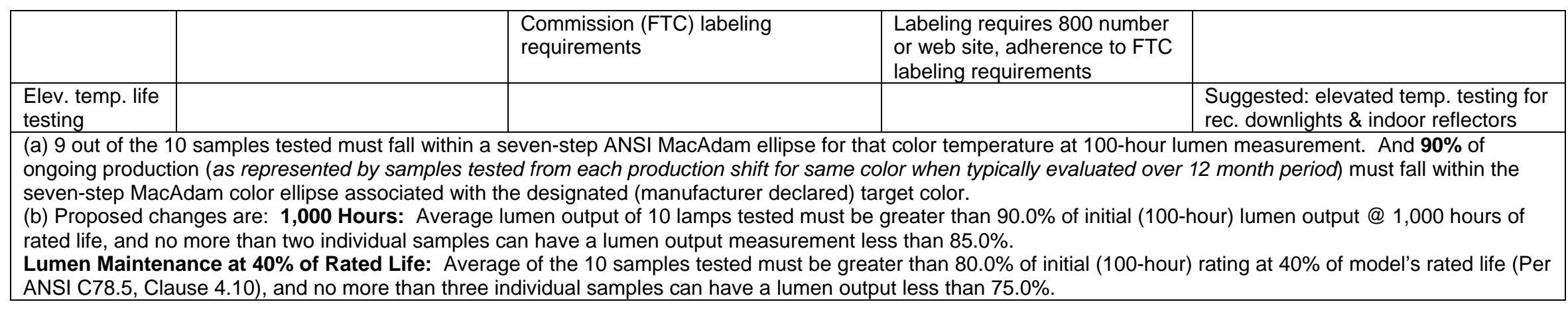


Table 3.3. Comparison of Minimum Efficacy Requirements for Past, Current, and Proposed ENERGY STAR Criteria for CFLs

\begin{tabular}{|c|c|c|}
\hline \multirow[b]{2}{*}{ Lamp Power (Watts) \& Configuration } & \multicolumn{2}{|c|}{$\begin{array}{c}\text { Minimum Efficacy: Lumens/watt (Based } \\
\text { upon initial lumen data }{ }^{2} \text { ) }\end{array}$} \\
\hline & $\begin{array}{l}\text { 1999, 2001, and } \\
2003 \text { Criteria }\end{array}$ & $\begin{array}{l}\text { Proposed } 2005 \\
\text { Criteria }\end{array}$ \\
\hline $\begin{array}{l}\text { Non-specialty, Bare lamp: } \\
\text { Lamp power }<10 \\
10 \leq \text { Lamp power }<15 \\
15 \leq \text { Lamp power } \leq 25 \\
\text { Lamp power }>25\end{array}$ & $\begin{array}{l}45.0 \\
60.0\end{array}$ & $\begin{array}{l}50.0 \\
55.0 \\
60.0 \\
65.0\end{array}$ \\
\hline $\begin{array}{l}\text { Specialty, bare lamp (3-way, dimmable): } \\
\text { Lamp power }<15 \\
15 \leq \text { Lamp power }<25 \\
\text { Lamp power } \geq 25\end{array}$ & & $\begin{array}{l}50.0 \\
55.0 \\
60.0\end{array}$ \\
\hline $\begin{array}{l}\text { Covered lamp (no reflector): } \\
\text { Lamp power }<15 \\
15<\text { lamp power }<1919<\text { Lamp power }> \\
25 \\
\text { Lamp power } \geq 25\end{array}$ & $\begin{array}{l}40.0 \\
48.0 \\
50.0 \\
55.0\end{array}$ & $\begin{array}{l}45.0 \\
50.0 \\
50.0 \\
55.0\end{array}$ \\
\hline $\begin{array}{l}\text { W/Reflector: } \\
\text { Lamp power }<20 \\
\text { Lamp power } \geq 20\end{array}$ & $\begin{array}{l}33.0 \\
40.0\end{array}$ & $\begin{array}{l}33.0 \\
40.0\end{array}$ \\
\hline
\end{tabular}

In August 2005, DOE released draft criteria that included the addition of specific test requirements for reflector CFLs identified for use within recessed downlights and indoor reflectors and increased efficacy requirements for bare and covered CFLs. The recessed downlights and indoor reflector CFL requirements included a short-term in-situ reflector testing procedure to determine initial luminous flux. The initial elevated temperature light output test procedure involves a two-step process. Lamps will initially be operated in a nominal 6" aperture, 8” deep insulated ceiling airtight (ICAT) downlight installed in the UL 1598 thermal test apparatus for IC-rated luminaries, less the insulation. This establishes the baseline illuminance corresponding to the light output determined under LM-66-00. Lamps will then be operated in the same apparatus with the insulation added. The ratio of the illuminance with insulation to the illuminance without insulation, expressed as a percentage, is Initial Elevated Temperature Light Output. The recessed downlights and indoor reflector CFLs will also be required to complete initial and final qualifications. Initial qualification includes elevated temperature testing at 1,000 hours of lumen maintenance, elevated temperature lumen maintenance at $40 \%$ of rated life, and elevated interim life testing. The final qualification is elevated temperature life testing.

See information on the revision to the ENERGY STAR criteria for CFLs at http://www.energystar.gov/index.cfm?c=revisions.cfls_spec 


\subsubsection{National Marketing: Change a Light Change the World}

In the fall of 2001, Change a Light, Change the World, a national media campaign was launched with sponsorship from EPA and other sponsors. According to Calwell, more than 100 utilities, hundreds of retailers, and 25 manufacturers participated in the promotion, including many who had not participated in previous ENERGY STAR ${ }^{\circledR}$ promotions. Over 5 million radio listeners heard radio stories about Change a Light, while radio, TV, and print advertising reached tens of millions more. Calwell credits the national campaign with driving "a great deal of additional purchasing activity" despite the intense competition for news coverage from the events of September 11, 2001. According to Calwell, GE's advertising ran in 16 major papers throughout the country and achieved 26 million impressions. Its sales during the Change a Light timeframe were up by approximately 300\% from the previous year.” $\{28\}$

\subsubsection{ENERGY STAR Participation and Lessons Learned}

Before DOE established the ENERGY STAR CFL Program, a number of utilities and energy efficiency groups operated their own CFL promotional programs; for example, the LightWise program supported by the Northwest Energy Efficiency Alliance operated from 1997 to 2000. A key contributor to the success of the ENERGY STAR program has been the fact that utilities and energy efficiency groups embraced the criteria and outreach programs established by ENERGY STAR. These groups have provided valuable input for improving the specifications. This mutual cooperation provided many benefits for all concerned:

- Allowed efficiency groups to support common performance criteria, thus reducing efforts to establish such criteria on their own.

- Enabled efficiency groups to leverage resources through a national promotional campaign with ready-made public service announcements, advertising, and support materials.

- Offered manufacturers one set of criteria versus many, depending on where the products were sold.

- Provided ENERGY STAR with an interested and engaged group of organizations that would help define specifications and offer programs that encouraged the sale of ENERGY STAR CFLs.

Southern California Edison, Pacific Gas and Electric, the Midwest Energy Efficiency Alliance, and the Consortium for Energy Efficiency have all built successful demand side management and energy efficiency programs in support of ENERGY STAR CFLs.

There are several lessons to be learned from ENERGY STAR:

- Acceptance of common product performance criteria and manufacturer participation requirements (i.e., reporting, use of logos, etc.), like ENERGY STAR, can be important to the success of a new product.

- Third-party testing, as in PEARL, can also serve an important role in cases where product performance and compliance with specifications is an issue.

- The opportunity to participate in a national promotional campaign leverages the marketing budgets of many smaller local and regional entities and presents the public with a common theme and message and brand identification.

- Establishment or identification of an organization, like ENERGY STAR, that works with industry and stakeholders to establish product performance standards, monitors compliance with those standards, and provides labeling and educational support for compliant products can greatly improve the success of the new technology category in the long run. 


\subsection{CFL Sales Peak in 2001}

After years of steady but unremarkable sales increases, CFL sales jumped in the United States in 2001. Relative to 2000 levels, national retail sales more than doubled, California sales increased by more than four times, and Northwest sales increased by roughly 10 times. National sales of CFLs grew from a $0.5 \%$ share of the screw-based lamp market in mid-2000 to a 1.6\% share in mid-2001 and reached $2.1 \%$ by the fourth quarter of 2001 (Figure 3.2). Calwell reports "Even accounting for sharp declines in the average selling price (ASP) of compact fluorescents, it is still interesting to note how much more dramatic the CFL market share became on a dollars basis. Remarkably enough, for the full year of 2001, CFLs outsold incandescent bulbs on a dollars basis in California." Calwell notes that these figures indicate CFLs' newfound importance to retailers as a source of revenues and profits. $\{28\}$

ECONorthwest reported Northwest sales totaling 8.6 million CFLs in the five quarters from fourth quarter 2000 through fourth quarter 2001, 20 times higher than the Northwest Energy Efficiency Alliance had predicted in their preprogram planning estimates. $\{29\}$

These higher sales in the west and northwest are attributable to the many factors mentioned above:

- $\quad$ power shortages in California and impacts on nearby regions

- deregulation and rising electricity rates

- improvements in CFL technology and testing for product quality

- lower wholesale CFL prices, due to economies of scale and greater competition

- expanded ENERGY STAR® promotions, including "Change a Light, Change the World"

- increased utility incentives and promotion in response to the energy crisis

- long-standing regional utility-funded efforts to build retail sales infrastructure and awareness. $\{28\}$

These figures show that CFLs had been well positioned to respond to the energy crisis of 2001 but sustaining sales and increasing market share would not happen automatically. It would take continued marketing and refinement of the message to reach those consumers still not yet convinced. Chapter Four discusses several marketing approaches and themes applied or proposed through two decades of CFL development and promotion. 


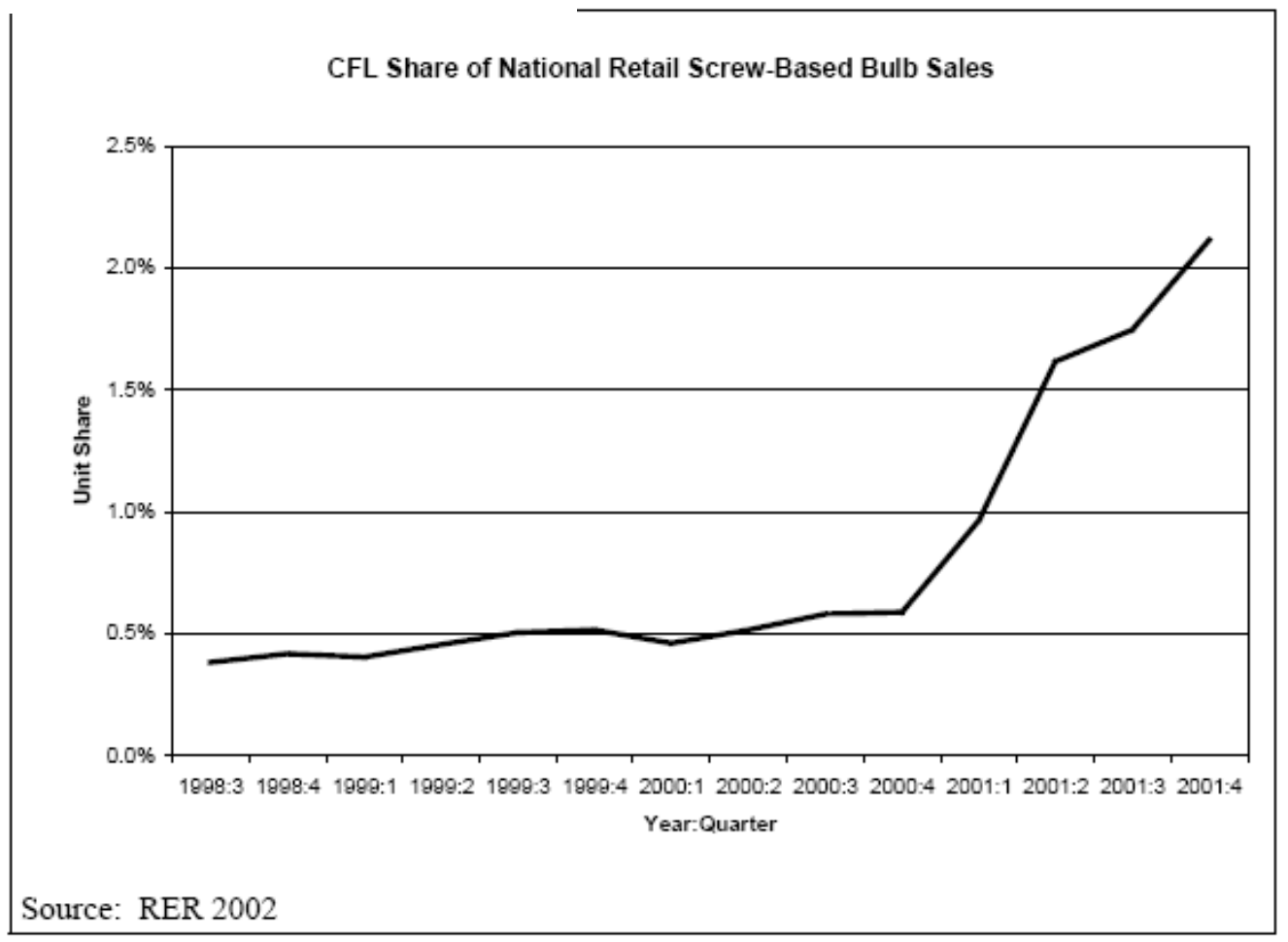

Figure 3.2. National CFL Market Share, Third Quarter 1998 to Fourth Quarter 2001. (Source is Residential Market Share Tracking: Lamps. Prepared by Regional Economic Research for Southern California Edison. April 30, 2002, as cited in \{28\}). 


\subsection{Marketing Messages, Tactics, and Trends - Suggestions from the Field}

As we have seen in our discussion of barriers, technology improvements alone do not guarantee market acceptance. Getting the word out about the new product, showing consumers its value, educating retailers on how to market it, working with manufacturers to leverage promotion efforts- all of these are critical pieces of the consumer acceptance pie. Marketing activities and strategies have evolved as improvements were made to the CFL technology, as market players became more familiar with the technology, and in response to outside influences like the Energy Crisis of 2001, foreign competition, and the rise of do-ityourself (DIY) home improvement centers. Table 4.1 summarizes some of the major marketing trends. These are further discussed below.

Table 4.1. Marketing Trends

\begin{tabular}{|l|l|l|}
\hline \multicolumn{1}{|c|}{ Trend } & \multicolumn{1}{|c|}{ 1980s-1990s } & \multicolumn{1}{|c|}{ 2000s } \\
\hline Key Messages & Talk about technology & $\begin{array}{l}\text { Talk about benefits to consumers: } \\
\text { longer life, cool and safe, less } \\
\text { bulb changes, \$ savings }\end{array}$ \\
\hline Source for Bulbs & Like an incandescent & Better than an incandescent \\
\hline Utility Incentives & Utilities (giveaways, direct & $\begin{array}{l}\text { Retailers (point of purchase } \\
\text { displays, retailer training) }\end{array}$ \\
\hline Shelf Display - Strategy & Given directly to consumer & $\begin{array}{l}\text { Given to manufacturer to pass on } \\
\text { higher savings to consumer }\end{array}$ \\
\hline $\begin{array}{l}\text { Shelf Display - Quantity and } \\
\text { Location }\end{array}$ & section of shelf & $\begin{array}{l}\text { CFLs integrated with other types } \\
\text { of lamps, grouped by application } \\
\text { and marked "good", "better", } \\
\text { "best" for energy efficiency }\end{array}$ \\
\hline Packaging & Plain white boxes & $\begin{array}{l}\text { Increasing amounts; increasingly } \\
\text { at eye level }\end{array}$ \\
\hline Advertising & $\begin{array}{l}\text { Informative packaging that } \\
\text { explains benefits }\end{array}$ \\
\hline Local and regional by \\
individual utilities and \\
retailers & $\begin{array}{l}\text { Joining national marketing efforts } \\
\text { like ENERGY STAR and } \\
\text { Change a Light Change the } \\
\text { World campaign }\end{array}$ \\
\hline Manufacturer Advertising & Almost none & $\begin{array}{l}\text { Manufacturers participating in } \\
\text { regional and national efforts }\end{array}$ \\
\hline Retail Availability & $\begin{array}{l}\text { Few available at retail. Direct } \\
\text { from utilities. }\end{array}$ & $\begin{array}{l}\text { Rising influence of big box DIY } \\
\text { stores, e.g., Home Depot and } \\
\text { Lowes and eventually in some } \\
\text { grocery stores }\end{array}$ \\
\hline
\end{tabular}




\subsection{Key Marketing Messages}

Although CFLs were first introduced in 1979, marketing of CFLs to residential consumers didn't really start until around 1990; at that time only about one-third of the sales of screw-based CFLS were through retail stores while the remainder were through commercial and industrial distribution channels like electrical wholesalers. $\{28\}$ A significant percentage of CFL distribution to residential users was via utilities. Many of the barriers in terms of availability, lack of advertising, and lack of consumer and retailer education have been identified above in Chapter 2.

Early utility messages focused on how to use the technology, for instance how to make the large, oddsized CFLs fit into home fixtures, and the energy savings possible, although as mentioned above, discussions of lumens per watt were meaningless to many members of the public.

In an effort to shape their programs more effectively, utilities early on asked focus group participants about marketing messages. Consumers in a 1992 San Diego Gas and Electric study expressed preferences for phrases such as "gives off the same amount of light," "saves $75 \%$ of lighting cost," "cost savings," "value for your money," "lasts 10 times as long," "longer bulb life,” and “energy savings.” \{9\} Long life, bulb coolness, and potential to minimize bulb changes in hard-to-reach places were all mentioned as benefits by consumers in this study. \{9\} Energy efficiency, brightness, and long-life were seen as the most appealing attributes of CFLs by members of this focus group who had been given six different CFL models to try. $\{9\}$ In fact the top reason for liking or not liking a bulb was brightness (or lack thereof). \{9\}

Based on user group feedback, utilities began including more customer benefits in their messages. For example, Madison Gas and Electric adjusted its print radio and TV advertising from simple description of the technologies and dollar incentives to customer benefits such as personal and environmental savings in its 1990 to 1994 CFL campaigns. $\{11\}$

In an article on green marketing, eco consultant Jacquelyn Ottman said "the first rule of green marketing is the first rule of marketing: focus on customer benefits i.e., the primary reason why consumers buy certain products in the first place. Do this right, and you'll motivate consumers to switch brands or even pay a premium for your greener alternative. Next, keep in mind that for green marketing to work, it is important that customers: $\{41\}$

- $\quad$ Are aware of and concerned about the environmental issues your product addresses

- Feel that by using your product they will make a difference ("empowerment")

- Believe your claims ...

- $\quad$ Feel your product will work as well as non-green alternatives ...

- Can afford any premiums.” $\{41\}$

She recommends from an organizational standpoint that environmental considerations be integrated into all aspects of new product development and marketing by encouraging cross-functional teams of marketers and engineers. She suggests that new stakeholders be enlisted besides suppliers and retailers, including educators, members of the community, regulators, and NGOs $\{41\}$.

A 1999 study by Heschong Mahone for the California Energy Commission noted that "utility companies (not lamp manufacturers) have been providing the primary path for public education about CFL lighting, with brochures and demonstration centers, but their reach has been limited and their focus has been on energy savings rather than consumer attitudes. While energy efficiency may be a social good, it is not generally the prime criterion by which people choose their lighting. Lighting has many other aspects which are more prominent - pleasant ambiance, aesthetics, brightness, long-life, safety, security, ease of 
replacement, etc. CFL lighting manufacturers must sell these aspects as well. $\{20\}$ They went on to recommend that the CEC provide public service advertising focused on associated, non-energy features of CFLs such as their long life and cool, safe operation. $\{20\}$

The NRDC, in their 1999 report, also recommended that utility energy efficiency programs use consumer education and marketing to shift consumer focus from product price to product value, including nonenergy-efficient attributes like longevity and convenience. $\{23\}$

Calwell of Ecos Consulting reasoned that product payback might be a good marketing message as paybacks of one year or less are possible with CFLs. The value of the energy savings of a single bulb might never enter the picture, because it is difficult to detect one bulb's impact on a monthly utility bill, payback in terms of replacement light bulbs alone is a more obvious and sellable benefit. For example, if the average consumer determines that a CFL lasts 10 times as long as a regular light bulb, he or she would be inclined to buy it if it costs less than 10 regular light bulbs. $\{24\}$

In a national consumer survey of lighting choices including incandescents by Philips, longer life rated highest in the attributes consumers were seeking from their lighting purchases, exceeding their desire to purchase "a major brand," to get a "good value" for their money, or to purchase a "high quality" lamp. \{23\} In a 1997 telephone survey of 500 purchasers of LightWise bulbs, $71 \%$ said energy savings is why they chose a CFL over an incandescent and 57\% said long life. $\{17\}$ In a 1998 study of 521 Southern California Edison LightSaver program participants, 75\% said they bought the bulb to save energy, while only $10 \%$ bought it to change light bulbs less, and only $8.3 \%$ said they purchased CFLs because of a rebate or discount. $\{18\}$

Product naming that emphasizes key benefits and de-emphasizes the fluorescent technology has been used in attempts to boost sales. It could be argued that Philips achieved greater early sales of CFLs than its competitors by naming its product something other than "fluorescent” (given the fear many consumers had of that technology) and co-branding it with a range of other efficient technologies in the hopes of shifting people away from the conventional incandescent lamp largely dominated by GE. Philips initially called its product EarthLight to highlight its environmental benefits then changed the name to Marathon to emphasize its long life. Heschong Mahone suggested in its 1999 report that the industry adopt a new industry-wide name for CFLs that would avoid the word "fluorescent” all together. $\{20\}$ And the NRDC noted that many energy-efficient lighting manufacturers have gone out of their way to avoid the use of the word "fluorescent” on product packaging, using phrases like "electronic light bulb” or "energy saving bulb” instead. Recognizing potential confusion with this, NRDC recommended that manufacturers develop a common language for lighting. $\{23\}$ Confusion over naming was noted in the barriers chapter above.

Noting another trend, while some early designs attempted to make CFLs look more like incandescent bulbs by hiding the tubes under plastic domes, the authors of a 1999 NRDC report advised that marketing strategies should celebrate the differences. "Most CFL marketing strategies to date have focused on the great similarity of CFLs to incandescent bulbs. This has probably been a mistake. If a product is so similar to what consumers already use and costs more, why should they bother switching? It may be time to use educational and marketing campaigns to celebrate the distinct advantages of energy efficient lighting, and the disadvantages of incandescent light bulbs. Incandescent bulbs have distinct disadvantages: high operating temperatures, short bulb life, and the inconvenience of more frequent bulb changes. There is also a style and design angle that can be explored. Incandescent bulbs create "hot spots" of light within fixtures and scalloping (alternating patterns of light and dark) on adjacent walls, while CFLs and especially linear fluorescents can provide a more diffuse, continuous light.” $\{23\}$ 
However, marketing must also shape consumers' expectations about a new product so that they are not disappointed. Several studies have indicated consumer dissatisfaction with the amount or brightness of the light produced by CFLs. Consumers who were promised a 60-watt or 75 watt equivalent were put off by the unexpected warm-up times of CFLs and the more diffuse light produced. As a 1999 NRDC study noted, due to their engineering, CFLs would never match incandescent and halogen sources for highly directional, focused lighting applications, whenever an extremely small, intense light source is needed. $\{24\}$

\section{“Shedding Light on Life Cycle Benefits” Jacquelyn Ottman of J Ottman Consulting, Inc.}

In an article on green marketing, Jacquelyn Ottman of J Ottman Consulting, Inc., discussed an early attempt at CFL marketing: "Philips Lighting's first shot at marketing a stand-alone compact fluorescent light (CFL) bulb was as clumsy as the funny-looking bulb that didn't easily fit most lamps. To boot, the "EarthLight" name confused consumers (I personally thought it was some type of plant light), and at \$15 each versus 75\& for incandescents, Earth Light couldn't climb out of a green niche. The brilliantly relaunched 'Marathon' CFL solved several problems: the 'super long life' positioning and incandescentlooking shape appealed to the convenience-oriented mainstream, while the promise of saving \$26 in energy costs over its lifetime lured thrifty consumers. With the ENERGY STAR label to add credibility, as well as new sensitivity to rising utility costs and electricity shortages, sales in 2001 were up $12 \%$ in a flat market." $\{41\}$

\subsection{Transition from Utility to Retailer Marketing}

As noted above, many utility efforts in the 1980s and early 1990s were DSM-driven programs focused on getting CFLs into the hands of consumers as expediently as possible, often through CFL giveaways, direct installation programs, and mail-order programs, all of which set up the utility as the direct provider to the consumer. In 1991 the majority of CFLs (43\%) were being purchased directly from the utility. At that time, 38\% of incandescents were purchased at supermarkets. \{8\} A 1999 NRDC report noted that utilities driven by annual sales goals were reluctant to stray from the "time-honored formula: pay rebates to entice people to buy products. However, these start-and-stop efforts rarely ratchet toward a long-term change in consumer preference. If anything, they only prove that everybody loves a sale, and that many people are willing to wait for the next one before buying again.” The NRDC recommended that utility residential lighting programs shift resources from product incentives to marketing investments and that utilities, manufacturers, retailers, and the government work together to build a message of value instead of price in customers' minds. \{23\} In the mid 1990s utility programs did begin moving to CFL programs that actively involved retailers, with point of purchase rebates and coupons distributed by retailers. This enabled consumers to take a more active role in their own CFL acquisition, it enabled utilities to transition from a provider role to an advisor role, and it recognized the role retailers can play in influencing purchase decisions.

While retailers praised utility coupon programs, they also acknowledged the need for consumer education by the utilities and they requested more marketing by manufacturers. \{8\} In November 1996 and May 1997 telephone surveys as part of the Lightwise Program, 60\% of retailers said they did not have enough information about CFLs to adequately sell the product. They felt unprepared to explain CFL terminology such as wattage conversions, power factor, and ballasts: To increase their marketing capabilities, retailers asked for consumer education and point-of-purchase materials such as brochures, demonstration models, and wall displays, along with price incentives. $\{17\}$ 
The California Residential Lighting and Appliance Program (CRLAP) is an example of one program designed to address these needs. Begun in 1999, the multi-year effort involved several California utilities in a massive statewide effort to build retailer infrastructure for marketing CFLs, including professional training of sales representatives and regular visits by field staff to each store to display merchandise attractively, tabulate inventory levels, and maintain point-of-purchase displays together with cooperative advertising programs to leverage investments by manufacturers and retailers in product promotions. The program was a decisive shift from bill-stuffers and utility-driven advertising to in-store advertising materials and events, including point of purchase banners and shelf-mounted signage, frequent sidewalk sales, and heavily publicized torchiere turn-in events. $\{28\}$

The utility shift to market transformation type programs encouraged more active participation by all market players. Recommendations for successful programs and players, which emerged from several program evaluation studies, include the following:

- Design multi-year programs around the lighting season (Sept to April) not the calendar year. $\{23\}$

- Leverage retailer and manufacturer capabilities by crafting a more visible and attractive presence for efficient residential lighting products in retail outlets. $\{23\}$

- Educate retail sales staff through training and field visits by utility staff or manufacturer representatives. $\{23\}$

- Conduct in-store product demonstrations. $\{17\}$

- Target a few key market segments to increase product availability, improve quality, and reduce long-term purchase price: dimmable and subcompact CFLs, recessed downlights, decorative porch lights and linear fluorescent fixtures, and lighting controls. $\{23\}$

- Provide point of purchase displays and signage.

- Leverage marketing dollars by combining the efforts of manufacturers and utilities and joining regional and national marketing efforts like ENERGY STAR.

- Promote CFLs through several different mediums to reinforce customer familiarity and positive associations with product. 10$\}$

Several recommendations were aimed at utilities in their advisor/educator role:

- Utilities should focus on information programs, which were praised as "the cornerstone on which all energy conservation efforts are built” $\{11\}$

- Utilities should conduct consumer education activities including utility bill stuffers, and CFL product demonstrations at local fairs, home shows, and energy shows. $\{17\}$

- Utilities should support public service advertising to educate consumers and bring efficiency forward as a lighting selection criterion. $\{20\}$

- Utilities should provide consumer education tools to retailers like brochures, posters, demonstrations, and wall displays. $\{17\}$

- Utilities should offer education programs like telephone hotlines and websites to consumers and training programs for builders, designers, and retailers. \{11\}

It was noted that, like retailers, buyers groups can also be an influencer on the availability of CFLs. Buyers groups were formed to help smaller retailers obtain a greater variety of products and improved pricing by entering into contracts with large manufacturers on behalf of several retailers. For example, True-Value stores typically purchase lighting and other products from one buyers group. Because buyers groups influence many smaller retailers (in 1999 there were 750 TruServ stores in the Northwest alone), they can have a significant influence on the success of CFLs and in 1999 they were noted as a group that had not yet been the focus of utility CFL efforts. $\{24\}$ Betterbulbsdirect.com was established by the 
Northwest Energy Efficiency Alliance in 2000 to help small and medium sized builders find and enter into effective volume purchase arrangements for ENERGY STAR CFLS.

One aspect of the transition in program formats was the switch from utilities giving their financial incentives directly to the consumers to giving the incentive to the manufacturers. $\{10\}\{17\}\{18\}\{22\}$ For example the CRLAP targeted "significant investments of incentive dollars to competitively allocated manufacturer buydowns, which maximized price leverage per dollar invested. More importantly, they greatly amplified competition among manufacturers. Those who moved their initial allocations of incentive dollars through retail channels by the program deadline could obtain additional allocations from their less successful competitors. This gave upstart manufacturers a foot in the door when competing for retail distribution space with larger, well-established competitors.” $\{28\}$

\section{California Residential Lighting and Appliance Program (CRLAP) (excerpted from} Calwell et al. 2002)

“In 1999, after years of individual efforts, California utilities embarked on a joint, multi-year effort to transform the retail landscape for ENERGY STAR ${ }^{\circledR}$ lighting. Working primarily through subcontractors Ecos Consulting and ICF Consulting, the California Residential Lighting and Appliance Program (CRLAP) sought to do more than simply bring down the price of CFLs. It undertook a broad, sustained initiative to build a conscious market preference for ENERGY STAR ${ }^{\circledR}$ labeled bulbs, torchieres, and hard-wired fixtures. Program features included

- Assignment of channel managers and unique marketing strategies to each key retail segment.

- A decisive shift from bill-stuffers and utility-driven advertising to in-store advertising materials and events, including point of purchase banners and shelf-mounted signage, frequent sidewalk sales, and heavily publicized torchiere turn-in events.

- A massive statewide effort to build retailer infrastructure for marketing the products, including professional training of sales representatives and regular visits by field staff to each store to display merchandise attractively, tabulate inventory levels, and maintain point-of-purchase displays.

- Cooperative advertising programs to leverage investments by manufacturers and retailers in product promotions.

- Significant investments of incentive dollars into competitively allocated manufacturer buydowns, which maximized price leverage per dollar invested. More importantly, they greatly amplified competition among manufacturers. Those who "moved" their initial allocations of incentive dollars through retail channels by the program deadline could obtain additional allocations from their less successful competitors. This gave upstart manufacturers a foot in the door when competing for retail distribution space with larger, well-established competitors. $\{28\}$

Collectively, these program elements helped accomplish something previous California utility programs had not: they built a truly competitive marketplace in efficient lighting. This occurred in two key ways. First, it meant that Lights of America, a dominant early participant in utility incentive programs for efficient residential lighting, began to face strong competition from similarly nimble manufacturers of affordable products. Second, it meant that energy efficient lighting became an important enough revenue source to Home Depot, Lowe's, Home Base, Orchard Supply, and other retailers to cause them to invest their own promotional resources (discounts, advertising, etc.) to grab market share from their competitors. Beyond increases in 
product sales, the CRLAP program achieved the following in 2000 (Latham 2001): $\{28\}$

- 837 sales staff in 179 participating national retail stores trained, with a 54 to $76 \%$ increase in proficiency test scores regarding ENERGY STAR® lighting $\{28\}$

- 1,409 self-standing displays placed in retail stores

- $\quad$ 13,567 pieces of point-of-purchase (POP) material placed in stores, include banners, hang tags, and shelf-mounted cars

- In-store product demonstrations conducted in 158 DIY, mass merchandiser, grocery and specialty hardware stores

- $\$ 600,000$ of cooperative advertising and promotion across 10 different projects, leveraging equivalent investments by manufacturers and retailers

- In-person recruitment meetings with 18 different ENERGY STAR ${ }^{\circledR}$ lighting product manufacturers $\{28\}$

The results of this large-scale effort to reshape the retail landscape became quickly evident. In 1998, California's CFL market share was about $0.8 \%$-- double the $0.4 \%$ share observed in the rest of the U.S. However, by 2000 , the California share surged to nearly $1.2 \%$, widening the gap with the rest of the U.S., where the share hovered between 0.4 and $0.6 \%$.” $\{28\}]$

\subsection{Shelf Displays}

Philips, in a national consumer survey cited by a 1999 NRDC report, learned through market research that only $30 \%$ of light bulb buyers enter a store knowing exactly what they want. The remaining $70 \%$ make that decision at the store, which drove Philips to revamp its point-of-purchase displays entirely to segment its products by application and purpose rather than by technology or wattage. Osram Sylvania made a similar change in its displays even earlier, and General Electric's displays also became more applicationfocused. Now a customer can go to the store seeking a bulb for a reading lamp, for example, and be presented with good/better/best options that correlate to longer product life and greater energy efficiency. This strategy was expected to increase CFL sales compared to the older strategy of placing all CFLs in a single part of the store, regardless of their light output, shape, or application.” $\{23\}$

Several studies found that shelf space allotted to CFLs increased over the course of the study, that more retailers moved CFLs from temporary dump bins to permanent shelf locations, an increasing percentage of CFLs were moved from the less desirable knee-level display shelves to the more desirable eye-level shelves, more retailers carried more models of CFLs, and more retailers carried CFLs year-round instead of just during promotions. $\{17\}\{32\}$

\subsection{Packaging}

Through the 1980s, CFLs were still being sold in plain white boxes. In the early 1990s, major manufacturers began explicitly packaging CFLs to the residential consumers with full-color packaging. $\{24\}$ Consumer research has identified packaging as an ideal medium for informing consumers about this technology, which is still unfamiliar to some. Several studies have specifically addressed the impact of various packaging messages. For example, studies found that the CFL packaging image showing 10 incandescents $=1 \mathrm{CFL}$ was well received $\{8\}$. The NRDC noted that many energyefficient lighting manufacturers avoid the use of the word "fluorescent" on product packaging, using phrases like "electronic light bulb” or "energy saving bulb” instead. This was confirmed in interviews PNNL conducted with lighting manufacturers for this report. Manufacturers also told us they use product packaging to highlight selling points like energy savings and long life. One manufacturer changed its 
packaging to focus on what consumers recognize easily, making it clear that CFLs are incandescent replacements. Their packaging refers to watt equivalents rather than lumens; for example, it clearly states that a 15-watt CFL is a replacement for a 60W incandescent, and it lasts 6 to 7 times as long.

Manufacturers also use graphics, such as a drawing of a CFL next to an incandescent showing that a 15watt CFL equals a 60-watt incandescent. One manufacturer said rather than explaining lumens, they talk about brightness on the packaging, saying "bright" was a word that resonates with consumers.

Manufacturers have also transitioned from boxes to blister packs, a move intended to reduce breakage in shipping that also has the advantages of providing more front-side surface for product information and allowing customers to see the product before they buy it.

A new move would add a color label to packaging to help identify whether the CFL product produces a warmer or cooler light. The effort, put forth by a color communication group consisting of representatives of lamp manufacturers, the National Electrical Manufacturers Association, DOE, EPA, and the Consortium for Energy Efficiency, would convey color through a label on the packaging that shows six colors, which are assigned letters. A large letter indicates the color of the light produced by that product (Figure 4.1). $\{45\}$

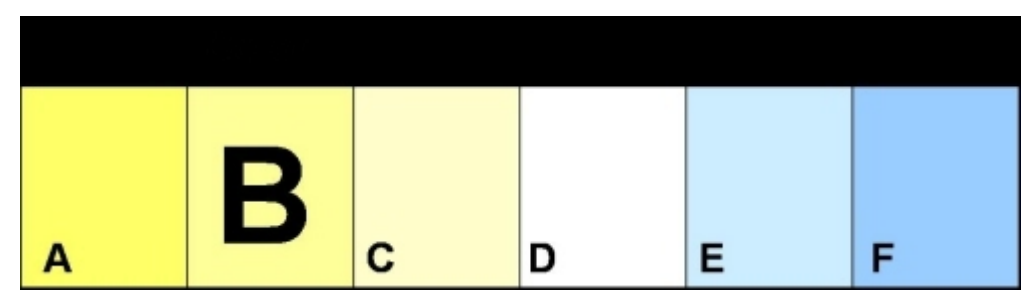

Figure 4.1. Proposed Lamp Color Label for CFL Product Packaging

\begin{abstract}
A Point of Purchase Display that Talks to You
Lights of America produced a point-of-purchase display as part of Southern California Edison's LightSaver Program which included an audio message activated by pushing a button that explained the cost and energy savings benefits of compact fluorescent bulbs.

"Do you know you can save up to \$127 each year just by changing a light bulb? Lights of America in cooperation with Southern California Edison, is offering compact fluorescent bulbs at a special price. Now you can cut your lighting costs way up to $80 \%$. Compact fluorescents produce three times the light of a regular bulb with less heat and last up to 16 times longer. They turn on instantly and produce high quality flicker free illumination. Look for the special red and white sticker on Lights of America products to receive this special price”. $\{18\}$
\end{abstract}

\title{
4.5 Advertising
}

Advertising efforts were marked by the trend from local utility-sponsored advertising to regional and national advertising that leveraged the efforts of all market players with the synergism of a national branding mechanism, the DOE-sponsored ENERGY STAR CFL program, and a national marketing campaign, the ENERGY STAR Change a Light, Change the World program. Seen in this trend was a move from limited to increased manufacturer advertising of CFLs.

As noted in Chapter 3, as early as 1989, utilities began joining forces in groups such as REAL, CEE, NEEP, the Northwest Energy Efficiency Alliance, WECC, MEEA, CRLAP, and the California Compact, to develop regional energy efficiency programs. "The relative cost of participating in regional and 
national collaborative forums is small," a 1994 Home Energy article summarized, "but the potential effectiveness of such efforts in simplifying and leveraging the response of trade allies is enormous." $\{11\}$

The lack of advertising by manufacturers was noted in the barriers chapter, but this changed as the technology matured and manufacturers became an active partner in CFL advertising. For example, the Northwest Energy Efficiency Alliance partnered with Osram Sylvania for an Earth Day 2003 promotion in the Portland and Seattle markets. The two organizations developed a full-page color advertisement that ran in The Oregonian, The Seattle Times, and The Seattle Post Intelligencer. In conjunction with the ad, the manufacturer offered a \$3 mail-in rebate at participating retailers, which included both DIY and independent hardware stores. The Alliance’s program combined $\$ 287,911$ in funding from retailers and manufacturers with $\$ 202,197$ from its own cooperative funds, for a total of $\$ 490,108$, which was used to promote ENERGY STAR lighting products throughout the Pacific Northwest. $\{30\}$

Once ENERGY STAR instituted its CFL program in 1999, regional programs had a consistent standard with high brand recognition to rally around, bringing synergistic marketing efforts to a whole new level. In the fall of 2001, when the national media campaign Change a Light, Change the World was launched and CFL advertising achieved a nation-wide scope.

\section{A Unique Medium for Getting the Message Across - Realtors}

The Northwest Energy Efficiency Alliance worked with John L Scott Real Estate to do a New Home Owner promotion in spring 2001, where they gave real estate agents welcome bags containing ENERGY STAR CFLs and coupons to give to new home owners. John L Scott conducted a media outreach and advertising campaign and the program was featured in nine industry newsletters, regional journals, and local daily newspapers exposing 4.5 million consumers to the ENERGY STAR message. $\{29\}$

\section{Advertising + a Quality Product $=$ Lasting Dividends}

Central Maine Power showed that good first impressions and strong advertising reinforcement can pay lasting dividends. The utility instituted a coupon program called Operation Lightswitch in September 1994 with a major drugstore and two supermarket chains in its service territory. Central Maine let retailers get bids from several CFL manufacturers but insisted they require high quality electronically ballasted lamps. Although the CFLs normally retailed for \$19-24 the retailers all agreed to lower their prices to $\$ 13$ or $\$ 14$. Then when one retailer started offering them at $\$ 3.99$ with the $\$ 7$ utility coupon they all switched to that price. Initially Central Maine mailed 450,000 coupons to customers in September and followed up with radio, tv, and newspaper advertising and point-of-purchase displays. When sales lagged in the first few weeks, a telephone survey revealed that $82 \%$ of customers had heard of the program but forgot to take the coupon with them when they went shopping. Coupons were then made available at all retailers and demonstrators were employed in high-volume stores. Sales skyrocketed with 171,000 sold by the program's end in December saving the utility 8 megawatts of capacity and 88 million kilowatt hours over the life of the bulb. Central Maine notes several retailers continued to stock CFLs and many have run their own promotions. $\{11\}$ 


\section{Utilities use Point of Purchase Coupons and Multiple Promotion Avenues}

Madison Gas and Electric was another utility who combined point of purchase coupons and heavy advertising. When it started its CFL program in 1990, less than 5\% of its customer base had tried CFLs, only 4 out of 100 retailers sold CFLs and only 6 models were offered. Several modifications were made over the course of the 4-year program, including changes in technology offered (e.g., dropping higher efficiency incandescents which had been part of the pilot program), increases in incentives (from $\$ 5$ to $\$ 10$ per CFL), a change from mailed coupons to point-ofpurchase coupons, increased newspaper radio, tv, and newsletter advertising; increased contact with manufacturers and retailers; and the addition of retailer training. The changes paid off, resulting in 28\% participation by customers, and 62 participating retailers selling 63 CFL models by $1994 .\{11\}$

\section{How One Utility Used Change a Light}

Connecticut Light and Power (CL\&P) and United Illuminating (another Connecticut utility) used the Change a Light campaign to enhance their own programs. Both companies provided staff support during a Change a Light event at 17 Home Depot stores in Connecticut in 2001. More CFLs were sold during that eight-day period than CL\&P had rebated or couponed during nine months in 2000. $\{30\}$

\subsection{The Growth of Home Improvement Stores and their Influence on CFL Sales}

In several early studies, consumers complained about the unavailability of CFLs at grocery stores, where they normally bought bulbs. A 1998 Southern California Edison telephone survey of over 500 consumers found that the overwhelming majority were still purchasing their light bulbs at grocery stores (46.5\%). \{18\} However, a report prepared by ECONorthwest for the Northwest Energy Efficiency Alliance published in August 2004 found that only 35\% of consumers said they tended to purchase lighting at grocery stores. $\{35\}$ This change may be due in part to the phenomenal growth of large home improvement centers. For example nearly $70 \%$ of the bulbs sold in the LightWise CFL bulb program conducted by the Northwest Energy Efficiency Alliance in 1996-98 were sold at home improvement centers while less than $15 \%$ were sold at grocery stores. $\{17\}$

Home improvement centers, also known as do-it-yourself (DIY) stores, have emerged over the last two decades; the market leaders are Lowe's Home Improvement Centers and The Home Depot. With fiscal year 2004 sales of $\$ 36.5$ billion, Lowe's Companies, Inc. is a Fortune ${ }^{\circledR} 50$ company that serves approximately 11 million customers a week at more than 1,100 home improvement stores in 48 states. Based in Mooresville, North Carolina, the 59-year old company is the second-largest home improvement retailer in the world. The Home Depot was founded in 1978 in Atlanta, Georgia, and has since become the world's largest home improvement retailer and the second largest retailer in the United States, operating more than 1,900 stores such as The Home Depot, EXPO Design Center, The Home Depot Supply, and other subsidiary companies across North America. The Home Depot is the fastest growing retailer to reach $\$ 30$ billion, $\$ 40$ billion, $\$ 50$ billion, $\$ 60$ billion and $\$ 70$ billion in sales. At the end of fiscal year 2004, revenue was $\$ 73.1$ billion. 
An NRDC 1999 study supports the finding that in recent years national chains, particularly home improvement centers, have grown tremendously in market share and influence. "The national chains now decide what products will be made available, and effectively marketed, to a large percentage of potential purchasers. Companies like Home Depot even have an on-staff energy manager, who helps keep the company's own energy bills low while promoting the benefits of energy efficiency to customers and retail staff as well. Significant opportunities to reach and influence national chains are trade shows and events such as the Dallas Market and the Chicago Housewares and Hardware Shows, where buyers for retailers are actively seeking to learn about new developments in lighting and select new products.” $\{24\}$

The NRDC study notes that Home Depot makes many of its buying decisions through regional "team captains.” These people share a dual responsibility within the company: to make all lighting buying decisions for the stores within their region, and to make recommendations to the other team captains on a particular category of lighting products within their area of expertise. As a result, conducting a successful program to promote ENERGY STAR CFLs within one region can increase the chances of such programs succeeding in other regions if the particular team captain involved is responsible for fluorescent lighting expertise within the company. Other retailers often entrust these decisions to a single national lighting buyer. $\{24\}$

\subsection{Role of Media}

No amount of marketing dollars can equal the impact of a front-page story in a major metropolitan daily or top billing on the evening news. The news media of course is a two-edged sword. In January 1999, Consumer Reports Magazine published a widely read and unflattering article that identified inconsistencies in CFL performance relative to claims made on product packaging. This article had unquestionable influence in prompting the discourse on the need for systematic testing of CFL performance. $\{24\}$

The media have also been a help in promoting CFLs. The trade and local press dutifully covered press conferences of the announcements of early CFL developments, even when they seemed to flare then fizzle, because the technology was premature $\{5\}\{24\}$

However CFLs have had some very positive portrayals in the media which have very likely contributed to positive consumer recognition and sales. These instances can be attributed to more than good timing, they were also the result of having an improved technology, a solid groundwork of manufacturer-retailerutility relationships, a flexibility to shape programs quickly, and an understanding of what key marketing messages applied to the current situation. Calwell notes, "national outreach and education campaigns like Change a Light are likely to be successful if they can capitalize on existing market trends and waves of interest in particular products. It is easier to interest retailers and manufacturers in co-sponsoring promotions of products that are already highly popular than to rely on the national campaign alone to generate that interest. Monitoring sales trends and partner interests closely before launching such campaigns will obviously help point them toward promising technologies at the right time.” $\{28\}$

Instances where CFLs capitalized on current events to gain positive media exposure included Earth Day 1990, the halogen torchiere debacle, and the Energy Crisis of 2001.

\subsubsection{Earth Day}

Earth Day 1990 represented something of a turning point in the national consciousness regarding energy efficiency in the home with messages of individual awareness and action to tackle global problems like ozone depletion and climate change. Curbside recycling became prevalent across the country. Books like 
50 Simple Things You Can Do to Save the Earth, Consumer Guide to Home Energy Savings, and The Green Consumer sold millions of copies and each of these recommended that consumers purchase CFLs. $\{24\}$

Subsequent Earth Day celebrations were additional rallying points for CFL promotions. For example in 1999 the Earth Day Campaign organized a promotion touting CFLs as a fundraiser and sent information to 20,000 schools across the United States inviting them to participate. In 2003, Osram Sylvania and the Northwest Energy Efficiency Alliance partnered for an Earth Day 2003 promotion in the Portland and Seattle markets. $\{30\}$

\subsubsection{Halogen Torchieres}

Appearing in the mid 1990s, halogen torchiere floor lamps were an apparent dream for consumers who snapped up the cheap, portable fixtures to light up apartments, dorms, home offices, and living rooms. The halogen lamps were however a nightmare for utilities, expending 300 to 500 watts per fixture. And at bulb temperatures of 750 to $1100^{\circ} \mathrm{F}$, they soon became a nightmare for consumers as well; by 1999 they were reportedly the cause of at least 435 fires that killed 32 people, injured 114 more, and caused millions of dollars in property damage. Halogen torchieres were the subject of more than 200 safetyrelated lawsuits against halogen manufacturers and retailers, and prominent retailers like Home Depot and Wal-Mart dropped the product entirely. Television news programs devoted substantial coverage to safety problems with the products, and many universities banned their use in dormitories

Fortunately, CFL manufacturers were ready with ENERGY STAR-compliant CFL torchiere floor lamps that used a dedicated pin-based CFL to provide the same amount of dimmable light as 300 watt halogens, but at operating temperatures of only 100 to $200^{\circ} \mathrm{F}$. The CFL torchieres were available without utility incentives for about $\$ 30$ to $\$ 70$, but thousands of customers across the country participated in highly publicized utility-sponsored torchiere turn-ins, turning in their old halogen torchieres for recycling and taking home an ENERGY STAR torchiere at sale prices. \{24\} In 2001 alone, the Northeast Energy Efficiency Project (NEEP) conducted over 60 torchiere turn-ins that resulted in the sale of more than 225,000 ENERGY STAR torchieres. \{30\} The CFL torchieres turned out to be an excellent means of introducing consumers to ENERGY STAR lighting; they were low-risk, highly affordable, and offered lifetime savings of $\$ 300$ in avoided electricity and replacement bulb costs. $\{24\}$

\subsubsection{West Coast Energy Crisis of 2001}

The West Coast Energy situation began gaining media attention in 1999 when San Diego Gas \& Electric became the first California utility to deregulate, allowing it to lift the price cap. Within a year, customers' bills tripled as the utility passed on high wholesale power costs. By mid June 2000, the crisis was making daily headlines with Californians experiencing rolling blackouts, utility bankruptcies, and stage three emergencies through 2001. The crisis spilled over into the Northwest as it tried to meet California needs while dealing with hydropower shortages from a summer drought and a cold winter. (http://www.pbs.org/wgbh/pages/frontline/shows/blackout/california/timeline.html)

Buying CFLs took on a patriotic flavor akin to buying WWII era liberty bonds as California's state and local governments mobilized a massive campaign to cut consumption and officials from the governor on down made public service announcements urging citizens to conserve. The California legislature mobilized \$20 million in emergency funding for the California Conservation Corps (CCC) to purchase and distribute 1.9 million CFLs and 1.4 million "Flex Your Power" brochures to low-income households in every county in the state. $\{28\}$ Conservation made headlines for helping to stave off blackouts 
(http://archives.cnn.com/2001/US/01/19/power.woes.01/index.html). News articles listed CFLs as an easy way to cut energy use and media web articles provided links to ENERGY STAR programs.

These events, and the media attention brought to them, combined with existing CFL programs that had helped drive increasing competition, brought down prices, sparking unprecedented sales of CFLs up and down the West Coast. By mid 2001 CFL market share reached $8 \%$ in California and $12 \%$ in the Northwest.

While no one can predict an energy crisis, there are lessons to be learned from this situation:

- $\quad$ Be mindful of current events.

- Be ready to share, have easy-to-understand consumer information and press kits prepared.

- Be flexible and able to adjust programs to meet current situations.

- Lay the groundwork by building relationships among market players early. 
4.14 


\subsection{Where the Market is Now}

CFL sales have grown considerably in the last decade spurred by improvements in the technology and coincident changes in marketing. Some of these technology changes are highlighted in Table 5.1. Recent national market figures are given in Section 5.1. More specific data on market penetration from four American markets are provided in Section 5.2, and remaining barriers are described in Section 5.3. The growth in the CFL fixture market is described in Section 5.4.

Table 5.1 gives a capsule view of some of the major changes in CFL technology over the past decade.

Table 5.1. How CFLs Have Changed

\begin{tabular}{|l|l|l|l|}
\hline Attribute & 1992 & 2002 & 2005 \\
\hline Price Range & $\$ 15-\$ 25$ & $\$ 3-\$ 10$ & $\$ 0.98-\$ 15$ \\
\hline Life & $\begin{array}{l}9,000 \text { to } 12,000 \\
\text { hours }\end{array}$ & $\begin{array}{l}6,000 \text { to } 12,000 \\
\text { hours }\end{array}$ & $\begin{array}{l}6,000 \text { to } 12,000 \\
\text { hours }\end{array}$ \\
\hline Type of ballast & $\begin{array}{l}\text { Magnetic or } \\
\text { electronic }\end{array}$ & electronic & electronic \\
\hline Dimmable & no & few & $\begin{array}{l}\text { some (significantly } \\
\text { more expensive) }\end{array}$ \\
\hline Incandescent Sized CFLs & none & some & many \\
\hline Available wattages & 9 to 34 & 2 to 59 & 2 to 59 \\
\hline $\begin{array}{l}\text { Number of CFL } \\
\text { manufacturers }\end{array}$ & Less than 10 & hundreds & hundreds \\
\hline Source: Platts with some data from Ecos Consulting June 2002 \{30\} & \\
\hline
\end{tabular}

\subsection{Market Share}

Retail sales of screw-based CFLS were 4 to 6 million units in 1990, while retail sales of incandescent bulbs that year were 1 billion units, giving CFLs a retail market share of 0.1 to $0.2 \%$ \{28\} In 1998 CFL market share had grown to $0.4 \%$ and it hovered between $0.4 \%$ and $0.6 \%$ in 2000 before jumping to $2.1 \%$ by the fourth quarter of 2001 thanks to national marketing efforts, media attention from the West Coast Energy Crisis, and a glut of new, low-cost CFLs from foreign manufacturers. $\{28\}$ There are no comparable data for CFLs' current market share, in part because key retailers Home Depot and Wal-Mart have removed themselves from the tracking surveys routinely conducted by industry analysts, but there is reason to believe that continued reductions in the average selling price of CFLs have pushed the products' market share steadily higher. 
California's market moved more briskly, from $0.8 \%$ in 1998 , to nearly $1.2 \%$ in 2000 , then surging to $4 \%$ share in the first quarter of 2001 with a peak of $8.5 \%$ in the second quarter before stabilizing between 5\% and $6 \%$ in the third and fourth quarters of 2001. Northwest sales rose higher reaching a market share close to $12 \%$ in 2001 before leveling off to at $5 \%$ to $8 \%$ of the market or 4 million sales annually after the energy crisis. $\{28\}$

National CFL penetration in 2002 showing data for number of CFLs in sockets, not sales, is shown in Figure 5.1.

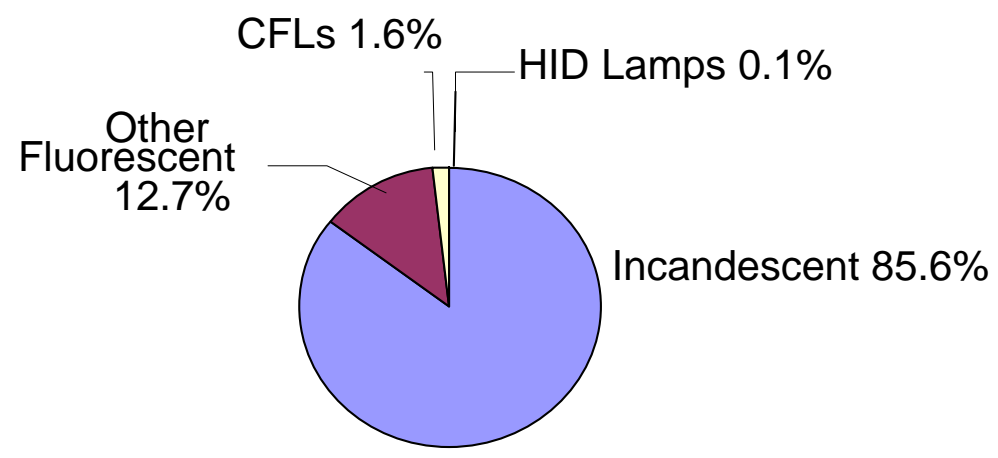

Figure 5.1. CFL Market Penetration. Incandescents filled $85 \%$ of sockets in 2002 compared to less than $2 \%$ for CFLs. Source Ecos Consulting $\{30\}$

Calwell summarized the state of the CFL market in 2002 (see Figure 5.2) "Stores like Home Depot, Ikea, Costco, and Kmart have made inexpensive CFLs a standard promotional item, in many cases bypassing major manufacturers to offer a private label brand at a lower price. Retailers now clearly understand the benefits of CFL technology, both to consumers (energy savings and convenience) and to the retailers themselves (higher sales revenues per unit of shelf space than incandescent bulbs). As a result, some level of in-store CFL promotion will now be self-sustaining, allowing the utilities to retarget or reduce their funding and still achieve a given level of market success. One overarching lesson from the events of 2001 is that market introduction takes time. CFLs ground their way to begrudging market acceptance for more than two decades before finally gaining traction with consumers. That period reflects multiple generations of revision to the technology itself, the trying and refining of numerous utility program approaches, and a great deal of hard work by a whole array of allies.” $\{28\}$ 

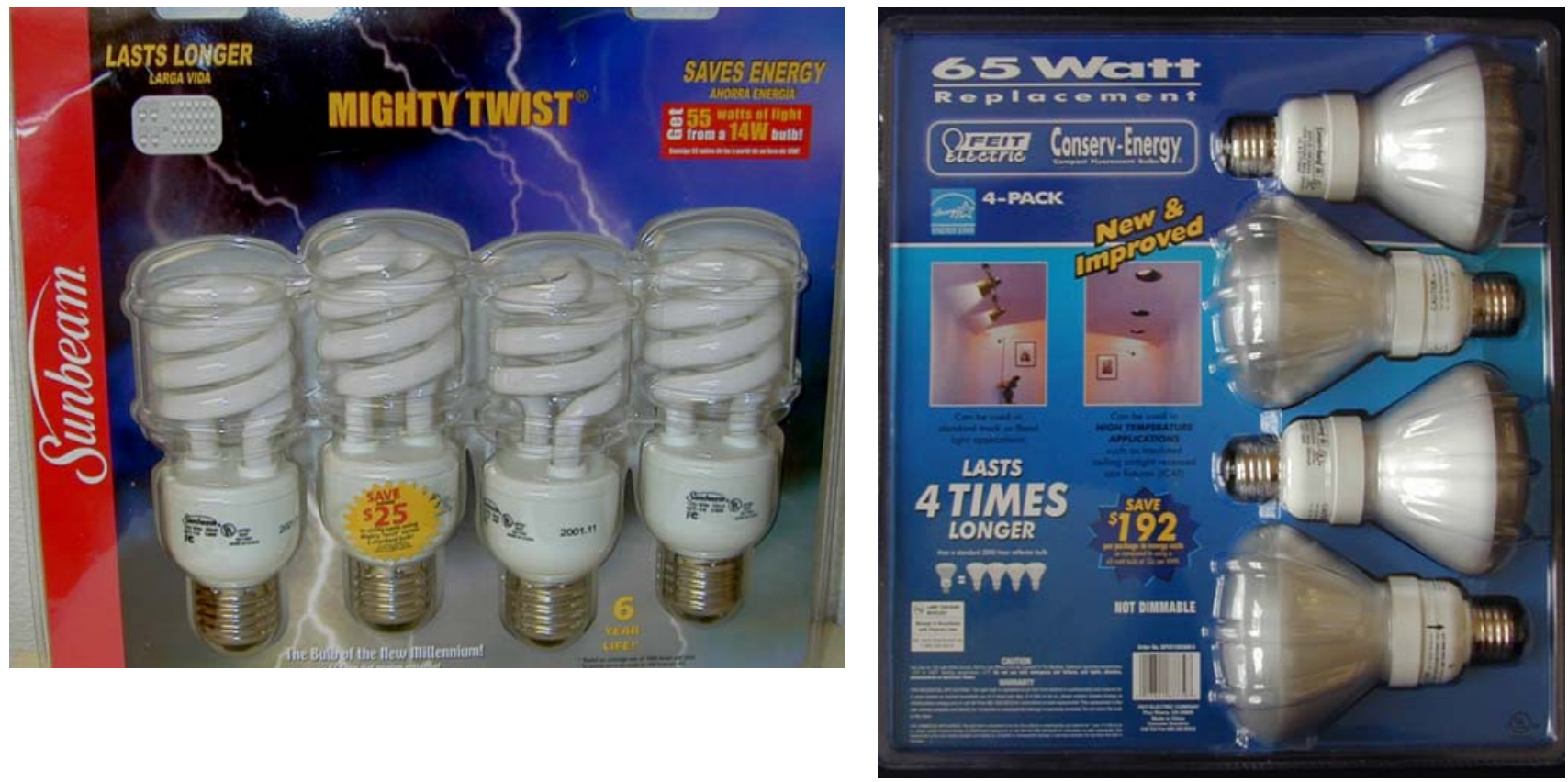

Figure 5.2. Can anyone in the U.S. get a CFL through a major retailer at a reasonable price with no utility support? Yes! Four CFLs for $\$ 9$ at a K-Mart in Durango, Colorado, $\{27\}$ and four Reflector CFLs for $\$ 11.99$ at Costco in Portland, Oregon (PNNL photo).

\subsection{Four Examples of Transforming Markets: the Pacific Northwest, British Columbia, New England, and California}

The following four case studies give a more detailed look at changes in market share, sales, and consumer attitudes in four regional markets: the Pacific Northwest, British Columbia, New England, and California.

\subsubsection{The Pacific Northwest Case Study}

A survey of Northwest residential lighting customers conducted by ECONorthwest in June 2001 found that "a majority of the population (82\%) is aware of CFLs and almost 30\% of those who had purchased light bulbs in the three months prior to the survey chose to purchase a CFL. Sales in the Northwest $r$ remained strong even after a high-visibility, \$6/unit coupon campaign wound down. Most respondents surveyed indicated that they would continue to purchase additional products in the future, with or without coupons. More than 6.8 million CFLs were sold in the region in 2001 -- about ten times the estimated sales in 2000. \{29\} This led to a peak CFL market share of about 11.5\% in the Northwest in 2001 -perhaps the highest regional share achieved in the U.S. so far. \{28\} Market share leveled off to 5\% to 8\% of the market or 4 million sales annually after the energy crisis, according to a Northwest Energy Efficiency Alliance February 2004 program report. This is a drop from the 8 million sales during the crisis and coupon campaigns, but sales remained significantly higher than pre-program levels, and the Northwest continues to have the highest market share of CFL sales of any region in the country according to the EPA. $\{38\}$

A June 2002 market progress evaluation report by ECONorthwest for the Northwest Energy Efficiency Alliance's Residential Lighting Program reported that following the Spring 2001 West Coast energy 
crisis, regional sales were 20 times higher than Alliance preprogram planning estimates, totaling 8.6 million distributed (7 million sold plus 1.6 million given away) in the five quarters from fourth quarter 2000 through fourth quarter 2001. In a June 2001 survey of 1,421 residential customers, 179 had purchased CFLs within the past 3 months (30\% of those who had purchased lighting of any kind in past 3 months). Only $3 \%$ of these were not satisfied with their purchase. Reasons they gave for satisfaction included longer lasting, energy efficiency, better light quality, and electricity bill savings. \{29\}

Reasons they gave for purchasing a CFL were to reduce their electricity bill (48\%), in response to the energy crisis (25\%), the savings were worth the higher price (19\%), energy efficiency (10\%), they wanted to try a CFL (10\%), they felt it was the right thing to do (15\%), and they wanted a longer lasting bulb (23\%). (Respondents could give more than one reason). Only 12\% said to redeem a coupon. \{29\}

Of those surveyed, 316 had purchased an incandescent in the last 3 months. When asked why they hadn't bought a CFL instead, 31\% listed cost, 15\% said they weren't aware of CFLs at the time of the purchase, and another $8 \%$ said they didn't have enough information. 11\% said they couldn't find the right type, style, or size. Of those surveyed, $72 \%$ said they intended to purchase a CFL within the next year (that included those who had purchased CFLs recently and those who had purchased incandescents recently). $94 \%$ of recent CFL purchasers said they would buy another CFL even without a coupon and 64\% said they would buy one in the future even without the energy crisis. Coupon sales accounted for only $39 \%$ of the 7 million CFLs sold during the five quarters. $\{29\}$

The drop in price for CFLs is one of the dramatic market shifts seen over the years, according to the Northwest Energy Efficiency Alliance. When regional efforts started, the price for a CFL ranged from \$15-20 per bulb. In 2003 the average price for a CFL was around $\$ 5$ a bulb or less than $\$ 3$ a bulb if purchased in the now widespread multi-packs. $\{38\}$

For the fixtures market, in 1997 the Northwest Energy Efficiency Alliance noted that it started out with a handful of manufacturers producing 20 to 25 models, mostly torchieres. In 2003 ENERGY STAR listed over 5,000 qualified fixture models manufactured by several hundred different manufacturers. For the bulb market in 1997 there were 4 to 5 main manufacturers of CFLs, mostly those who participated in the PNNL sub-compact effort. By 2003 there were over 1,300 different models from more than 110 qualified ENERGY STAR bulb manufacturers, with at least 50 active manufacturers in the Northwest market. \{38\}

A report prepared by ECONorthwest for the Northwest Energy Efficiency Alliance published August 16, 2004, found that consumer awareness in the Northwest was very high as measured in several consumer surveys: 82\% in May 2001, 88\% in April 2002, and 88\% in April 2003. The number of retailers stocking CFLs has increased, with $80 \%$ of retailers surveyed saying they planned to increase or maintain the number of models they carried. The price continued to drop with $48 \%$ of CFL purchasers saying they paid less than $\$ 6$ per bulb compared to $20 \%$ in 2002. Market share had increased from close to $0 \%$ in 2000 to $9 \%$ in 2003. Regional sales went from 294,000 in the fourth quarter of 2000 to a high of $2,378,000$ in the fourth quarter 2001, to a leveling off at 1,454,000 in the fourth quarter 2003. Consumer awareness of ENERGY STAR was high, consumer intentions to buy more CFLs in the future were high and retailers intended to offer the same or more CFLs models in the future. Consumer surveys done in 2003 showed $82 \%$ were more satisfied or as satisfied with their CFL purchases than with incandescent purchases. Reasons for satisfaction were: lasts longer 51\%, energy efficiency 51\%, better light quality $23 \%$, saves on electric bill $18 \%$, and works the same as an incandescent $13 \%$. $\{35\}$

As the 2001 Energy Crisis hit, the Northwest Energy Efficiency Alliance program worked with more than 320 retailers. During the crisis this expanded to over 1400 retailers by March 2002, ranging from big box, DIY retailers, and independents, to general merchandise and groceries. Retailer participation leveled off 
at 1100 participants post-coupon campaign with a majority receiving field staff visits, the Alliance reported in February 2004. One of the best retailer market shifts can be seen with the participation of Costco. Costco did not sell CFLs until the advent of multipacks and lower per bulb prices. By 2004 Costco sales accounted for over $50 \%$ of the CFLs sold in the region. $\{38\}$

\subsubsection{The British Columbia Case Study}

A March 2004 report on BC Hydro's CFL initiatives in 2001-2004 examined availability, accessibility, and affordability of CFLs sold in British Columbia through an in-store field survey of residential lighting displays at 55 stores in BC Hydro's service territory in November 2003 and compared to a baseline study conducted in 2002. They found significant improvements:

- CFLs occupied 8.9\% of total household lighting shelf space, up from 6.1\% in September 2002, and $48 \%$ of this is at eye level.

- Comparable increases in relative market share were observed in the South Interior and Northern regions despite limited BC Hydro CFL programming in these regions.

- The majority of the increase in total shelf space for CFLs had been stocked with spiral CFL product. Spiral CFLS accounted for $4.9 \%$ of the shelfspace for all household lighting, up from $1.4 \%$ in Sept 2002. Spiral CFLs represented 54\% of all CFLs for sale, up from 22\% in 2002.

- Blister packs containing two, three and four CFLs accounted for an estimated 52\% of all CFLs for sale.

- Over 170 different CFL models were available, an increase of 92\% since 2002.

- Product priced at $\$ 6$ or less accounted for $49 \%$ of all CFLs for sale. The majority of CFL product (84\%) was priced below $\$ 10$ per bulb.

- CFL purchase costs amortized over the life of the lamp had declined by as much as $76 \%$ since September 2002.\{32\}

A telephone survey of 802 BC Hydro residential customers was conducted in January 2004 and compared to previous telephone surveys conducted in 2002 and 2003 regarding household awareness of CFL technology and BC Hydro CFL programming.

- Awareness of CFL technology was at 90\%, up from 83\% in May 2003 and 74\% in May 2002.

- The percentage of households that recalled information, advertising or promotions regarding CFLs from BC Hydro had increased from 22\% to 65\% since 2002.

- The percentage of homes using CFLs had increased from 23\% in May 2002 to 55\% in January 2004.

- Households using CFLs had installed an average of 5.2 CFLs each, an increase of 53\% since May 2002.

- An estimated 4.2 million CFLs were installed in BC Hydro customer homes, up from 1.1 million in 2002. Sixty-four percent of all CFLs in use had been installed within the previous year.

- Thirty-seven percent of all BC Hydro residential customers had received a free bulb from BC Hydro.

- Nearly four out of every ten households (39\%) who acquired a free CFL went on to purchase additional CFLs. While most purchasers in the Lower Mainland acquired four additional CFLs each, a number of households purchased quantities of 15 and 20 CFLs each. 
- As of mid-January 2004, Lower Mainland residents had installed 68\% of all CFLs acquired through BC Hydro initiatives (giveaways or BC Hydro coupons). \{32\}

\subsubsection{The Connecticut and Massachusetts Case Study}

Recent data comes from New England where the percent of homes with at least one CFL now stands at 61\% in Massachusetts and 63\% Connecticut, according to a utility-sponsored in-home-visit survey reported in 2005. Sales climbed in Massachusetts from 158,000 in 1998 to 464,000 in 2002, then soared to 1.3 million in 2003, and to 3.1 million in 2004. Researchers attribute the shift to evolving efforts that transitioned from individual utility programs in the late 1980s, to a more concerted effort in the mid ' 90 s with utilities making programs more consistent with each other and employing shared advertising, the same qualifying product lists, and the same rebate levels. In 1998 they officially joined forces through the Northeast Energy Efficiency Partnerships (NEEP) and collaborated with the national DOE ENERGY STAR program and associated marketing efforts. $\{42\}$

In the fall of 2002, the program underwent a shift toward industry-sponsored initiatives using an industry buydown process involving market actors. This facilitated a dramatic drop in dollars spent per unit moved - from \$18 per product sold in 2000, to \$13 per unit in 2001, \$10 per in 2002, \$4.84 per in 2003, and $\$ 4.61$ per in 2004. Residential lighting programs now account for $22 \%$ of total utility energy savings achieved in New England. The mean number of CFLs per home is now 6.7 in Massachusetts and 6.8 in Connecticut, and 8\% of all bulb sockets in Massachusetts and 7\% of all sockets in Connecticut now contain CFLs. While these figures are impressive, the researchers noted some Massachusetts residents still cited barriers to CFL purchase, including more expensive up front cost $80 \%$, limited selection 52\%, don’t fit $40 \%$, aesthetically not pleasing $43 \%$, and don’t produce enough light $25 \%$. $\{42\}$

\subsubsection{The California Case Study}

A 2004-2005 study by RLW Analytics for California's investor owned utilities gives a snapshot of recent California CFL usage. They conducted 850 onsite surveys of single family, multi-family, and modular homes in California. Among their main findings were that the overall number of all fixtures per home increased from 20 to 23 between 2000 and 2005 and the number of lamps (bulbs) increased from 34 to 41. On average, $11 \%$ of all fixtures had at least one CFL up from less than $1 \%$ in 2000, with most CFLs in floor and table lamps even though ceiling fixtures were the most common type of fixture. The 2004-05 study found $57 \%$ of all homes had one or more CFLs installed compared to the 2000 CLASS study which found 12\% of all homes and the 2003 Residential Appliance Saturation Study which found 51\% of all homes had a CFL installed. More than $90 \%$ of installed CFLs were in the 13- to 26-watt range and had screw-in bases and integrated ballasts. The most likely rooms to have CFLs were the living room (24\%) and the master bedroom (20\%). Areas with the highest reported lighting use were the kitchen, living room, outside, and garage. $\{37\}$

\subsection{Remaining Barriers}

With their increased retail availability and growth in sales in recent years, can we claim that a significant level of CFL market acceptance has been achieved? Most studies have said it's too early to declare victory. Barriers do remain. Reasons noted for not buying CFLs include cost, fit, didn't know about, and buying incandescents out of habit $\{29\}$ and some consumers still indicate dissatisfaction with CFLs for various reasons: not bright enough, size, color consistency, and slow start-up time. $\{31\}\{36\}$ 
The fact remains: if CFLs captured 2.1\% of market share in 2001, then $97.9 \%$ of the U.S. bulb market was buying something else. Even in the Northwest, which has posted the highest quarterly CFL sales ratios in the country, 63\% of households surveyed still had not purchased one CFL according to a 2002 study. $\{29\}$

While it is clear that progress has been made in this market, it is also clear that sustained, higher levels of CFL sales will be necessary to achieve market penetration levels that could be reasonably equated with transformation of the residential lighting market, according to a Northwest Energy Efficiency Alliance February 2004 program report. \{38\} The notion of socket share should be kept in mind here - every CFL sold displaces the sale of about 6 to 14 incandescents over its lifetime, so percentage of units sold can be deceptive.

One industry consultant noted recently "In our experience, we find that "market penetration" and other metrics can be misleading if not done on a consistent basis. As witnessed by the increased in sales (driven by the advent of "multi-packs" in many regions), one can conclude that the overall penetration by CFLs is quite high. However, this is only partially true, as it masks the clear division between product accessibility for consumers in urban and rural areas. Many rural areas, even in the Northwest, still have very low product availability and high prices that were seen in surveys of many years ago. We suggest that a consistent baseline with specific indicators be consistently carried out to serve as a true gauge of market transformation.” (Personal. Comm, My Ton, 5/2/0/6.

\subsection{A Growth Area - CFL Fixtures}

Sales of dedicated fluorescent fixtures were more lackluster than sales of screw-based CFLs from the 1970s through the 1990s. From 1967 to 1997, fluorescent portable fixtures recorded essentially no gains in dollar sales, even as the overall market grew more than four-fold. When the impact of inflation is accounted for, the fluorescent portable fixture market shrank significantly. \{24\} Portable fixture sales picked up with the well-publicized torchiere turn-ins in the late 1990s; however, according to the Northwest Energy Efficiency Alliance, CFL fixture market share remained low, probably in the 1\%-2\% range and ENERGY STAR fixture sales were flat (at approx. 70,000-90,000 fixtures annually). Market barriers persisted in the areas of market fragmentation, performance, reliability, availability, lack of uniformity in pin-base configuration for lamp replacement, and lack of customer acceptance. In the early 2000s, DOE, EPA, and energy efficiency organizations such as CEE and the Northwest Energy Efficiency Alliance were pursuing programs to promote CFL fixtures in specific applications such as outdoor lighting and recessed can lighting. $\{38\}$ Today, the CFL fixture market is getting a lot of attention thanks to efforts by these organizations in recessed can lighting; a new design competition; greater efforts at ballast, socket, and pin standardization; new mandated California Title 24 requirements; and a wide range of new offerings from CFL fixture manufacturers. $\{33\}$

\subsubsection{New California Title 24 Requirements}

The slowest sector in CFL products, pin-based CFL fixtures, is expected to lag no longer since California's Title 24 Residential Lighting Building Code took effect October 1, 2005. The new code (www.energy.ca.gov/2005_standards/rulemaking/documents/index.html) requires all hard wired (i.e., permanently installed, not portable) fixtures in every room of the house over $70 \mathrm{sq}$. ft., except the kitchen, to be high-efficacy, or controlled by a motion sensor. In the kitchen, at least $50 \%$ of total installed wattage must be high efficacy and when calculating total installed wattage, the builder must assume for any incandescent or screw-based fixtures that the maximum rated wattage listed on the fixture by the manufacturer is used, not the wattage of the lamp put in the fixture at installation. For example, if a 
builder uses recessed cans with incandescent screw-based lamps in the kitchen, their total wattage must be less than half the total lighting wattage installed in that room.

The revised requirements apply to new construction single and multi-family homes, and hotel and motel guest rooms. Screw-based CFLs do not count as high-efficacy under the new requirements because they are too easy to replace with incandescent lamps.

Noah Horowitz of the NRDC, in an April 2004 presentation, predicted that this would greatly increase the demand for pin-based fixtures, especially recessed cans. He recommended that manufacturers create marketing materials targeted to the California market ("meets Title 24") and cluster qualifying products in their catalogs. He also warned that compatibility is likely to be an issue again, because there are many proprietary pin-socket combinations. Look-alike products could also be problematic if one product complies with ENERGY STAR and a similar looking product does not.\{33\}

The new Title 24 requirements are summarized in Table 5.2.

\subsubsection{Reflector CFLs}

As CFLs became more popular after the 2001 energy crisis, manufacturers began offering more varieties of specialty CFLs for use in specific fixtures that were not very accepting of standard CFLs for a variety of reasons. Reflector CFLs (R-CFLs) were one key application since newer homes often had upwards of 25 recessed can fixtures. With the huge increase in the popularity of recessed can fixtures installed in US homes, and the lack of CFL fixtures or screw based CFLs available, DOE sponsored two energy-efficient reflector lamp programs: one to develop new insulated can lights requiring dedicated pin-based CFL lamps and another encouraging the development of higher performing screw-based reflector CFL lamps for recessed can very wide flood light applications.

The recessed can downlight program requested fixture manufacturers to submit bids for ICAT downlight fixtures that would perform well in this high heat application. When it became clear that there were few choices in ICAT fixtures, DOE offered design assistance workshops to fixture manufacturers. Since then, the 2005 upgrade In California's Title 24 has led to numerous new ICAT cans; it is unclear how well these fixtures will perform in the next few years. The R-CFL Technology Procurement sponsored by DOE resulted in the introduction of R-CFLs designed specifically for operation in high-heat applications (ICAT cans). This project helped address a need for innovation in a niche category of CFLs where available products in early 2000 suffered from performance problems including fit and glare (protrusion below the recessed can opening) and from premature failure caused by excessive heat. Three lamp models, two from Philips and one from Feit, became available in 2005. 
Table 5.2. New 2005 California Title 24 Requirements Compared to 2001 Requirements $\{33\}$

\begin{tabular}{|c|c|c|c|}
\hline Requirements & 2001 & 2005 & Comments \\
\hline Recessed "can" lights & $\begin{array}{l}\text { Must be approved for zero clearance } \\
\text { insulation cover (IC rated) }\end{array}$ & $\begin{array}{l}\text { Must be approved for zero clearance insulation } \\
\text { cover (IC rated) and certified air tight (AT) }\end{array}$ & \\
\hline $\begin{array}{l}\text { Definition of high } \\
\text { efficacy }\end{array}$ & $\begin{array}{l}\text { Not less than } 40 \text { lumens per watt } \\
\text { Must not contain medium base } \\
\text { incandescent sockets }\end{array}$ & $\begin{array}{l}<15 \text { watt fixture: min. } 40 \text { lumens per watt } \\
\text { 15-40 watt fixture: min } 50 \text { lumens per watt } \\
>40 \text { watt fixture: } \min 60 \text { lumens per watt } \\
\text { Same; i.e., no screw-based fixtures qualify }\end{array}$ & $\begin{array}{l}\text { Low-efficacy = All screw-based lighting } \\
\text { without hardwired ballasts and = All } \\
\text { low-voltage incandescent, tungsten } \\
\text { halogen, MR-11 and MR-16 } \\
\text { High efficacy = all pin-based fluorescent }\end{array}$ \\
\hline Ballast Requirement & none & $\begin{array}{l}\text { Ballast for lamps of } 13 \text { watts or greater must be } \\
\text { electronic, output frequency } \geq 20 \mathrm{kHz}\end{array}$ & \\
\hline Switch requirement & $\begin{array}{l}\text { High-efficacy lighting must be operated } \\
\text { on separate switch from any } \\
\text { incandescent or low-efficacy lighting }\end{array}$ & Same & \\
\hline Kitchen Lighting & $\begin{array}{l}\text { General lighting must be high efficacy. } \\
\text { Decorative lighting does not need to be } \\
\text { high efficacy. }\end{array}$ & $\begin{array}{l}>50 \% \text { of all installed wattage must be high } \\
\text { efficacy. Must assume max wattage on any } \\
\text { incandescent/screw-based fixtures. }\end{array}$ & $\begin{array}{l}\text { Any incandescent or screw-based } \\
\text { lamps must equal less than half the } \\
\text { room's installed wattage. }\end{array}$ \\
\hline Bathroom definition & Each room containing a shower or tub & $\begin{array}{l}\text { A room containing a shower, tub, toilet or a sink } \\
\text { that is used for personal hygiene. }\end{array}$ & \\
\hline Bathroom & $\begin{array}{l}\text { Bathrooms addressed separately from } \\
\text { garages, laundry rooms and utility } \\
\text { rooms }\end{array}$ & $\begin{array}{l}\text { All hardwired lighting must be high efficacy, or } \\
\text { controlled by a manual-on, auto-off occupant } \\
\text { sensor,. Lighting in garages, laundry rooms and } \\
\text { utility rooms must meet the same requirements } \\
\text { as bathrooms }\end{array}$ & \\
\hline $\begin{array}{l}\text { Other rooms }>70 \text { sq.ft } \\
\text { (hallways, stairs, } \\
\text { dining, bedrms, closets }\end{array}$ & No requirement & $\begin{array}{l}\text { All hardwired lighting must be high efficacy, or } \\
\text { controlled by a manual-on, auto-off occupant } \\
\text { sensor, or controlled by a dimmer. }\end{array}$ & \\
\hline $\begin{array}{l}\text { Outdoor lighting } \\
\text { attached to a building }\end{array}$ & No requirement & $\begin{array}{l}\text { Must be high efficacy, or controlled by both a } \\
\text { motion sensor and photocontrol. }\end{array}$ & $\begin{array}{l}\text { Lighting not attached to a building is } \\
\text { exempt from this requirement. }\end{array}$ \\
\hline $\begin{array}{l}\text { Res. parking lots } \& \\
\text { garages for } 8+\text { cars }\end{array}$ & No requirements & $\begin{array}{l}\text { Must meet lighting requirements for non } \\
\text { residential buildings }\end{array}$ & \\
\hline $\begin{array}{l}\text { Common areas - low- } \\
\text { rise res. w/ } 4+\text { units }\end{array}$ & No requirements & $\begin{array}{l}\text { All hardwired lighting must be high-efficacy or } \\
\text { controlled by an occupancy sensor. }\end{array}$ & \\
\hline
\end{tabular}




\subsubsection{Lighting for Tomorrow}

In 2002 the American Lighting Association, the Consortium for Energy Efficiency, and DOE (represented by PNNL) teamed to conduct a national lighting fixture design competition called "Lighting for Tomorrow" whose aim was to get more high-end, dedicated, energy efficient fixtures into the market. The lack of fixture options was identified through talks with lighting showrooms as a primary barrier to more energy-efficient lighting options for homes. Lighting showrooms are a principal distribution channel for the residential new construction market, which is estimated to be approximately 1.3 million housing starts annually (U.S. Dept of Commerce, U.S. Census 2001 Housing Starts). The first year of the competition welcomed both new and existing designs, as well as student designs with a manufacturer partner. The paper designs were due March 15, 2003, and winners were announced at the American Lighting Association Annual Conference in Tucson in May 2004. Entries for the 2005 competition were judged in June 2005 and were announced at the American Lighting Association Annual Conference in Miami in September 2005. \{http://www.lightingfortomorrow.com\} \{30\} Prizes were awarded to ten fixture families in the indoor and outdoor fixture family and technical innovation categories. Entries are being accepted through June 15 for residential decorative lighting fixture families for the Lighting for Tomorrow 2006 competition. Winning entries will be highlighted in a "yearbook" catalog delivered to lighting showrooms and retailers across the country. An LED/solid state lighting competition is also underway in 2006. 


\subsection{Implications for LED Lighting}

\subsection{Recent Feedback from Lamp Manufacturers}

In fall and winter 2005-2006, PNNL interviewed product and marketing managers in the lighting divisions at Philips, GE, Osram Sylvania, and TCP (in most cases two staff at each company) to collect their thoughts on lessons learned from three decades of developing and marketing CFLS. They provided us with their thoughts on a variety of issues and challenges related to the market acceptance and increased adoption of CFL products discussed in this paper. They were also asked to extrapolate their experiences to new lighting technologies, such as LEDs (light emitting diodes).

While manufacturers did provide some insights, they stressed that LEDs are still very much a niche product, with applications limited to specialty uses such as automotive, electronics, signage, and holiday/decorative lighting, with no applications currently suitable for general illumination. In fact, they noted it may be 10 years or more before LEDs are ready for wider applications. One manufacturer stated "The buyers for these types of products are not the same as the buyers of CFLs. Buyers who might be interested in LEDs are more sophisticated and know their operating costs and the value of energy savings over time. In other words, they are most likely to be commercial rather than residential buyers.”

\subsubsection{Educating the Consumer}

The manufacturers' representatives were asked about the need to educate consumers on the benefits of CFLs, and lessons for marketing other new lighting technologies.

CFL lighting manufacturers felt that many consumers are unaware of or unconvinced of the benefits of CFLs. Manufacturers we spoke to said they were faced with fairly limited advertising budgets for CFLs, so large-scale consumer education campaigns were not an option. Also, one manufacturer said that TV advertising didn't seem to work when it came to building consumer awareness of CFLs. They felt it was much more successful to work with key retailers and to do in-store demonstrations. Another manufacturer took a more sweeping approach, saying they use packaging, signage, promotions, radio and TV advertising. This manufacturer noted that they participated in a “Change a Light” TV campaign last year.

Lighting manufacturers often use CFL packaging to convey product benefits and to help the consumer determine the right CFL for their application. Selling points are clearly listed on the product packaging. Two manufacturers said they specifically focus on energy savings and long life. One manufacturer changed its packaging to focus on what consumers recognize easily, making it clear that CFLs are incandescent replacements. Their packaging clearly states that a 15W CFL is a replacement for a $65 \mathrm{~W}$ incandescent, and it lasts 6 to 7 times as long. Consumers don't understand the value of 6,000- to 7,000hour lifetimes until it is translated into years, according to the manufacturers interviewed. One manufacturer said they believe that it is critical to educate the consumer by providing literature at the retail level. This manufacturer has developed a CFL pamphlet that they affix near the store shelf so consumers can read about CFLs and the manufacturer's product benefits. One manufacturer stated that you have to educate the consumers so they will look for the product and know where to get it. If a buyer goes to a Home Depot or other big box store, he/she may not be lucky enough to find in-store help that is educated. Another manufacturer noted that pre-educating the consumer was half the marketing battle, because, once in the store, consumers take only seven seconds to make their purchasing decision. 
Manufacturers said they would take the same approach when marketing a new lighting technology like LEDs as they have with CFLs - focus on the product benefits that consumers value most and prominently display these on packaging. Lighting manufacturers know that consumers can be hard to convince unless there is a compelling reason for them to switch from an incandescent to a new type of lighting product. They also believe that there is currently no compelling reason for a consumer to switch from incandescent to LED lighting. For example if a consumer wanted a blue-colored light, why would they pay significantly more for a blue LED bulb that is expensive when they can buy a blue incandescent at a much lower price? (White light in an LED is not even an option yet - and probably won't be for several years.) Another said as prices drop, consumers will become more interested in LEDs.

\subsubsection{Educating Retailers}

When asked about the importance of educating retailers to the success of a new lighting technology, manufacturers agreed that retailer education will be important for new products, as it has been for CFLs. Challenges are that educating retailers is expensive and there is a lot of variation across retailers when it comes to their understanding of lighting products. As one manufacturer noted, "We need to keep in mind though that we have been pushing CFLs since the 70s and most retailers still don't understand them.”

Manufacturers agreed that, while it is important that both consumers and retailers understand the benefits of a new lighting technology, it is generally easier and less expensive to train retailers. According to one manufacturer, "retailers are key," both in terms of making the product available to consumers and in terms of providing space for in-store displays and shelf space for informative packaging. Another manufacturer noted that if the retailers are knowledgeable, they can sell the product.

Getting retailers to carry the product can be a challenge. Retailers need to be convinced that a product is going to perform as stated by the manufacturer. One manufacturer said "If a retailer doesn't like the product, or doesn't think it will sell, he won't stock it.” If a retailer does sell a poor quality product, the retailer will suffer the consequences of product returns and no repeat sales. Manufacturers representatives recalled the glut of low-quality CFLs that hit the market in 2001 and noted that retailers need to be informed on what is and isn't a quality product, especially with new and unfamiliar technologies.

The package is a great place to educate, although retailers have asked about discontinuing the blister pack to gain more shelf space since this packaging requires more room. Lighting manufacturers are concerned

that this would leave less space for advertising copy. It is also critical for the consumer to see the product before purchasing.

According to one manufacturer, if you can get a big, well known retailer like a Home Depot to carry a product, that goes a long way with consumers since there is the perception that if a certain retailer carries a product, then "it must be good." In one manufacturer's experience, the best venue for CFLs from a consumer education standpoint has been small, local hardware stores where experienced sales staff are more likely to be available. However, it was noted that the product should not only be introduced via this venue, and a first approach would be to target mass retail outlets.

\subsubsection{Lumens versus Watts}

Lighting manufacturers were asked how they addressed consumer confusion over lumens versus watts. As one noted, you can't change 100 years of consumer experience with incandescents, so rather than educate consumers about lumens, manufacturers are using packaging that refers to watt equivalents to help consumers determine which lamps are best for a selected application. Manufacturers also use graphics, such as a drawing of a CFL next to an incandescent showing that a 15-watt CFL equals a 60-watt 
incandescent. One manufacturer said rather than explaining lumens, they talk about brightness on the packaging, saying "bright” was a word that resonates with consumers.

When marketing new lighting technologies such as LEDs to consumers, lighting manufacturers agreed that they will need to compare performance to products that consumers are already familiar with, such as fluorescents. They noted it will be important not to overstate benefits or make exaggerated claims. With early CFLs, some manufacturers mislabeled products and overstated the equivalency (for example saying a $13 \mathrm{~W}$ CFL $=75 \mathrm{~W}$ incandescent). Exaggerated claims of product performance or poor application comparisons will ultimately result in a disappointed customer and less likelihood of a repeat sale. One manufacturer felt that CFLs may help to pave the way for LEDs by encouraging consumers to think of lighting as a technology purchase, which, like computers and TVs, should be replaced with new technologies as the old becomes less effective.

\subsubsection{Negative Perceptions of Fluorescent Lighting}

Studies have shown that the word "fluorescent" has negative connotations for many consumers and we asked manufacturers how they deal with this negative association in their marketing efforts.

Two of the manufacturers told us that they avoid use of the word "fluorescent" on packaging; instead they use terms such as "energy saving bulb" or similar wording. The focus is on trying to show the product's benefits (long life and energy savings) and equivalency to incandescent lighting in terms of performance and color. One person told us they don't use the term fluorescent specifically because of the poor connotations, even though their fluorescent products have overcome most of the problems consumers associated with fluorescents. Another manufacturer said they don't mention fluorescent or CFL on their packaging but focus on wattage replacement instead. On the other hand, another manufacturer works to educate consumers on the benefits of CFLs and fluorescent lighting. According to this manufacturer, "in a number of markets where penetration rates for CFLs are high, attitudes are changing and the old negative connotations are going away. CFLs of today are a totally different product than they were early on.”

With regard to LEDs, manufacturers thought it was too early to tell whether consumers generally had a positive or negative image of the lighting category. According to one lighting staff person, "Consumers likely have few preconceived notions about LEDs. Right now, it's probably indifference. These products are likely seen as "futuristic." Another manufacturer felt that LEDs were still too unknown for consumers to have formed an opinion of them. This manufacturer said that manufacturers will probably need to come up with a new term to market them since the public won't know what a light emitting diode is; however, they speculated that the lighting industry was unlikely to collaborate on terminology. Once LEDs are ready for general illumination, long life and energy savings will likely still be important. According to one manufacturer, it's too early to tell for general lighting, but for holiday/decorative lights, the benefits of LEDs are nice color, long life, and low heat. One manufacturer felt that manufacturers should come up with a category of lamps term for solid state lighting, one that all of the industry could agree on.

\subsubsection{Energy-Efficiency Programs}

When asked about CFL market introduction programs conducted by utilities and other organizations, manufacturers agreed that energy-efficiency program support has been helpful to increasing consumer awareness and sales of CFLs. Manufacturers generally favored programs that focused on consumer and retailer education and training over direct incentives, such as manufacturer buy-down programs. 
However if direct incentive programs are pursued, manufacturers said they prefer manufacturer buy-down programs over coupons because of lower administration costs. One manufacturer stressed that utilities need to ensure a level playing field so that interested manufacturers have the chance to participate. "There have been times when all the incentive money has been spoken for by the time the offer even hits the street." There also need to be controls for quality - incentives should not be paid on poor-performing products because this hurts repeat purchases and the category of lighting as a whole.

In regard to ENERGY STAR, one manufacturer felt that ENERGY STAR should focus on consumers' dissatisfaction with CFLs to keep junk out of the market, but instead ENERGY STAR focused on high end efficacy and performance specifications that might limit style choices. This manufacturer also felt that manufacturers have trouble meeting ENERGY STAR specifications and that only a narrow type of product, like twister lamps, can qualify while other products like three-way and dimmable lamps can't qualify. This manufacturer felt ENERGY STAR sets an incandescent equivalency that is too low; thus consumers are dissatisfied with the light level. For example a 60 watt incandescent delivers 850 lumens typically, but ENERGY STAR does not require this. (Authors' Note, we found 19 three-way lamps and 20 dimmable lamp designs in the ENERGY STAR database.)

One manufacturer felt that the three strongest factors in encouraging CFL introduction were giving them away, the West Coast electricity crisis, and California's Title 24.

\subsubsection{The Issue of Price}

Manufacturers cautioned that using coupons and manufacturer buy-downs to lower the purchase price can be a double-edged sword - they put the product into people's hands, but give a false idea of price, which does not encourage future purchases, at full market prices. Manufacturers felt that utility give-away and manufacturer buy-down program approaches pushed the product into the marketplace, but did nothing to encourage retailers to sell the product, especially when they circumvented normal retail channels. One manufacturer said that buy-down programs and coupons can do more harm than good; most manufacturers felt that public service announcements, in-store demonstrations, and consumer education are better approaches for utilities and energy-efficiency groups.

According to one representative, "We have participated in ENERGY STAR events in the past with some success in terms of creating consumer awareness. However there are problems when the promotions involve incentives that significantly lower price. Once the incentives are gone, consumers experience sticker shock when they face higher prices (without incentives).”

Another manufacturer said, "coupons, rebates, etc., may hurt you if they lower price too much and the consumer does not make a repeat purchase because the (retail) price is perceived to be too high. If a consumer pays $\$ 1$ for a CFL once, they expect that to be the price next time.” As stand-alone strategies, the manufacturers felt these tactics do not work well; they simply don't have the power to 'move the needle.' Coupons and similar promotions should only be used as part of a bigger, overall marketing strategy and should not be used as the sole motivator to move the market. According to most manufacturers, education and demonstration/training activities are more effective than buy-down programs, which just cut into profits.

Manufacturers cautioned that it is premature to promote LEDs or develop any efforts with efficiency groups since the product is still in its infancy. Noted one manufacturer, "We don't want to promote them until they are ready - and they aren’t for general illumination.” 
Manufacturers noted that retailers must be convinced to carry products, and unless there is a profit involved for them - it's a hard sell. Pricing LEDs is going to be an issue since there needs to be a way for retailers (and manufacturers) to make a profit on them. If the LED is inexpensive and lasts 50,000100,000 hours, it could lead to overall reduced lighting sales and profits for retailers. If retailers make less on LEDs than they do on incandescents, there is no strong motive for them to carry the LEDs.

My Ton of ECOS Consulting suggests that utilities can add value to the product by making it "very clear through marketing messages that the utility is bringing the consumer a technically sound, environmentally efficient, money-saving product that saves electricity, reduces the consumer's bill, and decreases the utilities’ energy distribution load.” My Ton felt that CFL coupons that decrease year over year do transform the market while encouraging purchase by those who have never before tried CFLs.

\subsubsection{Poor Performance}

We noted that consumers had a number of complaints about the performance of early CFLs, often resulting in long-term distrust of CFLs as a lighting category in general. Manufacturers were asked what might be done differently when introducing a new lighting technology to avoid the same fate suffered by the CFLs

One representative noted "Of course the solution to this is for manufacturers and retailers to present goodquality products to consumers. Otherwise poor quality goods will prejudice the buyer, and he may not buy again (possible long-term ill-will).” The manufacturer went on to say that this isn't typically how things work. "Not surprisingly, manufacturers often want to jump into the market with a new technology to be one of the first entrants, which means they might introduce a technology prematurely, causing the consumer to develop negative perceptions of the entire lighting category if it does not perform as expected.

One manufacturer felt that reflector CFL lamps should not be included in ENERGY STAR because of poor performance. He noted that LEDs will make a much better light source for reflector lamps because of their directionality.

Another manufacturer said that LED quality guidelines are needed and that this was a lesson learned from CFLs.

According to another manufacturer, because light bulbs (CFLs, incandescents, etc.) are low interest, 'commodity' items, the marketer MUST know the key issues that will motivate a purchase, and this is only achieved by asking a buyer what his/her needs are. The manufacturer referred to this as "soliciting the voice of the customer" and viewed market research as critical to understanding buyer lighting needs. Their company believes that taking the time to do this can be a challenge since retailers sometimes pressure lighting manufacturers into releasing products prematurely. Lighting manufacturers agreed that it is first important to do market research to discover the market drivers for potential buyers, so that the key purchase motivators are identified. It's best to delay a product rollout until a value proposition has been developed.

According to one manufacturer, CFLs really didn't suffer in the long run. "Yes, in the early stages they did not perform well but that's the natural path of technology innovation - early products are expensive and may not perform very well. Manufacturers throw products out there to see how they do. You aren't going to have winners in the market early on until after there are some dogs that help fund more R\&D and over time the technology improves as do products." 


\subsubsection{Potential Approaches for Introducing New Lighting Technology}

We suggested several approached that might help introduce a new lighting technology, such as LEDs, without "harming" consumer perceptions of the new category of lighting. Below are the manufacturers' reactions to the various approaches.

1. A consumer education program led by industry or others.

"A good first step once products are ready. However I am not sure how you would organize this with industry. Might be able to work something out through NEMA.”

"The more people that are educated, the better it is to move the product into the marketplace, so this would be a good approach.”

"Its hard to know at this point since its too early to educate consumers on LED products. The Government should focus on supporting R\&D to help improve the overall technology.”

"The more education programs the better. No one wants to waste time buying light bulbs. Few people take the time to read the packaging and understand the technology. They just want to get in and out of the store.”

2. Delay product introduction until performance improves.

“This is key. Everyone wants to enter the market now, but that doesn't mean that just because you CAN launch something, you should. Premature release of a product that isn't going to satisfy consumers can hurt both the manufacturer and the industry.”

"Very important. It will be interesting to see how this pans out and whether some companies try to oversell benefits, which could hurt the market overall."

"This is unrealistic. Some manufacturers will undoubtedly launch lousy products with inferior technology.”

"Yes, but it must remembered that any product gets better over time. If you don't introduce the product at some point, you can’t earn money to sink back into R\&D. “

3. Offer only restricted sales to the consumer sector until performance improves.

"Yes, again this is important but easier said than done since some manufacturers will sell wherever they can with poor products. Then other manufacturers follow suit. This is hard to stop.”

"Yes, we are selling LEDs for limited applications to the commercial sector; however there is no way to restrict products being marketed to consumers by others."

"Yes, the consumer sector is much more demanding."

4. Promote the product only in niche market applications initially.

"Yes. Colored LEDs are already being sold."

"We are focusing on blue LEDs right now. Again, however, who knows what others will do."

"This is happening now."

5. Intensify retailer training so that salespeople understand the benefits/drawbacks and best applications for the technology. 
"Yes, we will be training retailers in 2006. We can only teach so much though, and we aren't the only ones out there training salespeople.”

6. Partner with utilities and energy-efficiency groups to promote the product.

"Yes. We will do this, but not yet - further down the road, when the products are closer to release date. Right now this is premature.”

"Yes, eventually when LEDs are ready."

"Yes but with a caveat - only for educational purposes. If the group ... understands that, from a business standpoint things take time, it could be beneficial. If they have unrealistic expectations, it's not a good idea."

\subsection{Early Examples of LED Lighting}

It appears that some early LED product offerings, in particular those that are being marketed as a replacement for incandescents for general service lighting, may be following a path similar to early CFL offerings and similar mistakes may be made. LED products for general service applications are very expensive, make overstated lumen equivalency and energy savings claims, and don't perform very well. The early applications of LED lights that have succeeded have capitalized on the unique nature of LED lighting - its high directionality, small size of the lamps, strong hues, brightness, solid state operation, and long life. In cases, where manufacturers are trying to force-fit them into general service applications, they are less likely to be successful and could in fact turn off consumers who might otherwise find LEDs perfectly acceptable for niche applications. Figure 6.1 shows an example of a reflector spotlight lamp, which takes advantage of LED's focused light source. Figure 6.2 shows some examples of LEDs that are being packaged as a replacement for an incandescent lamp.

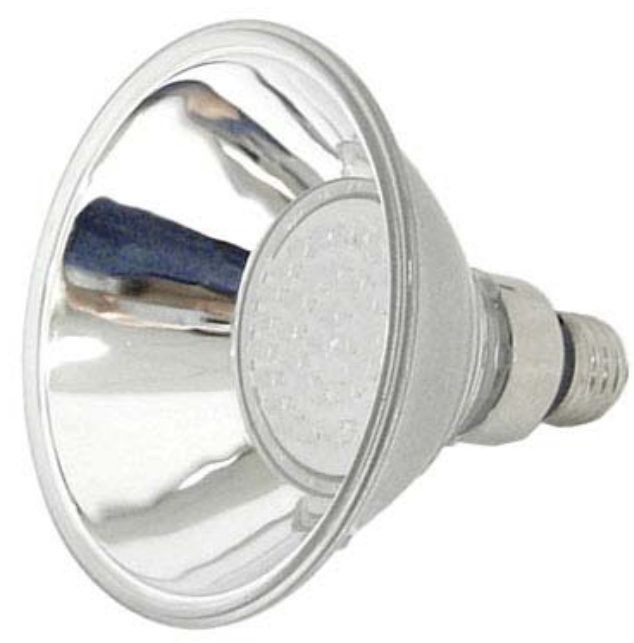

Figure 6.1. An LED Reflector Lamp. This design takes advantage of the directionality of LEDs by using them as the light source for a reflector lamp. 

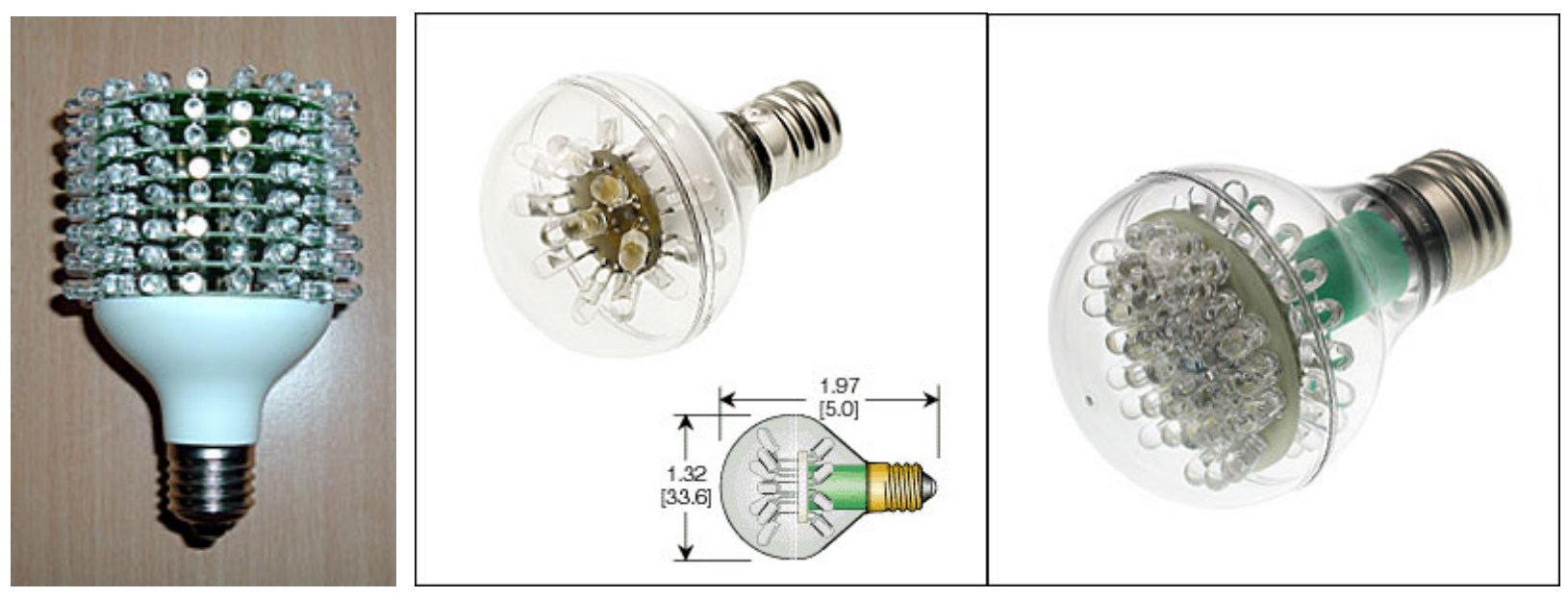

Figure 6.2. Two Examples of LEDs Configured as Replacements for a White Light Incandescent Bulb. While it is possible to configure LEDs in a shape that is similar in dimensions to an incandescent, this application does not take advantage of LED's unique qualities over incandescents, and comes at a cost that is currently much higher than an incandescent bulb. 


\subsection{Lessons Learned}

Lessons learned from reviewing the prior efforts of the many involved in increasing consumer acceptance of residential CFL lighting, and interviews with CFL manufacturers, retailers, and others are summarized below. These lessons are grouped into three categories: those pertaining to technology, program design, and marketing.

\subsection{Technology}

Introduce new lighting technology in niche applications where benefits are clearly defined and performance is not overstated. Initial exposure is highly influential in the market and first impressions count for a lot. Often, there are niche applications where consumers will likely be quite satisfied with their purchase. For CFLs, this could have been porch light applications in moderate-temperature climates where performance drawbacks such as buzzing, flickering, color rendering, and fit may have been less of an issue. Early use of CFLs in table lamps may also have been acceptable. Use of early-generation CFLs for general illumination in high-use areas such as kitchens, and spotlight applications, would have commonly been met with consumer dissatisfaction. This early dissatisfaction could result in a consumer that is unwilling to try a CFL again - even once performance has been improved. (See 1.1.2, 2.1.)

Be aggressive about dealing with technology failures that affect main benefit claims. If products are failing prematurely or otherwise not performing as claimed and as expected by the consumer, changes in the product and its marketing should be made immediately before more buyers are "turned off." (See 1.1.2, 2.1, 3.1.1.)

Performance is more important than appearance. There was some debate with early CFLs as to whether consumers would want something that looked "just like an incandescent," or whether new designs like twister lamps might succeed. Some early focus groups found that consumers liked lamps with familiar shapes; however, in the long run the nonstandard (i.e., twisters) have sold due to their size and performance. It seems clear that consumers are willing to look beyond an odd appearance if a product performs well. But they are less forgiving of poor initial performance. (See 2.3.) In effect, the light bulbs themselves rarely have an aesthetic because they are hidden in fixtures, but the light delivered by the fixture itself does have an aesthetic, which is heavily influenced by the performance of the bulb.

Know and admit technology limitations, e.g., CFLs can’t provide focused, highly directional, light the way halogen, incandescent, and LED sources can. (See 4.1.)

Manufacturers should work closely with energy efficiency groups to help establish minimum performance requirements that the manufacturers can meet and the efficiency groups are willing to support.

(Lightwise changed requirements on power factor and THD after losing a major manufacturer participant and discovering that the added requirements were increasing product cost without producing a corresponding consumer benefit.) (See 3.2.)

\subsection{Marketing and Consumer Education}

Identify niche markets (building sub-markets) where the benefits of the new technology make especially good sense, and where initial sales can be built. The hotel and multi-family housing markets, where energy savings and reduced maintenance costs were important drivers to the use of CFLs, were initially targeted by DOE and some utility programs. (See 2.1, 3.1.1, 3.1.4.) 
Focus message on areas where the technology can meet expectations, and reshape consumer expectations where new lighting technologies fall short. For example, CFLs are often a good choice for general illumination, but not for applications where a focused beam is needed (i.e., spotlight and narrow floodlights). (See 4.1.)

Marketing literature should show comparisons of savings to the standard technology, e.g. the $1 \mathrm{CFL}=10$ incandescents. (See 4.1.)

Consumers find that long-life claims are hard to believe and hard to relate to, unless backed up by guarantees or trusted labeling. (See 2.3.)

Consumers want to see how a new technology performs before they buy it; (i.e., they want to see lit CFLs in in-store displays). (See 4.1.) It is generally also better to show the new technology clearly in transparent "blister packs" than to hide it in an opaque cardboard box. Don't apologize for differences from standard products; celebrate them.

Consistent, meaningful terminology across the industry is important for new products. Get consumer feedback on terminology early on and use education to counter any image problems. Consider adopting a new industry-wide name, for example with CFLs that avoids the word "fluorescent" all together. (See 2.2.2, 2.4.2, 2.5.1, 4.1.)

Product advertising should be specific about benefits. How much longer do they last? How much energy do they save? (See 2.5.1, 4.1.)

Shift consumer focus from product price to product value, including non-energy-efficient attributes like longevity and convenience. (See 4.1.)

Consider using educational and marketing campaigns to celebrate the distinct advantages of energyefficient lighting and the disadvantages of incandescent light bulbs. (See 4.1.)

Conducting in-store product demonstrations is a good way to educate consumers. (See 4.2.)

Promote CFLs through several different mediums to reinforce customer familiarity and positive associations with product. (See 3.1, 3.2, 3.6.3, 4.2.)

Consumer education activities might include utility bill stuffers, and CFL product demonstrations at local fairs, home shows, and energy shows. Education tools like brochures, posters, demonstrations, and wall displays should be provided to retailers. (See 2.4.1, 4.2.)

Public service advertising should be supported to educate consumers and bring efficiency forward as a lighting selection criterion. (See 2.4.2, 2.5.1, 4.1.)

Utilities should offer education programs like telephone hotlines and websites to consumers and training programs for builders, designers, and retailers. (See 4.3.)

Arrange shelf displays by lighting application rather than manufacturer and identify good/better/best options that correlate to longer product life and greater energy efficiency. For example, a customer going to the store seeking a bulb for a reading lamp would be presented with good/better/best options for reading lamp bulbs. (See 4.3.)

Ideally, new lighting technologies should be available where consumers typically purchase bulbs - in grocery stores. However grocery stores are unlikely candidates for new lighting technologies. Therefore, consumers will need to need to be educated on where to shop for new energy efficient lighting products 
(hardware and home improvement, mass market discounters where higher priced items are norm instead of grocery stores). (See 2.2.1, 2.3, 4.2, 4.5.)

Build a message of value (costs more/worth more) rather than the short-term fix of a rebate. (See 3.1, 4.1.)

Mass media is vital to widespread adoption of a new technology. Pay attention to both paid and unpaid. Paid advertising would include advertising on TV, radio, newspapers and magazines. Unpaid means getting messages to media through news releases, press events and being ready with media messages when spotlight turns to energy efficiency (like the California energy crisis of 2000 or Earth Day) or safety (like halogen torchieres). (See 4.6.)

Packaging needs to be more clear concerning warranties and replacement of failed products.

Use a color label on packaging that clearly indicates the warmth or coolness of a CFL product's light output. (See 4.4.)

\subsection{Program Design}

Study market structure to see how best to introduce a new technology. If it is the consumer market you are after, then understanding the retail markets and distribution practices is critical. (See 2.3.)

Utility giveaway programs can increase buyer awareness but don't create lasting market transformation by themselves, because they bypass normal market distribution routes. They may also undermine retail sales. (See 3.1.1.)

If providing incentives, utilities should consider developing a program that focuses on retailers and manufacturers. This allows for a lower price to the consumer and involves manufacturers in the process. Retailers are another good focus for incentives since the incentives can be coordinated with retailer training. (See 3.1.3.)

As with most new technologies, prices are highest initially when sales volumes are low and manufacturing processes may not be optimized. Manufacturers should keep in mind however that it's hard for consumers to assign a value to a product (i.e., know when they are getting a good deal) if price keeps fluctuating (from free to $\$ 25+$ ). Utility rebates are likely to have exacerbated this problem with consumers. (See 2.2.1.)

Energy efficiency is often not the leading factor in energy-efficient lighting sales. Safety, for example, led to 1 million units sold in a year for the 1998 introduction of ENERGY STAR torchieres. Product marketing should focus on the product attributes deemed most important by consumers. (See 4.1, 4.6.2.)

Products shouldn't be given away unsolicited. Some action on the part of the consumer should be required, if not a purchase then mailing in a card. Action yields higher installation rates and greater awareness. (See 3.1.1.)

Utility program or manufacturer field representatives can be a very helpful link between manufacturers and retailers; they can educate and train retailers, set up displays, distribute promotions, and iron out problems. (See 3.1.4, 4.2.)

Utilities have found that developing enthusiastic and ongoing retailer participation is a key to market introduction programs. Lighting manufacturers, who generally have regional sales staff, should ensure that these staff are well trained on the new technology and can provide information to retailers. Utilities 
have found that building retailer trust can take 2 to 3 years, so ongoing communications are important. (See 3.1.2, 3.1.4.)

Programs that start with low-quality, poor performing (often low-cost) products to keep costs down may find that this approach can backfire. It is difficult to convince consumers to buy something they once received for free, especially if the initial experience wasn't a positive one. (See 2.1, 2.2.1, 3.1.1.)

Design multi-year programs around the lighting season (Sept to April) not the calendar year. Coordinating these programs with national campaigns, such as the ENERGY STAR Change a Light, Change the World program can leverage efforts for greater recognition and sales. (See 2.5.2, 3.6.3, 54.2.)

Lighting manufacturers, retailers, and utility energy efficiency programs should combine capabilities by crafting a more visible and attractive presence for efficient residential lighting products in retail outlets. Point-of-purchase displays and signage can be very helpful in driving initial sales. (See 3.2, 4.2, 4.3.)

Several studies showed that retailers were a primary source of information about lighting for consumers but surveys of retailers showed that they felt inadequately prepared to discuss energy efficient lighting. Retailers need and want more training so that they can feel more knowledgeable about energy efficient lighting. They also want tools to get the message across to the consumer: in-store displays, signage, brochures, more informative packaging, etc. (See 2.5.1, 4.2)

The enthusiastic and on-going participation of retailers was recognized by energy efficiency groups and utilities as one of the building blocks of successful programs, and one that needs to be acknowledged sincerely and frequently. \{See 3.1.2.)

Consistency is important among overlapping incentive programs. Multiple programs with conflicting incentives can confuse and frustrate customers and make program delivery more complicated. (See 3.1.4, 3.6.4.)

Once regional efforts are in place, a new lighting technology with strong energy-saving potential is likely to benefit from regional support and coordinated approaches to promotional programs, versus a variety of approaches introduced by individual utilities. Lighting manufacturers should join forces with utilities and national energy efficiency programs (e.g., ENERGY STAR) for best results. (See 3.6.3, 3.6.4, 4.2, 4.4.)

Manufacturers are concerned about how to price LEDs so that retailers will get return on shelf space profit.

\subsection{Application to LEDs and Other New Lighting Technologies}

The following lessons learned are culled frominterviews PNNL conducted with product and marketing managers in the lighting divisions at Philips, GE, Osram Sylvania, and TCP in fall and winter 2005-2006 based on their experiences developing and marketing CFLS. Although they all commented that LEDs are a developing technology currently restricted to niche applications, the insights they provided could be valuable to the lighting industry in seeking market acceptance of LEDs or other new lighting technologies.

A lot of consumer research is needed to determine what the consumer does and does not know before the initial product launch so that the launch is done right the first time.

Accurate incandescent equivalency on packaging is critical.

Rely as much as possible on retailers for customer education. 
Industry collaboration, perhaps through NEMA, would be helpful, though difficult to achieve given the large number of manufacturers.

Coordinate with energy-efficiency programs once products are available but don't start before products are ready.

Don't rely on giveaways and coupons or other programs that confuse consumers about the actual retail price. If the consumer's first experience of the product is through a give-away or drastically reduced price coupon offer, they will balk at paying a high retail price next time.

Avoid market introduction programs that distribute products outside normal retail channels, for example utility mail-order programs.

Performance claims must be accurate. Don't launch a product just because you can. Wait until performance issues are ironed out.

Initial education and performance issues will be more difficult to iron out if many manufacturers are involved in the initial introduction of LEDs.

Pricing is critical but tricky. For the manufacturer to make a profit on LEDs it must be priced low enough to encourage consumer demand but the retailer must be able to make money on it as well.

Education, of both consumers and retailers, is critical.

Understand that many people will not try a new product until price drops to a range near that of existing products providing similar functionality.

Niche marketing is the best approach for now. 


\subsection{References}

1. Smithsonian National Museum of American History. 2003. "Competition for a Modern Lamp." Lighting A Revolution. Available URL: http://americanhistory.si.edu/lighting/20thcent/comp20.htm (last updated March 2003).

2. Harris Tom. . "How Fluorescent Lamps Work.” HowStuffWorks. Available URL: http://home.howstuffworks.com/fluorescent-lamp.htm, searched June 2005.

3. “Fluorescent Lamp.” Answers.com. Available URL: http://www.answers.com/fluorescent\%20lighting, searched June 2005

4. Smithsonian National Museum of American History. 2003. "Inventing Six Modern Electric Lamps.” Lighting A Revolution. Available URL: http://americanhistory.si.edu/lighting/20thcent/invent20.htm (last updated March 2003).

5. Beardsley C. 1976. “And Now, the Hollister Lamp.” Lighting Design \& Application April:48-49.

6. Bouwknegt A. 1982. “Compact Fluorescent Lamps.” Journal of IES July:204-212.

7. Goett A, K Van Liere, and D Quigley. 1992. “Customer Acceptance and Use of Compact Fluorescents: Results from a Comprehensive Evaluation of PG\&E’s Program.” Program Evaluation - Proceedings from the ACEEE Summer Study on Energy Efficiency in Buildings, Volume 7, pp. 7.61-7.74. American Council for an Energy Efficient Economy, Washington, D.C.

8. EPRI. 1992. Perceptions of Compact Fluorescent Lamps in the Residential Market. EPRI TR100734, prepared by Macro Consulting, Inc., Mountain View, California, for the Electric Power Research Institute, Palo Alto, California.

9. SDGE. 1993. Appliance Efficiency Incentives: Residential Compact Fluorescents. 1992 Lighting Focus Groups and Follow-Up Interview Report. MIAP-92-P09-S01-R241, prepared by Marketing Information Masters, Inc. for San Diego Gas \& Electric, San Diego, California.

10. Rasky L. 1993. “Consumers and Compact Fluorescents.” Home Energy Magazine Online November/December 1993. Available URL:

http://homeenergy.org/archive/hem.dis.anl.gov/eehem/93/931106.html

11. Fernstrom GB. 1994. "Steps to Successful Lighting Programs.” Home Energy Magazine Online November/December 1994. Available URL: http://homeenergy.org/archive/hem.dis.anl.gov/eehem/94/941110.html.

12. Atkinson B. 1994. "Downsizing the CFL.” Home Energy Magazine Online January/February 1994. Available URL: http://homeenergy.org/archive/hem.dis.anl.gov/eehem/94/940103.html.

13. Goett AA. 1994. "Seeing the Light: Effective Strategies for Promoting Compact Fluorescent Lighting to Residential Customers.” Proceedings from the ACEEE Summer Study on Energy 
Efficiency in Buildings, Volume 10, pp. 10.41-10.47. American Council for an Energy Efficient Economy, Washington, D.C.

14. Polsby E. 1994. "Putting Energy-Efficient Lighting in Its Place.” Home Energy Magazine Online November/December 1994. Available URL:

http://homeenergy.org/archive/hem.dis.anl.gov/eehem/94/941112.html.

15. Haddad BM. 1994. "Why Compact Fluorescent Lamps Are Not Ubiquitous: Industrial Organization, Incentives, and Social Convention.” Proceedings from the ACEEE Summer Study on Energy Efficiency in Buildings, Volume 10, pp. 10.77-10.83. American Council for an Energy Efficient Economy, Washington, D.C.

16. HMG (Heschong Mahone Group). 1997. Lighting Efficiency Technology Report: Volume III: Market Barriers Report. P400-98-004VIII, prepared for the California Energy Commission, Sacramento, California. Available URL:

http://www.energy.ca.gov/efficiency/lighting/VOLUME03.PDF.

17. Gilmore Research Group. 1999. LightWise: Market Progress Evaluation Report \#1. Report \#E99-019, H Mermenet (ed.), Gilmore Research Group, Portland, Oregon.

18. Decision Sciences Research Associates, Inc. 1998. Residential Lighting: Market Transformation Study. Decision Sciences Research Associates, Inc., Pasadena, California.

19. Gilbride TL. 2002. DOE Sub-CFL Program Exceeds Sales Goal by 200\% . PNNL-SA-37704, Pacific Northwest National Laboratory, Richland, WA.

20. HMG (Heschong Mahone Group). 1997. Lighting Efficiency Technology Report: Volume IV: Recommendations Report. P400-98-004VIV, prepared for the California Energy Commission, Sacramento, California. Available URL:

http://www.energy.ca.gov/efficiency/lighting/VOLUME04.PDF.

21. Gilmore Research Group. 1999. LightWise: Market Progress Evaluation Report \#1: Appendix. Report \#E99-019, Gilmore Research Group, Portland, Oregon.

22. Dethman L. 1999. LightWise, No. 2 (9/99). Report \#99-038, prepared by Dethman \& Associates, Seattle, Washington, with data collected by Gilmore Research Group, Portland, Oregon, for the Northwest Energy Efficiency Alliance, Portland, Oregon.

23. Calwell C, C Granda, L Gordon, and M Ton. 1999. Lighting the Way to Energy Savings: How Can We Transform Residential Lighting Markets? Volume 1: Strategies and Recommendations. Prepared by Ecos Consulting for the Natural Resources Defense Council, San Francisco, California.

24. Calwell C, C Granda, L Gordon, and M Ton. 1999. Lighting the Way to Energy Savings: How Can We Transform Residential Lighting Markets? Volume 2: Background and Reference. Prepared by Ecos Consulting for the Natural Resources Defense Council, San Francisco, California. 
Saffell BF, CH Imhoff, MR Brambley, MR Ledbetter, RE Jarnagin, RW Reilly, JW Graybeal, WC Weimer, and JJ Dooley. 1999. Transforming Markets for Energy-Efficient Products . PNNL-SA32014, Pacific Northwest National Laboratory, Richland, WA.

25. National Research Council. 2001. Energy Research at DOE: Was It Worth It? Energy Efficiency and Fossil Energy Research 1978 to 2000. National Academies Press, Washington, D.C.

26. Gordon KL and MR Ledbetter. 2001. Technology Procurement Screening Study. PNNL-13710, Pacific Northwest National Laboratory, Richland, Washington.

27. Calwell C, J Zugel, P Banwell, and W Reed. 2002. 2001 - A CFL Odyssey: What Went Right? PowerPoint Presentation, Ecos Consulting and U.S. EPA, Portland, Oregon.

28. Calwell C, J Zugel, P Banwell, and W Reed. 2002. “2001—A CFL Odyssey: What Went Right?” Paper presented at ACEEE 2002 Summer Study Conference, Asilomar, California, pp. 6.15-6.27.

29. ECONorthwest. 2002. ENERGY STAR® Residential Lighting Program, No. 1: Market Progress Evaluation Report: Final Report. Report \#E02-101, prepared for the Northwest Energy Efficiency Alliance, Portland, Oregon.

30. Fulbright V, A Jacob, and C Calwell. 2003. Compact Fluorescent Light Programs Shine through the West Coast Power Crisis. ER-03-11, prepared by Ecos Consulting for Platts Research and Consulting, Boulder, Colorado.

31. Seattle City Light. 2003. Conservation Kit Program Evaluation: Transforming the Residential Use of Compact Fluorescent Lighting. Evaluation Unit Energy Management Services Division, Seattle, Washington.

32. Sampson Research. 2004. Market Effects of BC Hydro's Residential CFL Initiatives: Summary Report. Prepared for Power Smart Evaluation, Burnaby, British Columbia.

33. Horowitz N. 2004. “An Illuminating Summary of California’s New Title 24 Residential Lighting Building Code.” http://www.energystar.gov/ia/partners/presentations/Noah_Horowitz_Title_24.pdf

34. Hedman B, S Baggett, and D Bruchs. 2004. EM\&V Report: ENERGY STAR ${ }^{\circledR}$ CFL Program for Small Hardware and Grocery Retailers. Prepared by Quantec, LLC, Portland, Oregon, for Ecos Consulting, Inc. Portland, Oregon.

35. ECONorthwest. 2004. ENERGY STAR® Residential Lighting Program: Market Progress Evaluation Report, No. 2. Report \#E04-130, prepared for the Northwest Energy Efficiency Alliance, Portland, Oregon.

36. Lighting Research Center. 2003. Increasing Market Acceptance of Compact Fluorescent Lamps (CFLs). Prepared for the U.S. Environmental Protection Agency by Lighting Research Center, Rensselaer Polytechnic Institute, Troy, New York. 
37. RLW Analytics. 2005. 2005 California Statewide Residential Lighting and Appliance Efficiency Saturation Study, prepared for San Diego Gas and Electric, Southern California Gas Company, Southern California Edison, and Pacific Gas and Electric by RLW Analytics, Sonoma, CA.

38. Northwest Energy Efficiency Alliance. 2004. Alliance Accomplishments Toward Its Strategic Mission - 1997 to 2002. Northwest Energy Efficiency Alliance. www.nwalliance.org

39. Navigant Consulting. 2002. U.S. Lighting Market Characterization. Volume 1. National Lighting Inventory and Energy Consumption Estimate. Navigant Consulting, Chicago, for the U.S.

Department of Energy, Washington DC.

40. Energy Information Administration. 1993. “1993 Residential Energy Consumption Survey.” U.S. Department of Energy, Washington DC.

41. Ottman, JA. 2003. “Green Marketing, Eco-Innovation and Your Customer: Lessons from the Green Graveyard.” J Ottman Consulting, Inc. New York.

42. Kates, Brad, Opinion Dynamics Corp and Steve Bonanno, NSTAR Electric and Gas, "Energy Efficient Lighting in the Residential Market” presented April 2005. Available at http://www.energystar.gov/ia/partners/downloads/meetings/EfficientLightingi nResidentialMarket_Kates_Bonnano.pdf.

43. California Energy Commission. 2004. "Market Failures, Consumer Preferences, and Transaction Costs in Energy Efficiency Purchase Decisions.” CEC-500-2005-020. November 2004. pp. 15-16.

44. ENERGY STAR Homes Northwest. 2006. Residential Sector Initiative Update, January 2006. http://www.northwestenergystar.com/files/9354RSI_Newsletter_January_2006_.pdf

45. CEE. 2006. “CEE and NEMA work on 'color' label for CFLs.” CEE Newsletter, Spring 2006, Consortium for Energy Efficiency http://www.cee1.org/resrc/news/06-04nl/11_cfl.html 
Appendix A

A Brief History of the Development of Fluorescent Lighting 



\section{Appendix A}

\section{A Brief History of the Development of Fluorescent Lighting}

Incandescent lamps produce light from heat, in this case the heat created by electricity passing through a filament. Fluorescent lamps create light through a two-step process involving chemical reactions and the chemical phenomena known as fluorescence. All fluorescent lamps consist of a tube containing mercury vapor. When an electric charge passes through the mercury vapor, ultraviolet radiation is discharged. The UV strikes chemical phosphors coating the wall of the glass tube; these absorb the UV and "fluoresce" or emit light.

In 1856, Heinrich Geissler developed what was probably the earliest ancestor of the fluorescent lamp when he obtained a bluish glow from a gas sealed in a tube excited by an induction coil. The French physicist Alexandre Becquerel experimented with coating electric discharge tubes with luminescent materials. At the 1893 World's Fair in Chicago, a type of light using fluorescence developed by Nikola Tesla was displayed. In 1894, D. McFarlane Moore created the Moore lamp, a commercial gas discharge lamp using nitrogen and carbon dioxide meant to compete with the incandescent light of his former boss Thomas Edison. In 1901 American Peter Cooper Hewitt demonstrated the low pressure mercury arc lamp, which was very close to the modern design but not quite ready for residential use due to its bluish-green light.



Figure A.1. A drawing of Peter Cooper Hewitt's low-pressure mercury arc lamp taken from the patent application (patent 889,692 issued in 1901), called by some the very first prototype of today's modern fluorescent lamp. $\{2\}$

In 1926 Edmund Germer and coworkers in Germany coated the tube with fluorescent powder which converts the ultraviolet light emitted by a rare gas into better spectrally distributed light (also increasing 
the pressure). General Electric bought the rights to Germer's patent; GE’s George Inman and others made several improvements and filed their own patent in April 1936 for the first practical fluorescent lamp, which they began selling in 1938. Several others had patented various less successful versions of a fluorescent lamp, including Edison whose 1896 patent described a fluorescent lamp (never commercially produced) that used $x$-rays instead of mercury vapor to excite the phosphor. $\{2\}\{3\}$

Fluorescent lighting caught on with commercial and industrial building owners due to its cost savings, but the lengthy tubes seemed impractical in residential settings. In the early and mid 1970s, General Electric, GTE Sylvania, Westinghouse, Philips, Lighting Technology Corporation, Spellman Electronics, and others filed patents on designs to shrink fluorescent lights. Most of these efforts proved impractical from a mass manufacturing standpoint, but gradually improvements were achieved, made possible in part by new developments in materials and manufacturing and the shrinking of electronic components.

Successful compact fluorescent lamp designs were ultimately put fourth by Philips and Westinghouse and soon by others. All of these designs required substantial investment in new production machinery, $\{4\}$ a major reason for the high initial price of these lamps $\{4\}$ and a likely factor in the speed (or lack thereof) with which manufacturers increased production of these new lamps. Some have speculated that Philips' patent also kept prices high for a long time, since manufacturers owed royalties to them until the late 90's or early 2000’s whenever they employed rare earth phosphors.

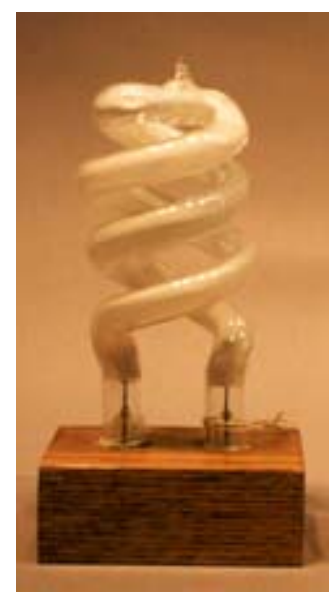

Figure A.2. The "Spiral Lamp" developed by Edward Hammer at GE in 1976. Existing lamp machinery had difficulty making the fragile spiral, and GE felt that new machinery would be too expensive, so they shelved the design. However, spiral lamps appeared on the market in 1995 as other manufacturers decided to see if the design could be competitive. Spiral CFL Smithsonian Institute image \#lar2-2d1 
Appendix B

A Timeline of Events in CFL History 



\section{Appendix B}

\section{A Timeline of Events in CFL History}

\section{Year What}

1910 Tungsten Light Bulb invented

1933 First Fluorescent tubes installed

1939 Fluorescents made available for wider sale.

1976 Compact Fluorescent "Spiral Lamp" design introduced but GE deems it too fragile to make with existing manufacturing technology.

Hollister introduces magnetic-fluorescent lamp (but not manufactured)

Phillips unveils first electronic ballast CFL

1982 Phillips starts using new rare earth phosphors that emit warmer color of light and increase light output

1985 GE produces first competing product

Late

Utilities start offering CFL bulbs to customers.

1990 April 22, 1990 Earth Day turning point in national consciousness about energy efficiency, climate change, ozone depletion. Three books (50 Simple Things You Can Do to Save the Earth, Consumer Guide to Home Energy Savings, and The Green Consumer) sell millions of copies, recommend CFLs.

1990 Worldwide sales of CFLs $=83$ million

1991 CFLs have 1\% of US bulb sales volume, $2 \%$ of world bulb sales.

1995 Spiral lamps appeared on the market

1997 Philips and TCP introduce dimmable screw-based CFLs

1997 Worldwide sales of CFLs $=356$ million

1997 ENERGY STAR Residential Light Fixtures Program started. This brought a benchmark of lighting performance and quality as well as a clearly recognizable national brand to the marketplace.

1998 ENERGY STAR torchieres hit the market and sell a million units by Sept 1999

1998 DOE's Sub-compact CFL Technology Procurement program started, administered by PNNL

1999 The DOE ENERGY STAR screw base CFL program was launched. This continued to help the utilities and regional market transformation groups to rally their marketing strategies.

2000 Beginning of West Coast Energy Crisis

2000 Program for Evaluation and Analysis of Residential Lighting (PEARL) started in 2000 as a watchdog organization in response to complaints received by utility managers about the quality of ENERGY STAR rated products.

2001 DOE launches R-CFL Technology Procurement Project to encourage the development of reflector style CFLs that perform well in high heat applications, such as recessed can fixtures.

2001 EU imposes an anti-dumping duty of $66.1 \%$ on CFL-I bulbs, so China turns to US resulting in glut of low-cost CFLs on US market. (EU Regulation 1470/2001)

2001 Rolling blackouts in California prompt massive regional CFL promotions and giveaways

2001 Drought in Northwest prompts regional CFLs programs due to hydro power shortages

2001 Change a Light, Change the World campaign launched with nationwide radio, tv and print advertising of ENERGY STAR CFLs.

2001 New ENERGY STAR requirements including third-party testing and interim life testing.

2001 US CFL sales surge to fourth quarter highs of $2.1 \%$ of national lamp market, to $8.5 \%$ in California and to $12 \%$ in Northwest. 
2002 CFL prices are down from $\$ 20+$ per bulb in 1990 to $\$ 9$ for a 4-pack without utility subsidy in mass merchandise stores like K-mart, Wal-Mart and Costco around the US.

2003 DOE, American Lighting Association, and Consortium for Energy Efficiency start CFL lighting fixture design competition called "Lighting for Tomorrow"

2005 EU extends the anti-dumping duty from 2001 to include shipments from Philippines, Pakistan, and Vietnam. Apparently some of the Chinese companies affected by the 2001 action had been shipping "kits" of partially manufactured CFLs to these countries for completion and sales. EU Regulation 866/2005

2005 Title 24 (California building code) updates take effect Oct 1,2005. Requires "high efficacy" lights in nearly every room in house. All CFLs must be pin-based, no screw based allowed. 